\title{
Structure-Activity Relationship Studies of Tetrahydroquinolone Free Fatty Acid Receptor 3 Modulators
}

\author{
Elisabeth Rexen Ulven,* Tezz Quon, Eugenia Sergeev, Natasja Barki, Matjaz Brvar, Brian D. Hudson, \\ Palash Dutta, Anders Højgaard Hansen, Line Ø. Bielefeldt, Andrew B. Tobin, Christine J. McKenzie, \\ Graeme Milligan, and Trond Ulven
}

Cite This: J. Med. Chem. 2020, 63, 3577-3595

Read Online

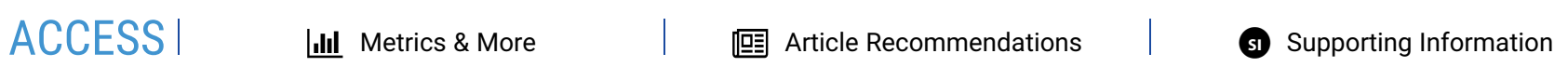

ABSTRACT: Free fatty acid receptor 3 (FFA3, previously GPR41) is activated by short-chain fatty acids, mediates health effects of the gut microbiota, and is a therapeutic target for metabolic and inflammatory diseases. The shortage of wellcharacterized tool compounds has however impeded progress. Herein, we report structure-activity relationship of an allosteric modulator series and characterization of physicochemical and pharmacokinetic properties of selected compounds, including previous and new tools. Two representatives, 57 (TUG-1907) and 63 (TUG-2015), showed improved solubility and preserved potency. Of these, 57, with $\mathrm{EC}_{50}=145 \mathrm{nM}$ and a solubility of $33 \mu \mathrm{M}$, showed high clearance in vivo but is a preferred tool in vitro.

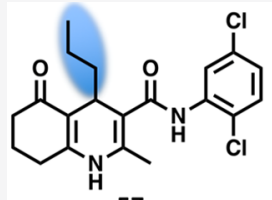

57

$\mathrm{EC}_{50}(\mathrm{hFFA3})=145 \mathrm{nM}$

$\mathrm{Sol}_{\mathrm{aq}}=33 \mu \mathrm{M}$

$\mathrm{F}=36 \%$

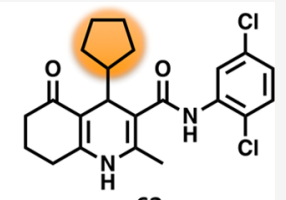

63

$\mathrm{EC}_{50}(\mathrm{hFFA3})=162 \mathrm{nM}$

Sol $_{\mathrm{aq}}=9 \mu \mathrm{M}$

$F=66 \%$ In contrast, 63, with $\mathrm{EC}_{50}=162 \mathrm{nM}$ and a solubility of $9 \mu \mathrm{M}$, showed lower clearance and seems better suited for in vivo studies. Using 57, we demonstrate for the first time that FFA3 activation leads to calcium mobilization in murine dorsal root ganglia.

\section{INTRODUCTION}

Short-chain fatty acids (SCFAs) are produced in large amounts by the lower gut microbiota and are known to affect human health in various and often beneficial ways. ${ }^{1}$ Free fatty acid receptors 2 and 3 (FFA2 and FFA3) are G protein-coupled receptors activated by SCFAs and mediate many of the physiological effects of SCFAs. ${ }^{2,3}$ The receptors were discovered and reported simultaneously in 2003 and are co-expressed in enteroendocrine cells, pancreatic $\beta$-cells, some immune cells, and certain cancers. ${ }^{4-7}$ Both FFA2 and FFA3 have been reported to be expressed in the adipose tissue, although most studies now suggest that only FFA2 is present. ${ }^{6-10}$ Of the two receptors, FFA2 has received more attention, showing promise as a target for the treatment of various metabolic and inflammatory conditions, ${ }^{6}$ with one compound reaching clinical trials for ulcerative colitis before being discontinued due to limited efficacy, despite the fact that the compound did inhibit neutrophil infiltration. ${ }^{11}$

Several studies have also suggested interesting therapeutic potential for FFA3. For example, Offermanns and co-workers demonstrated that deletion of FFA2 and FFA3 in combination, but not individually, improved insulin secretion and glucose tolerance in mice, indicating that dual antagonism of the receptors may counteract type 2 diabetes. ${ }^{12}$ Activation of both receptors is also reported to counteract cancer development. ${ }^{13,14}$ FFA3 is linked to hypoxia-induced apoptosis and may have potential as a target for ischemia/reperfusion-related injury. ${ }^{15}$ Marsland and co-workers found that FFA3 but not FFA2 mediates the protective effect of circulating SCFAs against allergic lung inflammation and is therefore of interest for treatment of allergic asthma. ${ }^{16}$ FFA3 has also been reported in both autonomic and somatic sensory ganglia. ${ }^{17}$ In sympathetic ganglia, propionate is found to promote sympathetic nervous system activation and to be involved in regulation of the body energy balance. $^{18}$

Most of the studies involving FFA3 have relied on SCFAs as tools and/or knockout mice. These studies should be interpreted with caution because SCFAs are generally able to activate both FFA2 and FFA3 but with different profiles on human and rodent orthologues ${ }^{19}$ and because it has been found that knockout of one receptor may affect the expression of the other. ${ }^{10}$ More studies are therefore required to elucidate the therapeutic potential of FFA3 alone and in combination with FFA2. An important reason for the paucity in studies on FFA3 is the lack of well-characterized high-quality tool compounds for this receptor. ${ }^{20}$ Studies that use SCFAs often employ propionate (C3) as a dual agonist of FFA2 and FFA3, acetate as a FFA2selective agonist, and butyrate as a FFA3-selective agonist; however, the selectivity for these compounds are modest at best. ${ }^{19}$ Recently, the FFA3-selective SCFA-analogue 1-methylcyclopropylcarboxylate (1-MCPC) has also been employed, but its potency remains very low. ${ }^{21}$

Received: December 9, 2019

Published: March 6, 2020 
Currently, the only tools for FFA3 with potency in the singledigit micromolar range are from a series of tetrahydroquinolones originally disclosed by Arena Pharmaceuticals (represented by $\mathbf{1}$, Table 1) and that were subsequently shown to be allosteric modulators of the receptor. ${ }^{22,23}$ Although they have occasionally been used as tools, ${ }^{24-28}$ moderate potency and the lack of proper characterization have limited the use of these compounds. The compounds act as allosteric modulators and are not affected by mutation of arginine residues in the orthosteric site that are indispensable to the activity of propionate. ${ }^{22}$ Small structural changes of the tetrahydroquinolones have shown to affect the mode of action, ranging from pure allosteric agonists to modulators that either enhance the potency of propionate (positive allosteric modulators, PAMs), reduce the efficacy of propionate (negative allosteric modulators, NAMs), or acting as both agonists on their own but also enhance the potency of propionate (PAM agonists).

Herein, we present the results from a thorough examination of the structure-activity relationships (SAR) within this compound series and further characterize bioavailability and pharmacokinetic properties of the most promising analogues. Moreover, we use a key compound to demonstrate the functional activity of FFA3 in cells of murine dorsal root ganglia.

\section{SYNTHESIS}

The tetrahydroquinolone target compounds were typically synthesized from the appropriate 3-ketoamide, aldehyde, and 3-aminoenone using the Hantzsch dihydropyridine synthesis (Scheme 1). Heating at $80{ }^{\circ} \mathrm{C}$ in $i$-PrOH for up to 5 days generally gave the best outcome, with longer reaction times for more hindered substrates. ${ }^{29}$ Microwave heating or synthesis from 3-ketoamide, aldehyde, 1,3-dione, and ammonia provided the product in shorter time but at the expense of lower yield and purity. The 3-ketoamide substrates were most conveniently accessed by heating of the appropriate aniline in neat methyl acetoacetate. These intermediates were also synthesized by heating of the aniline with 2,2,6-trimethyl-4H-1,3-dioxin-4-one or in the presence of Lewis acid catalysts but generally with an inferior outcome. The preferred route to the typical tetrahydroquinolone is shown in Scheme 1.

\section{RESULTS AND DISCUSSION}

The ligands were initially screened in a human FFA3-dependent $\left[{ }^{35} \mathrm{~S}\right] \mathrm{GTP} \gamma \mathrm{S}$ binding assay as this assay reflects receptormediated activation of $\mathrm{G}_{\mathrm{i} / \mathrm{o}}$ proteins and is known to generally correlate well with ligand affinity. ${ }^{30}$ Analogues of particular interest were tested further in a cAMP inhibition assay as this is an important downstream effect of $\mathrm{G}_{\mathrm{i}}$-activation. The latter was applied as a standard assay because of higher reproducibility. It is furthermore performed in whole cells, is more downstream, includes $G$ protein signal amplification, and therefore better reflects a more natural ligand-receptor response. Because the series binds to an allosteric site on FFA $3,{ }^{22}$ selected compounds were also tested together with a fixed submaximal concentration of the SCFA propionate to investigate potential allosteric effects on orthosteric agonist function.

Tetrahydroquinolones $\mathbf{1}$ and $\mathbf{2}$ were disclosed by Arena Pharmaceuticals in $2006 .{ }^{23}$ We resynthesized these compounds, confirming FFA3 agonist activity in the low micromolar range. ${ }^{22}$ 2-Furyl derivative $\mathbf{1}$ showed agonist activity with approximately 2 -fold higher potency than 3 -furyl derivative 2 in the GTP $\gamma$ S assay (Table 1).
Table 1. Initial SAR Investigations of $1,4,7,8$ Tetrahydroquinol-5-one-3-carboxamides

\begin{tabular}{|c|c|c|c|c|c|c|}
\hline & $\mathrm{R}^{1}$ & $\mathrm{R}^{2}$ & $\begin{array}{l}\text { GTP } \gamma \mathrm{S} \\
\text { pEC } \\
\left(\mathrm{E}_{\max }\right)^{a}\end{array}$ & $\begin{array}{l}\operatorname{cAMP} \\
\mathrm{pEC}_{50}\left(\mathrm{E}_{\max }\right)^{a}\end{array}$ & $\begin{array}{l}\mathrm{PAM} \\
\mathrm{pEC}_{50}{ }^{a, b}\end{array}$ & $c \log \mathrm{P}^{c}$ \\
\hline $\mathrm{C}^{d}$ & & & $\begin{array}{l}4.97 \pm 0.08 \\
(100)\end{array}$ & $\begin{array}{l}4.93 \pm 0.10 \\
(100)\end{array}$ & & \\
\hline $1-\mathrm{MCPC}^{d}$ & & & $\begin{array}{l}3.88 \pm 0.11 \\
(84)\end{array}$ & $\begin{array}{l}4.65 \pm 0.15 \\
(81)\end{array}$ & & \\
\hline $1^{d}$ & & & $\begin{array}{l}5.65 \pm 0.07 \\
(100)\end{array}$ & $\begin{array}{l}6.28 \pm 0.06 \\
(105)\end{array}$ & $6.27 \pm 0.15$ & 2.18 \\
\hline $2^{d}$ & & & $\begin{array}{l}5.24 \pm 0.08 \\
(135)\end{array}$ & $\begin{array}{l}6.27 \pm 0.03 \\
(97)\end{array}$ & & 2.18 \\
\hline 3 & & & $\begin{array}{l}4.75 \pm 0.11 \\
(103)\end{array}$ & $\begin{array}{l}5.91 \pm 0.04 \\
(98)\end{array}$ & & 3.00 \\
\hline 4 & & & $\begin{array}{l}5.52 \pm 0.18 \\
(111)\end{array}$ & $\begin{array}{l}5.79 \pm 0.04 \\
(102)\end{array}$ & $5.92 \pm 0.04$ & 2.65 \\
\hline $5^{d}$ & & & $\mathrm{nr}^{e}$ & & & 3.86 \\
\hline 6 & & & $\begin{array}{l}5.49 \pm 0.08 \\
(89)\end{array}$ & $\begin{array}{l}5.87 \pm 0.06 \\
(99)\end{array}$ & & 3.86 \\
\hline 7 & & & $\begin{array}{l}5.43 \pm 0.09 \\
(85)\end{array}$ & $\begin{array}{l}5.79 \pm 0.03 \\
(103)\end{array}$ & & 3.86 \\
\hline 8 & & & $\begin{array}{l}4.81 \pm 0.13 \\
(118)\end{array}$ & $\begin{array}{l}5.55 \pm 0.05 \\
(98)\end{array}$ & & 3.88 \\
\hline 9 & & & $\begin{array}{l}5.12 \pm 0.13 \\
(116)\end{array}$ & $\begin{array}{l}5.31 \pm 0.06 \\
(101)\end{array}$ & & 3.88 \\
\hline 10 & & & $\begin{array}{l}4.52 \pm 0.11 \\
(88)\end{array}$ & $\begin{array}{l}5.44 \pm 0.04 \\
(97)\end{array}$ & & 3.50 \\
\hline 11 & & & $\begin{array}{l}4.08 \pm 0.26 \\
(143)\end{array}$ & $\begin{array}{l}5.17 \pm 0.08 \\
(96)\end{array}$ & & 4.03 \\
\hline $12^{d}$ & & & $\begin{array}{l}5.11 \pm 0.12 \\
(81)\end{array}$ & $\begin{array}{l}5.45 \pm 0.03 \\
(97)\end{array}$ & & 2.33 \\
\hline 13 & & & $\begin{array}{l}5.34 \pm 0.15 \\
(78)\end{array}$ & $\begin{array}{l}5.80 \pm 0.04 \\
(100)\end{array}$ & & 2.83 \\
\hline 14 & & & $\begin{array}{l}5.27 \pm 0.12 \\
(88)\end{array}$ & $\begin{array}{l}6.16 \pm 0.03 \\
(100)\end{array}$ & & 2.83 \\
\hline 15 & & & $\begin{array}{l}4.71 \pm 0.28 \\
(124)\end{array}$ & $\begin{array}{l}6.43 \pm 0.03 \\
(99)\end{array}$ & & 1.66 \\
\hline $16^{d}$ & & & $\begin{array}{l}5.74 \pm 0.11 \\
(120)\end{array}$ & $\begin{array}{l}6.89 \pm 0.02 \\
(106)\end{array}$ & & 2.90 \\
\hline 17 & & & $\begin{array}{l}5.68 \pm 0.13 \\
(109)\end{array}$ & $\begin{array}{l}5.00 \pm 0.06 \\
(109)\end{array}$ & $6.28 \pm 0.14$ & 3.42 \\
\hline 18 & & & $\begin{array}{l}5.26 \pm 0.16 \\
(88)\end{array}$ & $\begin{array}{l}4.98 \pm 0.11 \\
(97)\end{array}$ & & 3.87 \\
\hline 19 & & & $\begin{array}{l}5.41 \pm 0.15 \\
(129)\end{array}$ & $\begin{array}{l}5.57 \pm 0.18 \\
(89)\end{array}$ & & 3.89 \\
\hline 20 & & & $\begin{array}{l}5.41 \pm 0.13 \\
(105)\end{array}$ & $\begin{array}{l}6.15 \pm 0.06 \\
(94)\end{array}$ & & 3.43 \\
\hline 21 & & & $\begin{array}{l}4.67 \pm 0.22 \\
(89)\end{array}$ & $\begin{array}{l}4.98 \pm 0.08 \\
(104)\end{array}$ & & 3.00 \\
\hline
\end{tabular}

${ }^{a}$ Mean of $\geq 3$ independent experiments \pm standard error. Efficacy $\left(E_{\max }\right)$ is relative to maximal response of propionate. ${ }^{b}$ cAMP assay in the presence of $1 \mu \mathrm{M}$ propionate. ${ }^{c}$ Calculated by ChemDraw Professional version 16. ${ }^{d}$ Previously published. ${ }^{21,22}{ }^{e}$ No response. 
Scheme 1. General Synthetic Route for Tetrahydroquinolone Ligands

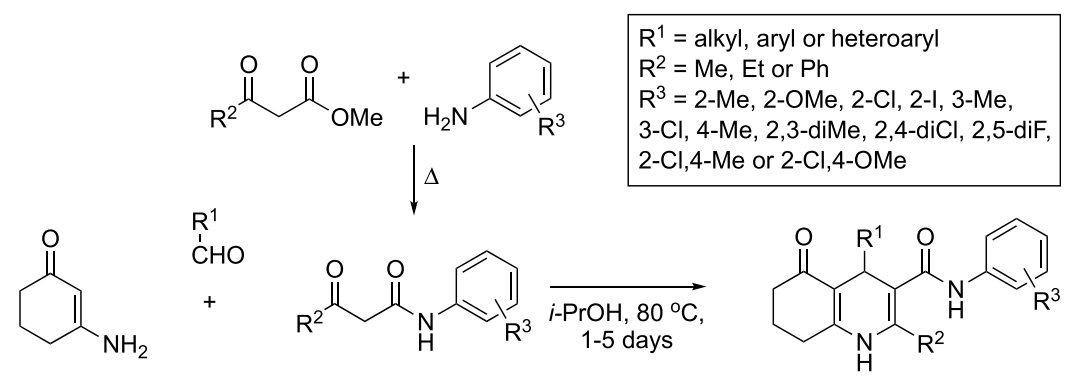

Table 2. Scaffold Exploration of Furyl and Isobutyl Analogues

\begin{tabular}{|c|c|c|c|c|c|}
\hline & $\begin{array}{l}\text { cAMP } \\
\text { pEC }_{50} \\
\left(\mathrm{E}_{\max }\right)^{a}\end{array}$ & $\begin{array}{l}\text { PAM } \\
\text { pEC }_{50, b}\end{array}$ & & $\begin{array}{l}\text { cAMP } \\
\text { pEC }_{50} \\
\left(\mathrm{E}_{\max }\right)^{a}\end{array}$ & $\begin{array}{l}\text { PAM } \\
\text { pEC }_{50}{ }^{a, b}\end{array}$ \\
\hline 22 & $\begin{array}{l}5.47 \pm \\
0.04(95)\end{array}$ & & 26 & $\mathrm{nr}^{c}$ & $\begin{array}{l}6.16 \pm \\
0.12\end{array}$ \\
\hline 23 & $\mathrm{nr}^{c}$ & & 27 & $3.99 \pm 0.01$ & $\begin{array}{l}6.42 \pm \\
0.09\end{array}$ \\
\hline 24 & $\mathrm{nr}^{c}$ & $\mathrm{nr}^{c, d}$ & 28 & $\mathrm{nr}^{c}$ & $\begin{array}{l}6.21 \pm \\
0.10\end{array}$ \\
\hline 25 & $\mathrm{nr}^{c}$ & $\mathrm{nr}^{c}$ & 29 & $\mathrm{nr}^{c}$ & $>4$ \\
\hline
\end{tabular}

${ }^{a}$ Mean of $\geq 3$ independent experiments \pm standard error. Efficacy $\left(E_{\max }\right)$ is relative to maximal response of propionate. ${ }^{b}$ cAMP assay in the presence of $1 \mu \mathrm{M}$ propionate. ${ }^{c}$ No response. ${ }^{d} \mathrm{GTP} \gamma \mathrm{S}$ assay.

Replacing the 2-furyl with phenyl (3) led to significant deterioration of potency, whereas 2-thienyl (4), a group with a size and polarity that more closely resembles phenyl than furyl, largely preserved potency in the GTP $\gamma$ S assay.

The analogue with 2-bromophenyl (5) was previously characterized and found to be inactive alone but to act as a PAM of propionate, implying that 5 binds to FFA3 but is unable to activate the receptor directly. ${ }^{22}$ Introducing bromosubstituents in the 3- (6) or 4-position (7) of phenyl derivative 3 regained most of the activity relative to 2 -furyl derivative 1 in the GTP $\gamma \mathrm{S}$ assay, whereas the potency was essentially constant for 3-4 and 6-7 in the cAMP assay. Analogues with 3- (8) and 4trifluoromethyl (9) and 4-methyl (10) substituents were full agonists with potencies similar to or lower than that of the unsubstituted 3, whilst extension to 4-ethyl (11) eroded potency.

Replacement of $o$-tolyl by phenyl (12) gave a $>3$-fold drop in potency, whereas $m$-tolyl (13) or $p$-tolyl (14) resulted in a more moderate drop, indicating the ortho-position as the most interesting. Introduction of methoxy (15) further eroded potency in the GTP $\gamma$ S binding assay but retained potency in the cAMP inhibition assay. The 2,5-dichloro-substituted AR420626 (16) also originates from Arena Pharmaceuticals and has been described as a tool compound in the literature and characterized by us. ${ }^{22,24,25}$ Like $\mathbf{1}$, this compound exhibited only moderate potency in the GTP $\gamma$ S assay ${ }^{22}$ but is an order of magnitude more potent in the cAMP assay. It thus represents one of the most potent compounds but is also known to have poor solubility.
We also wished to explore aliphatic $\mathrm{R}^{1}$ groups, and we were pleased to find that isobutyl (17) behaved as an FFA3 agonist with a potency similar to that of $\mathbf{1}$ in the $\left.{ }^{[35} \mathrm{S}\right] \mathrm{GTP} \gamma \mathrm{S}$ binding assay. Introducing 2,3-dimethyl (18), 2-iodo (19), 2-chloro (20), or 2,6-difluorophenyl (21) on the $\mathrm{R}^{2}$ phenyl while keeping $\mathrm{R}^{1}$ as isobutyl produced active compounds with potencies comparable to that of $\mathbf{1 7}$, with 20 representing an improvement in the cAMP but not in the GTP $\gamma \mathrm{S}$ assay. In general, results from the cAMP assay corresponded satisfactorily with the GTP $\gamma \mathrm{S}$ data, although some of the compounds deviated considerably. Notably, increased potency of 10-, 14-, and 50-fold was observed for 2,3 , and 15 , respectively. In contrast, only 17 and 18 exhibited a lower potency of 5- and 2-fold, respectively. On the other hand, together with $1 \mu \mathrm{M}$ propionate, 17 exhibited a potency that was equal with $\mathbf{1}$ (with or without propionate). As the cAMP assay is more downstream and showed a reproducibility that was at least as good as the GTP $\gamma \mathrm{S}$ assay, this was chosen as the primary assay for the remaining compounds.

We next turned our attention to the other parts of the structure (Table 2). An extension of the ortho-methyl at the dihydropyridine to ethyl (22) led to an order of magnitude decrease of potency while a phenyl (23) produced a completely inactive compound. Oxidation of the dihydropyridine to pyridine (24) also produced an inactive compound, perhaps unsurprisingly because this compound represents substantial structural changes.

Using 17 as a starting point, opening of the cyclohexanone and formation of a phenone (25) or methyl ester (26) both produced compounds that were inactive $\left(\mathrm{pEC}_{50}<4\right)$ alone but 
Table 3. SAR Exploration of Aliphatic and Heterocyclic Analogues

\begin{tabular}{|c|c|c|c|c|c|c|c|c|c|}
\hline & $\mathrm{R}^{1}$ & $\begin{array}{l}\text { cAMP } \\
\mathrm{pEC}_{50} \\
\left(\mathrm{E}_{\max }\right)^{a}\end{array}$ & $\begin{array}{l}\text { PAM } \\
\mathrm{pEC}_{50} a, b\end{array}$ & $\operatorname{clog} \mathrm{P}^{c}$ & & $\mathrm{R}^{1}$ & $\begin{array}{l}\text { cAMP } \\
\mathrm{pEC}_{50} \\
\left(\mathrm{E}_{\max }\right)^{a}\end{array}$ & $\begin{array}{l}\text { PAM } \\
\mathrm{pEC}_{50}{ }^{a, b}\end{array}$ & $\operatorname{clog} \mathrm{P}^{c}$ \\
\hline 17 & & $\begin{array}{l}5.00 \pm \\
0.06 \\
(109)\end{array}$ & $\begin{array}{l}6.28 \pm \\
0.14\end{array}$ & 3.42 & 38 & & $\begin{array}{l}4.21 \pm \\
0.27 \\
(97)\end{array}$ & $\begin{array}{l}6.23 \pm \\
0.03\end{array}$ & 3.91 \\
\hline 30 & & $\begin{array}{l}5.00 \pm \\
0.07 \\
(110)\end{array}$ & $\begin{array}{l}6.30 \pm \\
0.04\end{array}$ & 3.42 & $39^{d}$ & & $\begin{array}{l}4.34 \pm \\
0.18 \\
(113)\end{array}$ & $\begin{array}{l}6.14 \pm \\
0.07\end{array}$ & 3.60 \\
\hline 31 & & $\begin{array}{l}5.26 \pm \\
0.10 \\
(91)\end{array}$ & & 3.99 & 40 & & $\begin{array}{l}4.95 \pm \\
0.08 \\
(96)\end{array}$ & & 2.25 \\
\hline 32 & & $\begin{array}{l}6.54 \pm \\
0.02 \\
(102)\end{array}$ & & 3.43 & 41 & & $\begin{array}{l}4.45 \pm \\
0.09 \\
(97)\end{array}$ & & 2.07 \\
\hline 33 & & $\begin{array}{l}6.22 \pm \\
0.10 \\
(102)\end{array}$ & & 2.32 & 42 & & $\begin{array}{l}5.96 \pm \\
0.03 \\
(100)\end{array}$ & & 2.68 \\
\hline 34 & & $\begin{array}{l}5.38 \pm \\
0.13 \\
(106)\end{array}$ & $\begin{array}{l}6.45 \pm \\
0.16\end{array}$ & 2.49 & 43 & & $\begin{array}{l}5.86 \pm \\
0.04 \\
(102)\end{array}$ & & 3.15 \\
\hline 35 & & $\begin{array}{l}5.92 \pm \\
0.01 \\
(101)\end{array}$ & $\begin{array}{l}6.16 \pm \\
0.10\end{array}$ & 3.02 & 44 & & $\begin{array}{l}6.61 \pm \\
0.02 \\
(95)\end{array}$ & & 3.04 \\
\hline 36 & & $\begin{array}{l}5.86 \pm \\
0.03\end{array}$ & $\begin{array}{l}6.58 \pm \\
0.06\end{array}$ & 3.55 & 45 & & $\begin{array}{l}6.00 \pm \\
0.02 \\
(98)\end{array}$ & & 3.56 \\
\hline 37 & & $\begin{array}{l}5.60 \pm \\
0.17\end{array}$ & $\begin{array}{l}6.40 \pm \\
0.10\end{array}$ & 4.08 & 46 & & $\begin{array}{l}5.11 \pm \\
0.04 \\
(95)\end{array}$ & & 4.03 \\
\hline
\end{tabular}

${ }^{a}$ Mean of $\geq 3$ independent experiments \pm standard error. Efficacy $\left(E_{\max }\right)$ is relative to maximal response of propionate. ${ }^{b}$ cAMP assay in the presence of $1 \mu \mathrm{M}$ propionate. ${ }^{c}$ Calculated by ChemDraw Professional version 16 . ${ }^{d}$ Previously published. ${ }^{31}$

26 acted as PAM with propionate, indicating that some larger changes in the structure also produced compounds with affinity for FFA3. Introduction of a nitrile (27) produced a compound that was active alone, albeit with low potency, but that was substantially potentiated by the presence of propionate. We also wished to explore the significance of the ketone; however, all attempts to reduce the cyclohexanone carbonyl or derivatize, for example, to form oximes, were unsuccessful, partly due to low electrophilicity due to stabilization by conjugation to the enamine of the dihydropyridine system and partly due to instability of products.

Replacement of the anilide part by a methyl ester (28) or a phenone (29) produced compounds that also were inactive alone but exhibited PAM properties. Introduction of a carboxylic acid in this position produced a compound that could not be characterized or tested due to insufficient solubility.

We next reverted to the $\mathrm{R}^{1}$ group to further explore aliphatic substituents (Table 3). Introduction of sec-butyl (30) resulted in a compound with very similar properties to isobutyl 17 . The sterically more well-defined cyclohexyl (31) gave marginally increased potency which could be a result of a hydrophobic effect. Surprisingly, the slightly smaller cyclopentyl (32) increased potency 20 -fold to $288 \mathrm{nM}$. Cyclopropyl (33) maintained good potency at $600 \mathrm{nM}$ with an order of magnitude reduced lipophilicity. A series of $n$-alkyls from ethyl to pentyl (34-37) resulted in agonists with micromolar potency, with propyl (35) and butyl (36) being the most potent and the shorter ethyl (34) the least potent. Further extension with phenethyl (38), styryl (39), and pyrazolylethyl (40) continued this trend with $\mathrm{pEC}_{50}$ values $<5$, interestingly, with the less lipophilic 40 exhibiting the highest potency of the three. All compound were full agonists.

Identification of the cyclopentyl as the most potent aliphatic substituent motivated another venture into similarly sized aromatic substituents. N-Methyl-2-pyrazole (41) was a lowpotency compound, in line with ortho-substituted phenyls such as 5. Furyls and thienyls with small substituents resulted in better potency, with 5-bromo-2-furyl (44) and 2-benzofuryl (45) as the most potent. The lower potency of 3-benzothienyl 46 is likely due to the positioning of the benzene ring.

In an attempt to increase aqueous solubility by decreasing lipophilicity, the 2 -furyl of 16 was replaced by 2 -thiazolyl (47), 5-thiazolyl (48), and 4-thiazolyl (49) (Table 3). This strategy failed, as the solubility dropped from 5 to below $2 \mu \mathrm{M}$ for the thiazolyl analogues in a kinetic solubility assay, although the potency was only slightly decreased for 47 (Table 4). Also, even though clogP of 47-49 indicated an order of magnitude improvement of lipophilicity relative to $16\left(\log D_{7.4}=3.19\right)$, measured $\log D_{7.4}$ revealed similar or increased lipophilicity. Replacement by 4-oxazolyl (50) improved solubility $>10$-fold but had a detrimental effect on potency. On the other hand, 2oxazolyl (51) improved potency but reduced solubility to $1 \mu \mathrm{M}$. 
Table 4. SAR Exploration of 2,5-Dichloro Analogues

48

${ }^{a}$ Mean of $\geq 3$ independent experiments \pm standard error. Efficacy $\left(E_{\max }\right)$ is relative to maximal response of propionate. ${ }^{b}$ Calculated by ChemDraw Professional version $16 .{ }^{\circ}$ Kinetic solubility at $25{ }^{\circ} \mathrm{C}$ in phosphate buffered saline $\mathrm{pH} 7.4\left(\mathrm{PBS}_{7.4}\right) .{ }^{d}$ No response.

With a focus on solving the solubility problem, we returned to the aliphatic substituents aiming to incorporate a positive charge. Unfortunately, both small polar and larger, lipophilic amine substituents (52-54) produced inactive compounds. Analogues with negatively charged carboxylate groups in the same position (not shown) were also explored but were completely inactive. Boc-protected intermediates (55-56) were tested and found to be inactive alone. 52-55 were also inactive in the presence of $3 \mu \mathrm{M}$ propionate and were therefore also not PAMs. However, 56, representing the compound with the largest $\mathrm{R}^{1}$ substituent explored in this study, turned out to be a NAM, effectively inhibiting receptor signaling at $30 \mu \mathrm{M}$ concentration (Figure 1). This is in line with previous compounds characterized as FFA3 NAMs, where $\mathrm{R}^{1}$ was 3 - or 4-phenoxyphenyl and substantially larger than other $\mathrm{R}^{1}$-groups explored in the series. Thus, a larger $\mathrm{R}^{1}$ increases the chance of finding a NAM or antagonist.

We reasoned that the generally poor physicochemical properties of the 2,5-dichlorophenyl compounds are worsened with aromatic or larger, lipophilic $\mathrm{R}^{1}$-groups. With the failure of positively charged $\mathrm{R}^{1}$ groups to produce FFA3 agonists, we therefore proceeded with exploration of smaller neutral groups. The combination of $n$-propyl with 2,5-dichlorophenyl (57) indeed produced a compound with similar potency to 16 but 6 fold increased solubility (Table 5). Hoping to further increase solubility, we next investigated the requirements of chlorinated $\mathrm{R}^{2}$-groups in relation to potency. The 2-chloro (58) or 5-chloro
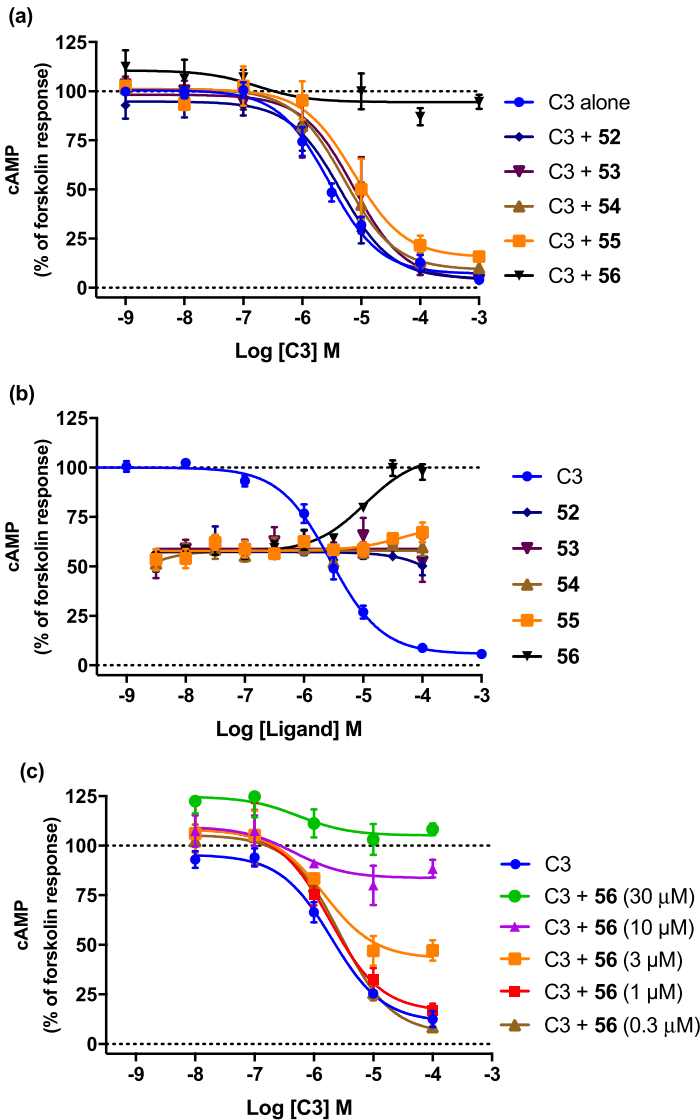

Figure 1. NAM 56 in the cAMP assay. (a) Concentration-response curves for propionate (C3) alone or together with $30 \mu \mathrm{M}$ 52-56. (b) Concentration-response curves for $\mathrm{C} 3$ and 52-56 with $3 \mu \mathrm{M} \mathrm{C} 3$. (c) Concentration-response curves for $\mathrm{C} 3$ alone and with increasing concentrations of $\mathbf{5 6}$ (from $300 \mathrm{nM}$ to $30 \mu \mathrm{M}$ ). Data represent the mean of three independent experiments and is normalized to forskolin.

Table 5. SAR of Neutral Aliphatic $\mathbf{R}^{1}$ and Chlorinated $\mathbf{R}^{2}$

\begin{tabular}{|c|c|c|c|c|c|c|}
\hline & $\mathrm{R}^{1}$ & $\mathrm{R}^{2}$ & $\begin{array}{l}\text { cAMP pEC } \mathrm{C}_{50} \\
\left(\mathrm{E}_{\max }\right)^{a}\end{array}$ & $\operatorname{cog} \mathrm{P}^{b}$ & $\begin{array}{l}\text { Aq. } \\
\text { solub. } \\
(\mu \mathrm{M})\end{array}$ & $\log \mathrm{D}_{7.4}$ \\
\hline 57 & & & $\begin{array}{l}6.84 \pm 0.02 \\
(113)\end{array}$ & 3.75 & 33 & 4.25 \\
\hline 58 & & & $\begin{array}{l}6.06 \pm 0.05 \\
(105)\end{array}$ & 3.03 & 169 & 3.22 \\
\hline 59 & & & $\begin{array}{l}5.97 \pm 0.05 \\
(105)\end{array}$ & 3.88 & 137 & 3.77 \\
\hline 60 & & & $\begin{array}{l}6.19 \pm 0.10 \\
(103)\end{array}$ & 3.79 & 145 & 3.57 \\
\hline 61 & & & $\begin{array}{l}5.96 \pm 0.08 \\
(96)\end{array}$ & 3.31 & 157 & 3.07 \\
\hline 62 & & & $\begin{array}{l}6.60 \pm 0.06 \\
(98)\end{array}$ & 3.04 & 5 & 3.73 \\
\hline 63 & & & $\begin{array}{l}6.79 \pm 0.05 \\
(99)\end{array}$ & 4.16 & 9 & $>4.3$ \\
\hline
\end{tabular}

${ }^{a}$ Mean of $\geq 3$ independent experiments \pm standard error. Efficacy $\left(E_{\text {max }}\right)$ is relative to maximal response of propionate. ${ }^{b}$ Calculated by ChemDraw Professional version $16 .{ }^{d}$ No response. 
(a)

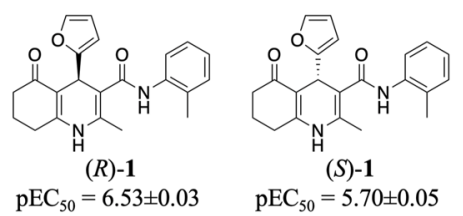

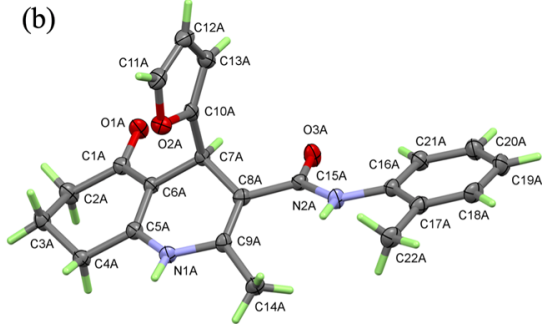

Figure 2. Identification of the most potent enantiomer. (a) cAMP data for $(R)-\mathbf{1}$ and $(S)$-1, data are mean of $\geq 3$ independent experiments \pm standard error. Structure and numbering scheme of one of the two molecules (molecule A) in the asymmetric unit of $(R)-1$.
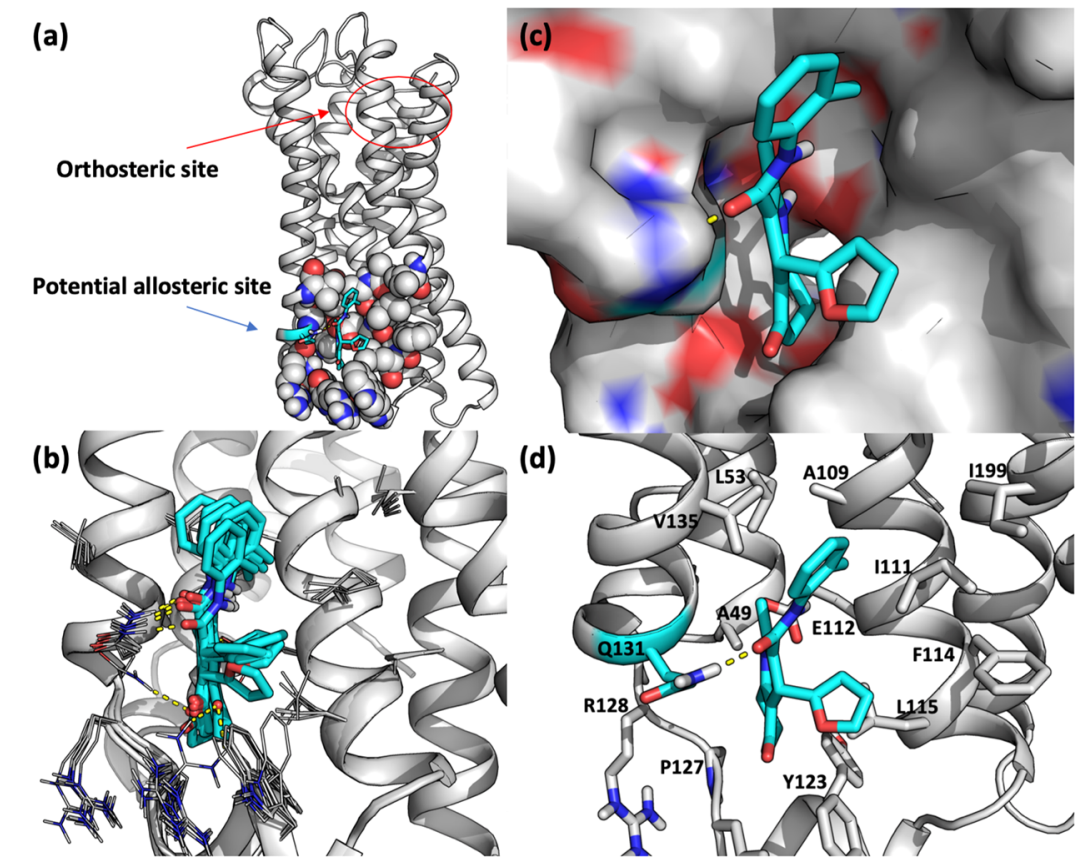

Figure 3. Proposed allosteric binding site in a homology model of hFFA3 in complex with (R)-1. (a) Full receptor marked with the orthosteric binding site and potential allosteric binding site. (b) Overlay of 7 out of 10 docking poses. (c) Binding pocket surface. (d) Binding pose highlighting Q131.

(59) substituents alone were accompanied by 4-5-fold increased solubility compared to $\mathbf{5 7}$ but reduced potency down to a level similar to $o$-tolyl (35, Table 3 ). The solubility of 35 was $199 \mu \mathrm{M}$ and its $\log D_{7.4}$ was 2.64 and thus favorable compared to all chlorinated compounds and comparable with $\mathbf{1}$ (190 $\mu \mathrm{M}$ solubility, $\left.\log D_{7.4} 2.05\right)$. A tendency toward higher potency for $\mathbf{5 8}$ indicated that the 2-chloro is more important than the 5-chloro, in line with observations for methyl substituents (cf. 1, 13, 14, Table 1). In an attempt to regain potency but keep the solubility properties, the 5-chloro of $\mathbf{5 7}$ was replaced by methyl $(60)$ or methoxy $(61)$. This indeed resulted in compounds with solubilities similar to the other monochlorinated compounds, but the potency was also similar or only marginally improved. Chemical stability was also tested, and all compounds (58-61) were completely recovered after 1 week at $37{ }^{\circ} \mathrm{C}$ in PBS. Finally, revisiting small aliphatic cycles, cyclopropyl (62) partly regained and cyclopentyl (63) fully regained the potency of the 2 -furyl analogue 16 , but with similar or only moderately increased solubility. Compounds $\mathbf{6 2}$ and 63 were also tested in the cAMP assay together with $1 \mu \mathrm{M}$ propionate but did not reveal significant PAM effects. Overall, of the compounds tested as PAMs, none with $\mathrm{pEC}_{50}>6$ showed significantly enhanced potency in the presence of propionate.

To identify the most active enantiomer, racemic 1 was resolved by chiral HPLC and crystallized. The single crystal X- ray structures for one enantiomer (Figure 2) along with that of the racemate (Figure S1) were determined. The absolute configuration of the most active enantiomer $(R)-1$ was determined by anomalous dispersion effects with a Flack parameter of $0.04(12)$. However, the assignment must be viewed with some caution because of the high standard deviation in the Flack parameter. Crystal packing is influenced by the presence of a single or both enantiomers in the lattices of $(R)-1$ and $(R, S)-1$, respectively. Both structures show that the strongest intermolecular interaction between molecules is the $\mathrm{H}$-bonding between the cyclic carbonyl (O1) and the amine $\mathrm{NH}$ group (N1) of the adjacent molecule (Figure S2). These Hbonds link the molecules in ribbons approximately parallel to the $a$ - and $c$-axis in the structures of $(R)-\mathbf{1}$ and $(R, S)-\mathbf{1}$, respectively (Figures S5 and S2). The ribbons stack with the 2-furyl rings located on the same side of every molecule in (R)-1 (Figure S6). In $(R, S)-\mathbf{1}$, they are alternating in the up and down positions in accordance with the $\mathrm{H}$-bonded ribbons comprising alternating $R$ and $S$ enantiomers (Figure S3).

The previously published compound 1 was not affected by mutation of either R185A or R258A in the orthosteric binding site, and the compounds were therefore believed to be allosteric modulators. In the search for the potential allosteric binding site, we mutated a third arginine residue in a neighboring site (R71A); however, this did not affect the potency of $\mathbf{1}$. After the 
Table 6. In Vitro Stability and in Vivo Pharmacokinetic Properties of Selected Compounds in Mice

\begin{tabular}{|c|c|c|c|c|c|c|c|c|c|c|c|c|}
\hline & \multirow[b]{2}{*}{$\begin{array}{l}\text { cAMP } \\
\text { pEC }_{50}{ }^{a}\end{array}$} & \multirow[b]{2}{*}{$\begin{array}{l}\text { aq. sol. } \\
(\mu \mathrm{M})^{a}\end{array}$} & \multirow[b]{2}{*}{$\log _{a}$} & \multirow[b]{2}{*}{$\underset{(\%)^{b}}{\operatorname{MLM}}$} & \multicolumn{3}{|c|}{ iv dosing $(5 \mathrm{mg} / \mathrm{kg})$} & \multicolumn{4}{|c|}{ po dosing $(10 \mathrm{mg} / \mathrm{kg})$} & \multirow[b]{2}{*}{$\begin{array}{c}F \\
(\%)\end{array}$} \\
\hline & & & & & $\begin{array}{c}t_{1 / 2} \\
(\mathrm{~min})\end{array}$ & $\begin{array}{c}V_{\mathrm{d}} \\
(\mathrm{mL} / \mathrm{kg})\end{array}$ & $\begin{array}{c}\mathrm{CL}_{\text {total }} \\
(\mathrm{mL} / \mathrm{min} / \mathrm{kg})\end{array}$ & $\begin{array}{c}t_{1 / 2} \\
(\mathrm{~min})\end{array}$ & $\left(\begin{array}{l}t_{\max } \\
\min )\end{array}\right.$ & $\begin{array}{c}c_{\max } \\
(\mathrm{ng} / \mathrm{mL})\end{array}$ & $\begin{array}{c}\mathrm{AUC}_{\text {inf }} \\
(\mathrm{ng} \mathrm{min} / \mathrm{mL})\end{array}$ & \\
\hline 1 & 6.28 & 190 & 2.05 & 52 & 62.2 & 759 & 8.45 & 89.7 & 15 & 7470 & 865000 & 73 \\
\hline 16 & 6.89 & 5 & 3.19 & 1 & 22.3 & 629 & 19.6 & 60.8 & 30 & 5740 & 423000 & 88 \\
\hline 35 & 5.92 & 199 & 2.64 & 23 & & & & & & & & \\
\hline 47 & 6.60 & 1 & 3.39 & 2 & & & & & & & & \\
\hline 51 & 6.72 & 1 & 2.59 & 12 & & & & & & & & \\
\hline 57 & 6.84 & 33 & 4.25 & 1 & 11.4 & 1150 & 70.3 & 63.5 & 30 & 561 & 33800 & 36 \\
\hline 62 & 6.60 & 5 & 3.73 & 1 & & & & & & & & \\
\hline 63 & 6.79 & 9 & $>4.3$ & 41 & 37.8 & 1110 & 20.3 & 51.8 & 15 & 3800 & 325000 & 66 \\
\hline
\end{tabular}

publication of the FFA1 crystal structure in complex with an allosteric agonist located in the TM region close to the intracellular site, ${ }^{32}$ a homology model of hFFA3 was constructed using Modeller. The model revealed a similar potential binding site on FFA3 and initial docking studies of $(R)$-1 indicated three amino acids that might be involved in binding (Figure 3a). Mutation of E112A and R126A did not affect the potency of (R)-1 or propionate, whereas Q131A significantly reduced the potency of $(R)-1$ (>3-fold, $p<0.001)$ but did not affect the potency of propionate. Thus, additional docking of $(R)-1$ in this site were performed to find poses where Q131, but not R126, show a central role in binding. Seven out of 10 poses showed a hydrogen bond interaction between Q131 and either the amide carbonyl or the ketone without any constraints used and only one of the poses showed an additional hydrogen bonding to R126 (Figure 3b). The narrow binding cavity around the core scaffold is in agreement with the restrained SAR observed for this series and the furan moiety pointing out of the binding cavity might explain the flexibility in substituents at this site (Figure 3c,d). Although Q131A impacts the potency of $(R)-1$ with high significance, the magnitude of the effect is lower than what would be generally expected for the removal of a hydrogen bond interaction; thus, additional studies are required to confirm the proposed binding site.

With several compounds with improved properties in hand, we wished to investigate the suitability of the compounds as tools for in vivo studies in rodents. Because of the moderate potency and low solubility associated with this series, it has been presumed that they are poorly suited as in vivo tools. A basic requirement is preserved activity on the relevant species orthologues, which generally has been observed to be low within the free fatty acid receptor group. ${ }^{19}$ We confirmed that propionate maintained potency between human and rodent species. 1 and 16 both lost 3-10-fold potency from human to rodent species $\left(1 \mathrm{pEC}_{50}=5.87 \pm 0.07\right.$ on $\mathrm{rFFA3}, 5.42 \pm 0.04$ on mFFA3; $16 \mathrm{pEC}_{50}=6.34 \pm 0.04$ on $\mathrm{rFFA} 3,5.88 \pm 0.05$ on mFFA3), whereas 63 now tended toward the highest potency on the rodent orthologues $\left(\mathrm{pEC}_{50}=6.39 \pm 0.03\right.$ on rFFA3; $\mathrm{pEC}_{50}=$ $5.96 \pm 0.04$ on mFFA3).

We next investigated the chemical stability of the compounds and stability toward liver microsomes. Representative compounds were shaken in PBS at $\mathrm{pH}$ 7.4. Apart from some that precipitated, all compounds were quantitatively recovered after 1 week. On the other hand, the tested compounds exhibited varying stability towards mouse liver microsomes (MLM, Table 6). In the one end, 1 and $\mathbf{6 3}$ showed good stability, comparable with the propranolol reference compound $(61 \%)$. In the other end, only $1-2 \%$ was recovered of $16,47,57$, and 62 . The remaining compounds were in the intermediate range. Apart from a generally higher stability of the $o$-tolyl compounds 1 and 35 than the remaining 2,5-dichlorophenyl compounds, it was difficult to see a clear relationship between structural or physicochemical properties and microsomal stability.

Based on the results so far, 63 appeared as a good compromise between the properties of $\mathbf{1}$ and 16, and 57 represented a good compromise between potency and solubility. We therefore selected these four compounds for pharmacokinetic studies in mice. Although the microsomal data for at least 16 and $\mathbf{5 7}$ indicated that these compounds would have a fast clearing, we decided to run the pharmacokinetic study using the same time frame for all compounds. Overall, the four compounds had surprisingly favorable PK properties and especially 1, 16, and 63 showed high bioavailability. Compound 1 exhibited the longest half-life, approximately an hour after iv dosing, and the lowest clearance, whereas 16 showed a half-life of $20 \mathrm{~min}$. 63 was somewhat in between the two, and $\mathbf{5 7}$ had the shortest iv halflife. Half-life after oral dosing was satisfactory for all compounds. $1,16,57$, and 63 were counterscreened on the related FFA receptors FFA1 and FFA2, the more distant FFA receptors FFA4 and GPR84, and the L-type calcium ion channels, a target for related dihydropyridine ligands. No significant activity was detected at any of the receptors at $10 \mu \mathrm{M}$ concentration (see Supporting Information).

Because of its good compromise between solubility and potency $\left(\mathrm{EC}_{50}=2 \mu \mathrm{M}\right.$ at mFFA3 vs $30 \mu \mathrm{M}$ for propionate in the $\mathrm{GTP} \gamma \mathrm{S}$ assay), $\mathbf{5 7}$ was considered for further in vitro studies. To further ensure the suitability of $\mathbf{5 7}$ as a tool compound for in vitro studies, the chemical stability was also evaluated in dimethyl sulfoxide (DMSO). An NMR sample was stored at 4 ${ }^{\circ} \mathrm{C}$, and recordings after 1 and 30 days showed complete stability. A sample stored at rt (not protected from light) was fully stable for 7 days, whereas minor decomposition was detected after 30 days (see Supporting Information).

Thus, $\mathbf{5 7}$ was selected for studies in cells from dorsal root ganglia (DRGs) isolated from wild-type and FFA3 KO mice. Addition of $57(5 \mu \mathrm{M})$ gave a large elevation in intracellular calcium levels in wild type but not FFA3 $\mathrm{KO}$ cells, indicating a FFA3-specific effect of $\mathbf{5 7}$ on DRG cells (Figure 4). These results suggest, in line with previous studies, ${ }^{17,18}$ a key role for FFA3 in mediating effects for SCFAs from the gut microbiome within the peripheral nervous system. They furthermore for the first time demonstrate a pharmacological intervention at ganglionic FFA3, that $\mathbf{5 7}$ is able to evoke a response with high selectivity and that ganglionic FFA3 has potential as a therapeutic target for pain and metabolic disorders. Further 


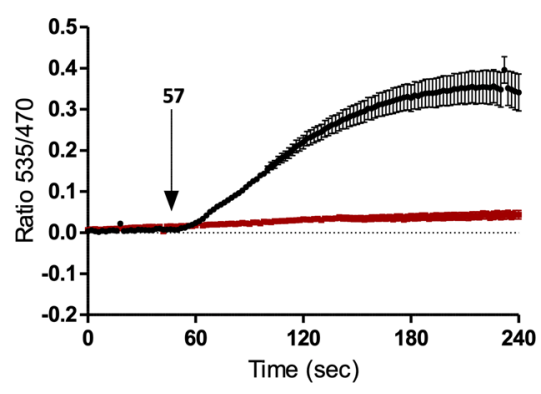

Figure 4. Compound 57 promotes FFA3-dependent elevation of intracellular $\mathrm{Ca}^{2+}$ in cells dissociated from mouse dorsal root ganglia. The arrow indicates addition of $\mathbf{5 7}(5 \mu \mathrm{M})$. Results are expressed as relative fluorescence; WT (black): $N=3$ (number of mice), $n=34$ (number of cells) and $\mathrm{KO}$ (red): $N=3, n=28$.

studies of the role of FFA3 in dorsal root ganglions using $\mathbf{5 7}$ as a tool compound are in progress.

\section{CONCLUSIONS}

We have performed an extensive SAR investigation around a series of 1,4,7,8-tetrahydroquinol-5-one FFA3 allosteric modulators that has led to the identification of key structural parts required for inducing effects on FFA3 and parts where modifications are permitted. The studies revealed that the aromatic substituents at the 4-position (referred to as $\mathrm{R}^{1}$ ) can be replaced by small aliphatic substituents with fully preserved potency. Extension of the $\mathrm{R}^{1}$-group leads to loss of agonist activity but may produce antagonists or NAMs. The 2,5dichlorophenyl at the amide $\left(\mathrm{R}^{2}\right)$ has a beneficial effect on potency but a detrimental effect on solubility. The combination of N-2,5-dichlorophenyl with a smaller aliphatic substituent in the 4-position on the tetrahydroquinol-5-one resulted in compounds with preserved potency and improved solubility. The most potent enantiomer was found to have the $(R)$ configuration. We have for the first time evaluated the in vitro solubility, lipophilicity, and metabolic stability and in vivo pharmacokinetic properties of members of this compound series. Despite largely suboptimal result from in vitro studies, the compounds overall demonstrated surprisingly favorable in vivo pharmacokinetic properties. Compound 63 was found to have well preserved potency on rodent orthologues, good stability toward MLMs, and favorable PK properties for use as an in vivo tool compound. The previously characterized agonists 1 and 16 were also found to have surprisingly favorable PK profiles, although the former suffers from moderate potency and the latter from low solubility. Compound $\mathbf{5 7}$ was found to have sufficiently good aqueous solubility and good potency but showed the least favorable PK properties of the studied compounds; thus this is the preferred compound for in vitro but not in vivo studies. Studies of $\mathbf{5 7}$ in isolated DRGs demonstrated potent and FFA3-specific calcium mobilization in DRG cells. The study shows that compounds from this series, in the absence of highly potent FFA 3 agonists, have merits as both in vitro and in vivo research tools.

\section{EXPERIMENTAL SECTION}

All commercial starting materials and solvents were used without further purification, unless otherwise stated. Chemicals were obtained from Sigma-Aldrich, except 3-oxo- $\mathrm{N}$-(o-tolyl)butanamide (Fluorochem), 2',5'-dichloroacetoacetanilide (Alfa Aesar), oxazole-2-carboxaldehyde (Combi-Blocks), and 2-(dimethylamino)acetaldehyde (Combi-Blocks). THF was freshly distilled from sodium/benzophe- none. DCM was freshly distilled and stored over $4 \AA$ sieves. TLC was performed on TLC Silica gel $60 \mathrm{~F} 254$ plates and visualized at $254 \mathrm{~nm}$ or by staining with ninhydrin, phosphomolybdic acid, or $\mathrm{KMnO}_{4}$. Petroleum ether refers to alkanes with bp $60-80{ }^{\circ} \mathrm{C}$. Purification by flash chromatography was carried out using silica gel $60(0.040-0.063$ $\mathrm{mm}$, Merck) or in prepacked columns on a Reveleris X2. ${ }^{1} \mathrm{H}$ and ${ }^{13} \mathrm{C}$ NMR spectra were recorded at 400 (or 500) and $101 \mathrm{MHz}$ at $300 \mathrm{~K}$. Spectra were calibrated relative to residual solvent peaks: ${ }^{1} \mathrm{H}$ NMR $\left(\mathrm{CDCl}_{3}\right): 7.26 \mathrm{ppm} ;{ }^{13} \mathrm{C} \mathrm{NMR}\left(\mathrm{CDCl}_{3}\right): 77.16 \mathrm{ppm} ;{ }^{1} \mathrm{H} \mathrm{NMR}$ (DMSO- $d_{6}$ ): $2.50 \mathrm{ppm} ;{ }^{13} \mathrm{C}$ NMR (DMSO- $\left.d_{6}\right): 39.52 \mathrm{ppm} ;{ }^{1} \mathrm{H}$ NMR (CD $\left.{ }_{3} \mathrm{OD}\right): 3.31 \mathrm{ppm} ;{ }^{13} \mathrm{C}$ NMR ( $\left.\mathrm{CD}_{3} \mathrm{OD}\right): 49.00 \mathrm{ppm} ;{ }^{1} \mathrm{H}$ NMR (acetone- $d_{6}$ ): $2.05 \mathrm{ppm} ;{ }^{13} \mathrm{C}$ NMR (acetone- $d_{6}$ ): $29.84 \mathrm{ppm}$. Purity was determined by HPLC and confirmed by inspection of NMR spectra $\left({ }^{1} \mathrm{H}\right.$ and ${ }^{13} \mathrm{C}$ NMR). HPLC analysis was performed using a Dionex 120 C18 column $(5 \mu \mathrm{m}, 4.6 \times 150 \mathrm{~mm})$ or Gemini C18 column $(5 \mu \mathrm{m}, 4.6$ $\times 150 \mathrm{~mm}$ ); flow: $1 \mathrm{~mL} / \mathrm{min}$; $10 \% \mathrm{MeCN}$ in water $(0-1 \mathrm{~min}), 10-$ $100 \% \mathrm{MeCN}$ in water $(1-10 \mathrm{~min})$, and $100 \% \mathrm{MeCN}(10-15 \mathrm{~min})$, with both solvents containing $0.1 \%$ formic acid as modifier; UV detection at $254 \mathrm{~nm}$. Purification of enantiomers was performed on a chiral LUX cellulose-1 column. High-resolution mass spectra (HRMS) were recorded on a Bruker micrOTOF-Q II (ESI). None of the test compounds showed patterns associated with PAINS or aggregators by screening in Zinc (http://zinc15.docking.org/patterns/home/). All test compounds were of $\geq 95 \%$ purity with the exception of $41(82.1 \%)$ and 46 (94.3\%).

$\mathrm{X}$-ray crystal diffraction data were collected at $100(2) \mathrm{K}$ on a Synergy, Dualflex, AtlasS2 diffractometer using $\mathrm{CuK} \alpha$ radiation $(\lambda=$ $1.54184 \AA$ ) and the CrysAlis PRO 1.171.38.43 suite. Using Olex $2,{ }^{33}$ the structures were solved with the ShelXT ${ }^{34}$ structure solution program using Intrinsic Phasing and refined with the ShelXL ${ }^{34}$ refinement package using Least Squares minimization. All nonhydrogen atoms were refined using anisotropic atomic displacement parameters, and hydrogen atoms were inserted at calculated positions using a riding model, except those belonging to the secondary amine and the amide groups. These hydrogen atoms were located in different electron density maps, and their positions were refined. The methyl group C22 in $(R, S)-1$ is disordered over both ortho positions on the aromatic ring, and the occupancy was refined to $76 \%: 24 \%$ occupancy. Crystal data for $(R, S)-1: \mathrm{C}_{22} \mathrm{H}_{22} \mathrm{~N}_{2} \mathrm{O}_{3}(M=362.41 \mathrm{~g} / \mathrm{mol}):$ monoclinic, space group $P 2_{1} / c$ (no. 14), $a=17.6367$ (2) $\AA, b=7.53560$ (10) $\AA, c=14.3717(2) \AA$, $\beta=111.5790(10)^{\circ}, V=1776.17(4) \AA^{3}, Z=4, T=100(2) \mathrm{K}, \mu(\mathrm{CuK} \alpha)$ $=0.732 \mathrm{~mm}^{-1}, D_{\text {calc }}=1.355 \mathrm{~g} / \mathrm{cm}^{3}, 36815$ reflections were measured $\left(10.788^{\circ} \leq 2 \Theta \leq 133.202^{\circ}\right)$, and 3132 are unique $\left(R_{\text {int }}=0.0364, R_{\text {sigma }}\right.$ $=0.0139)$, which were used in all calculations. The final $R_{1}$ was 0.0471 $(I>2 \sigma(I))$ and $w R_{2}$ was 0.1318 (all data). Crystal data for $(R)-1$ : $\mathrm{C}_{22} \mathrm{H}_{22} \mathrm{~N}_{2} \mathrm{O}_{3}(M=362.41 \mathrm{~g} / \mathrm{mol})$ : triclinic, space group $P 1$ (no. 1$), a=$ 7.1817(3) $\AA$, $b=7.4711(3) \AA, c=16.6298(4) \AA, \alpha=87.768(3)^{\circ}, \beta=$ $87.408(3)^{\circ}, \gamma=87.615(3)^{\circ}, V=889.98(6) \AA^{3}, Z=2, T=100(2) \mathrm{K}$, $\mu(\mathrm{CuK} \alpha)=0.730 \mathrm{~mm}^{-1}, D_{\text {calc }}=1.352 \mathrm{~g} / \mathrm{cm}^{3}, 16586$ reflections were measured $\left(11.864^{\circ} \leq 2 \Theta \leq 152.862^{\circ}\right)$, and 6283 are unique $\left(R_{\text {int }}=\right.$ $\left.0.0454, R_{\text {sigma }}=0.0384\right)$, which were used in all calculations. The final $R_{1}$ was $0.0371(I>2 \sigma(I))$ and $\mathrm{w} R_{2}$ was 0.0952 (all data). Flack parameter was $0.04(12)$. Further details of the X-ray diffraction data, including bond lengths and angles, can be found in the Supporting Information. CCDC 1905506 and 1905507 contain the supplementary crystallographic data for $(R, S)-\mathbf{1}$ and $(R)-\mathbf{1}$, respectively. These data can be obtained free of charge from the Cambridge Crystallographic Data Centre via www.ccdc.cam.ac.uk/data_request/cif.

General Tetrahydroquinoline (THQ) Procedure. A vial was charged with 3 -aminocyclohex-2-en-1-one (1 equiv.), aldehyde (1-1.2 equiv.), 3-oxo- $N$-(o-tolyl)butanamide (1 equiv.), and isopropanol (IPA) $(5 \mathrm{~mL} / \mathrm{mmol})$. The vial was capped and heated to $80{ }^{\circ} \mathrm{C}$ for 1-5 days. Afterward, the reaction mixture was cooled to room temperature, diluted with EtOAc, and concentrated on Celite before purification by flash chromatography.

General THQ-II Procedure. A MW vial was charged with aldehyde ( 1 equiv.), cyclohexane-1,3-dione (1 equiv.), 3-oxo- $N$-phenylbutanamide derivative ( 1 equiv.), and ammonium acetate ( 1 equiv.). The vial was heated to $150{ }^{\circ} \mathrm{C}$ until gas evolution had ceased and the mixture solidified. The residue was purified by flash column chromatography. 
2-Methyl-5-oxo-4-phenyl- $N$-(o-tolyl)-1,4,5,6,7,8-hexahydroquinoline-3-carboxamide (3). Compound 3 was prepared from benzaldehyde (144 mg, $1.36 \mathrm{mmol}), 3$-aminocyclohex-2-en-1-one (167 $\mathrm{mg}, 1.50 \mathrm{mmol})$, and 3-oxo- $\mathrm{N}$-(o-tolyl)butanamide $(287 \mathrm{mg}, 1.50$ $\mathrm{mmol}$ ) according to the general THQ procedure to give $257 \mathrm{mg}(51 \%)$ of a yellow solid ( $t_{\mathrm{R}}=10.43 \mathrm{~min}$, purity $98.8 \%$ by HPLC) after purification by flash chromatography $\left(\mathrm{SiO}_{2}, \mathrm{EtOAc} /\right.$ petroleum ether, 1:1): ${ }^{1} \mathrm{H}$ NMR (400 MHz, $\left.\mathrm{CDCl}_{3}\right) \delta 7.77-7.68(\mathrm{~m}, 1 \mathrm{H}), 7.52-7.43$ $(\mathrm{m}, 2 \mathrm{H}), 7.31(\mathrm{t}, J=7.0 \mathrm{~Hz}, 2 \mathrm{H}), 7.21(\mathrm{t}, J=6.8 \mathrm{~Hz}, 1 \mathrm{H}), 7.13(\mathrm{t}, J=7.4$ $\mathrm{Hz}, 1 \mathrm{H}), 7.06-7.00(\mathrm{~m}, 1 \mathrm{H}), 7.00-6.92(\mathrm{~m}, 2 \mathrm{H}), 6.60-6.41(\mathrm{~m}, 1 \mathrm{H})$, $5.04(\mathrm{~s}, 1 \mathrm{H}), 2.40(\mathrm{~s}, 3 \mathrm{H}), 2.37-2.23(\mathrm{~m}, 4 \mathrm{H}), 1.98-1.75(\mathrm{~m}, 2 \mathrm{H})$, $1.61(\mathrm{~s}, 3 \mathrm{H}) ;{ }^{13} \mathrm{C}$ NMR $\left(101 \mathrm{MHz}, \mathrm{CDCl}_{3}\right) \delta 195.6,166.4,150.2$, $145.1,141.8,136.2,130.4,129.2,128.8,128.3,127.4,126.5,124.7$, 122.9, 112.4, 107.8, 37.5, 37.1, 27.5, 21.0, 18.9, 17.1; ESI-HRMS calcd for $\mathrm{C}_{24} \mathrm{H}_{25} \mathrm{~N}_{2} \mathrm{O}_{2}(\mathrm{M}+\mathrm{H})^{+}$373.1912; found, 373.1911.

2-Methyl-5-oxo-4-(thiophen-2-yl)- $\mathrm{N}$-(o-tolyl)-1,4,5,6,7,8hexahydroquinoline-3-carboxamide (4). Compound 4 was prepared from thiophene-2-carbaldehyde $(84 \mu \mathrm{L}, 0.90 \mathrm{mmol}), 3-$ aminocyclohex-2-en-1-one $(100 \mathrm{mg}, 0.90 \mathrm{mmol})$, and 3-oxo- $\mathrm{N}$ - $(o$ tolyl)butanamide $(172 \mathrm{mg}, 0.90 \mathrm{mmol})$ according to the general procedure THQ to give $132 \mathrm{mg}(35 \%)$ of a red foam $\left(t_{\mathrm{R}}=10.30 \mathrm{~min}\right.$, purity $99.5 \%$ by HPLC) after purification by flash chromatography $\left(\mathrm{SiO}_{2}, \mathrm{EtOAc} /\right.$ petroleum ether, 5:1): $R_{\mathrm{f}}=0.19\left(\mathrm{SiO}_{2}, \mathrm{EtOAc} /\right.$ petroleum ether, 5:1); ${ }^{1} \mathrm{H}$ NMR $\left(\mathrm{CDCl}_{3}\right) \delta 7.75(\mathrm{~d}, J=7.9 \mathrm{~Hz}, 1 \mathrm{H})$, $7.42(\mathrm{~s}, 1 \mathrm{H}), 7.31(\mathrm{~s}, 1 \mathrm{H}), 7.16(\mathrm{dd}, J=5.1,1.1 \mathrm{~Hz}, 1 \mathrm{H}), 7.15-7.09(\mathrm{~m}$, $1 \mathrm{H}), 7.08-7.01(\mathrm{~m}, 2 \mathrm{H}), 6.97(\mathrm{td}, J=7.5,0.9 \mathrm{~Hz}, 1 \mathrm{H}), 6.91(\mathrm{dd}, J=5.1$, $3.5 \mathrm{~Hz}, 1 \mathrm{H}), 5.31(\mathrm{~s}, 1 \mathrm{H}), 2.35(\mathrm{~s}, 3 \mathrm{H}), 2.42-2.25(\mathrm{~m}, 4 \mathrm{H}), 1.95-1.87$ $(\mathrm{m}, 1 \mathrm{H}), 1.86-1.80(\mathrm{~m}, 1 \mathrm{H}), 1.77(\mathrm{~s}, 3 \mathrm{H}) ;{ }^{13} \mathrm{C} \mathrm{NMR}\left(\mathrm{CDCl}_{3}\right) \delta 195.5$, $166.4,151.0,149.7,142.5,136.1,130.5,128.9,127.2,126.5,125.3$, $125.0,124.7,122.8,111.5,107.2,36.9,32.6,27.1,21.0,18.6,17.0$. ESIHRMS cald for $\mathrm{C}_{22} \mathrm{H}_{22} \mathrm{~N}_{2} \mathrm{NaO}_{2} \mathrm{~S}(\mathrm{M}+\mathrm{Na})^{+}$401.1294; found, 401.1285.

4-(3-Bromophenyl)-2-methyl-5-oxo- $N$-(o-tolyl)-1,4,5,6,7,8hexahydroquinoline-3-carboxamide (6). Compound 6 was prepared from 3-bromobenzaldehyde (278 $\mathrm{mg}, 1.50 \mathrm{mmol}), 3-$ aminocyclohex-2-en-1-one $(167 \mathrm{mg}, 1.50 \mathrm{mmol})$, and 3-oxo- $\mathrm{N}$ - $(o$ tolyl)butanamide ( $287 \mathrm{mg}, 1.50 \mathrm{mmol}$ ) according to the general THQ procedure to give $128 \mathrm{mg}(19 \%)$ of a yellow solid $\left(t_{\mathrm{R}}=11.08 \mathrm{~min}\right.$, purity $96.6 \%$ by HPLC) after purification by flash chromatography $\left(\mathrm{SiO}_{2}, \mathrm{EtOAc} /\right.$ petroleum ether, 1:1): ${ }^{1} \mathrm{H} \mathrm{NMR}\left(400 \mathrm{MHz}, \mathrm{CDCl}_{3}\right) \delta$ $7.71(\mathrm{~d}, J=8.1 \mathrm{~Hz}, 1 \mathrm{H}), 7.56(\mathrm{br} \mathrm{s}, 1 \mathrm{H}), 7.44(\mathrm{~d}, J=7.7 \mathrm{~Hz}, 1 \mathrm{H}), 7.35$ $(\mathrm{d}, J=8.0 \mathrm{~Hz}, 1 \mathrm{H}), 7.21-7.10(\mathrm{~m}, 2 \mathrm{H}), 7.09-7.03(\mathrm{~m}, 1 \mathrm{H}), 7.03-6.95$ (m, 1H), $6.91(\mathrm{~s}, 1 \mathrm{H}), 6.65-6.46(\mathrm{~m}, 1 \mathrm{H}), 5.02(\mathrm{~s}, 1 \mathrm{H}), 2.39(\mathrm{~s}, 3 \mathrm{H})$, $2.44-2.24(\mathrm{~m}, 4 \mathrm{H}), 2.00-1.77(\mathrm{~m}, 2 \mathrm{H}), 1.71(\mathrm{~s}, 3 \mathrm{H}) ;{ }^{13} \mathrm{C}$ NMR $(101$ $\left.\mathrm{MHz}, \mathrm{CDCl}_{3}\right) \delta 195.5,166.2,150.6,147.5,141.9,136.0,131.1,130.7$, $130.5,128.9,127.1,126.6,124.9,123.4,123.1,111.7,107.3,37.4,37.0$, 27.5, 20.9, 19.0, 17.3; ESI-HRMS calcd for $\mathrm{C}_{24} \mathrm{H}_{24} \mathrm{BrN}_{2} \mathrm{O}_{2}(\mathrm{M}+\mathrm{H})^{+}$ 451.1016; found, 451.1017.

4-(4-Bromophenyl)-2-methyl-5-oxo- $N$-(o-tolyl)-1,4,5,6,7,8hexahydroquinoline-3-carboxamide (7). Compound 7 was prepared from 4-bromobenzaldehyde (278 $\mathrm{mg}, 1.50 \mathrm{mmol}), 3$ aminocyclohex-2-en-1-one $(167 \mathrm{mg}, 1.50 \mathrm{mmol})$, and 3-oxo- $\mathrm{N}$-(otolyl)butanamide ( $287 \mathrm{mg}, 1.50 \mathrm{mmol})$ according to the general THQ procedure to give $226 \mathrm{mg}(33 \%)$ of a yellow solid $\left(t_{\mathrm{R}}=11.14 \mathrm{~min}\right.$, purity $96.5 \%$ by HPLC) after purification by flash chromatography $\left(\mathrm{SiO}_{2}, \mathrm{EtOAc} /\right.$ petroleum ether, 1:1): ${ }^{1} \mathrm{H}$ NMR $\left(400 \mathrm{MHz}, \mathrm{CDCl}_{3}\right) \delta$ $7.70(\mathrm{~d}, J=7.9 \mathrm{~Hz}, 1 \mathrm{H}), 7.45-7.38(\mathrm{~m}, 2 \mathrm{H}), 7.38-7.30(\mathrm{~m}, 2 \mathrm{H}), 7.12$ $(\mathrm{t}, J=7.5 \mathrm{~Hz}, 1 \mathrm{H}), 7.09-7.00(\mathrm{~m}, 1 \mathrm{H}), 7.00-6.93(\mathrm{~m}, 1 \mathrm{H}), 6.90(\mathrm{br} \mathrm{s}$, $1 \mathrm{H}), 6.52(\mathrm{br} \mathrm{s}, 1 \mathrm{H}), 5.01(\mathrm{~s}, 1 \mathrm{H}), 2.38(\mathrm{~s}, 3 \mathrm{H}), 2.46-2.25(\mathrm{~m}, 4 \mathrm{H})$, $1.98-1.76(\mathrm{~m}, 2 \mathrm{H}), 1.71(\mathrm{~s}, 3 \mathrm{H}),{ }^{13} \mathrm{C}$ NMR $\left(101 \mathrm{MHz}, \mathrm{CDCl}_{3}\right) \delta$ $195.5,166.1,150.4,144.1,141.7,136.0,132.2,130.5,130.0,128.8$, $126.6,124.8,122.9$, 121.2, 111.9, 107.4, 37.1, 37.0, 27.5, 21.0, 18.9, 17.2; ESI-HRMS calcd for $\mathrm{C}_{24} \mathrm{H}_{24} \mathrm{BrN}_{2} \mathrm{O}_{2}(\mathrm{M}+\mathrm{H})^{+} 451.1016$; found, 451.1006.

2-Methyl-5-oxo- $\mathrm{N}$-(o-tolyl)-4-(3-(trifluoromethyl)phenyl)$1,4,5,6,7,8$-hexahydroquinoline-3-carboxamide (8). Compound 8 was prepared from 3-(trifluoromethyl)benzaldehyde $(87 \mathrm{mg}, 0.50$ $\mathrm{mmol})$, cyclohexane-1,3-dione $(56 \mathrm{mg}, 0.50 \mathrm{mmol})$, 3-oxo- $N-(o-$ tolyl)butanamide ( $96 \mathrm{mg}, 0.50 \mathrm{mmol})$, and ammonium acetate $(39 \mathrm{mg}$, 0.51 ) according to the general THQ-II procedure to give $105 \mathrm{mg}(48 \%)$ of a yellow solid $\left(t_{\mathrm{R}}=11.18 \mathrm{~min}\right.$, purity $97.5 \%$ by HPLC) after purification by flash chromatography $\left(\mathrm{SiO}_{2}, \mathrm{EtOAc} /\right.$ petroleum ether, 1:1): ${ }^{1} \mathrm{H}$ NMR (400 MHz, $\mathrm{CDCl}_{3}$ ) $\delta 7.72-7.67(\mathrm{~m}, 3 \mathrm{H}), 7.52-7.40$ (m, 2H), 7.17-7.10 (m, 1H), 7.08-7.02 (m, 1H), 7.02-6.94 (m, 1H), 6.85 (br s, 1H), 6.42 (br s, 1H), $5.14(\mathrm{~s}, 1 \mathrm{H}), 2.40(\mathrm{~s}, 3 \mathrm{H}), 2.47-2.25$ $(\mathrm{m}, 4 \mathrm{H}), 2.00-1.78(\mathrm{~m}, 2 \mathrm{H}), 1.65(\mathrm{~s}, 3 \mathrm{H}) ;{ }^{13} \mathrm{C}$ NMR $(101 \mathrm{MHz}$, $\left.\mathrm{CDCl}_{3}\right) \delta 195.5,166.1,150.6,146.1,141.8,135.9,131.9(\mathrm{q}, J=1.1 \mathrm{~Hz})$, $131.4(\mathrm{q}, J=32.1 \mathrm{~Hz}), 130.5,129.6,128.9,126.7,125.0,124.7(\mathrm{q}, J=$ $3.8 \mathrm{~Hz}), 124.21(\mathrm{q}, J=272.5 \mathrm{~Hz}), 124.19(\mathrm{q}, J=3.7 \mathrm{~Hz}), 123.1,111.7$, 107.3, 37.6, 37.0, 27.5, 20.9, 18.9, 17.1; ESI-HRMS calcd for $\mathrm{C}_{25} \mathrm{H}_{24} \mathrm{~F}_{3} \mathrm{~N}_{2} \mathrm{O}_{2}(\mathrm{M}+\mathrm{H})^{+}$441.1784; found, 441.1795.

2-Methyl-5-oxo- $\mathrm{N}$-(o-tolyl)-4-(4-(trifluoromethyl)phenyl)1,4,5,6,7,8-hexahydroquinoline-3-carboxamide (9). Compound 9 was prepared from 4-(trifluoromethyl)benzaldehyde $(87 \mathrm{mg}, 0.50$ $\mathrm{mmol})$, cyclohexane-1,3-dione (56 mg, $0.50 \mathrm{mmol})$, 3-oxo- $\mathrm{N}$-(otolyl)butanamide ( $95 \mathrm{mg}, 0.93 \mathrm{mmol}$ ), and ammonium acetate $(39 \mathrm{mg}$, 0.51 ) according to the general THQ-II procedure to give $85 \mathrm{mg}$ (39\%) of a yellow solid ( $t_{\mathrm{R}}=11.23 \mathrm{~min}$, purity $96.8 \%$ by HPLC) after purification by flash chromatography $\left(\mathrm{SiO}_{2}, \mathrm{EtOAc} /\right.$ petroleum ether, 1:1): ${ }^{1} \mathrm{H}$ NMR $\left(400 \mathrm{MHz}, \mathrm{CDCl}_{3}\right) \delta 7.66(\mathrm{~d}, J=8.0 \mathrm{~Hz}, 1 \mathrm{H}), 7.62-$ $7.53(\mathrm{~m}, 4 \mathrm{H}), 7.13(\mathrm{t}, J=7.6 \mathrm{~Hz}, 1 \mathrm{H}), 7.08-7.03(\mathrm{~m}, 1 \mathrm{H}), 6.99(\mathrm{t}, J=$ $7.4 \mathrm{~Hz}, 1 \mathrm{H}), 6.86(\mathrm{br} \mathrm{s}, 1 \mathrm{H}), 6.58(\mathrm{br} \mathrm{s}, 1 \mathrm{H}), 5.12(\mathrm{~s}, 1 \mathrm{H}), 2.37(\mathrm{~s}, 3 \mathrm{H})$, $2.45-2.24(\mathrm{~m}, 4 \mathrm{H}), 1.97-1.77(\mathrm{~m}, 2 \mathrm{H}), 1.67(\mathrm{~s}, 3 \mathrm{H}) ;{ }^{13} \mathrm{C}$ NMR $(101$ $\left.\mathrm{MHz}, \mathrm{CDCl}_{3}\right) \delta 195.6,166.2,150.9,149.1(\mathrm{q}, J=0.6 \mathrm{~Hz}), 141.4,135.8$, $130.5,129.5(\mathrm{q}, J=32.4 \mathrm{~Hz}), 129.1,128.6,126.6,126.0(\mathrm{q}, J=3.7 \mathrm{~Hz})$, $125.1,124.2(\mathrm{q}, J=271.8 \mathrm{~Hz}), 123.2,111.5,107.6,37.7,37.0,27.5$, 20.9, 18.8, 17.1; ESI-HRMS calcd for $\mathrm{C}_{25} \mathrm{H}_{23} \mathrm{~F}_{3} \mathrm{~N}_{2} \mathrm{NaO}_{2}(\mathrm{M}+\mathrm{Na})^{+}$ 463.1604; found, 463.1622.

2-Methyl-5-oxo-N-(o-tolyl)-4-(p-tolyl)-1,4,5,6,7,8-hexahydroquinoline-3-carboxamide (10). Compound 10 was prepared from 4-methylbenzaldehyde (112 $\mathrm{mg}, 0.93 \mathrm{mmol})$, cyclohexane-1,3dione $(104 \mathrm{mg}, 0.93 \mathrm{mmol})$, 3-oxo- $N$-(o-tolyl)butanamide $(178 \mathrm{mg}$, $0.93 \mathrm{mmol})$, and ammonium acetate $(72 \mathrm{mg}, 0.93)$ according to the general THQ-II procedure to give $254 \mathrm{mg}(71 \%)$ of a yellow solid $\left(t_{\mathrm{R}}=\right.$ 10.92 min, purity $96.3 \%$ by HPLC) after purification by flash chromatography $\left(\mathrm{SiO}_{2}, \mathrm{EtOAc} /\right.$ petroleum ether, 1:1): ${ }^{1} \mathrm{H}$ NMR (400 $\left.\mathrm{MHz}, \mathrm{CDCl}_{3}\right) \delta 7.73(\mathrm{~d}, J=8.0 \mathrm{~Hz}, 1 \mathrm{H}), 7.36(\mathrm{~d}, J=8.0 \mathrm{~Hz}, 2 \mathrm{H}), 7.16-$ $7.09(\mathrm{~m}, 3 \mathrm{H}), 7.05-6.99(\mathrm{~m}, 2 \mathrm{H}), 6.99-6.93(\mathrm{~m}, 1 \mathrm{H}), 6.57$ (br s, $1 \mathrm{H})$, $4.99(\mathrm{~s}, 1 \mathrm{H}), 2.38(\mathrm{~s}, 3 \mathrm{H}), 2.41-2.24(\mathrm{~m}, 4 \mathrm{H}), 2.29(\mathrm{~s}, 3 \mathrm{H}), 1.92-1.73$ $(\mathrm{m}, 2 \mathrm{H}), 1.65(\mathrm{~s}, 3 \mathrm{H}) ;{ }^{13} \mathrm{C} \mathrm{NMR}\left(101 \mathrm{MHz}, \mathrm{CDCl}_{3}\right) \delta 195.6,166.5$, 150.2 , 142.2, 141.7, 137.0, 136.2, 130.4, 129.9, 128.8, 128.2, 126.5, $124.6,122.9,112.5,107.8,37.1,37.1,27.5,21.2,21.0,18.8,17.1$; ESIHRMS calcd for $\mathrm{C}_{25} \mathrm{H}_{27} \mathrm{~N}_{2} \mathrm{O}_{2}(\mathrm{M}+\mathrm{H})^{+} 387.2067$; found, 387.2070.

4-(4-Ethylphenyl)-2-methyl-5-oxo- $\mathrm{N}$-(o-tolyl)-1,4,5,6,7,8hexahydroquinoline-3-carboxamide (11). Compound 11 was prepared from 4-ethylbenzaldehyde $(134 \mathrm{mg}, 1.00 \mathrm{mmol})$, cyclohexane-1,3-dione (112 mg, $1.00 \mathrm{mmol})$, 3-oxo- $\mathrm{N}$-(o-tolyl)butanamide $(191 \mathrm{mg}, 1.00 \mathrm{mmol})$, and ammonium acetate $(77 \mathrm{mg}, 1.00 \mathrm{mmol})$ according to the general THQ-II procedure to give $77 \mathrm{mg}$ (19\%) of a yellow solid ( $t_{\mathrm{R}}=11.44 \mathrm{~min}$, purity $95.0 \%$ by HPLC) after purification by flash chromatography $\left(\mathrm{SiO}_{2}\right.$, EtOAc/petroleum ether, 1:1): ${ }^{1} \mathrm{H}$ $\operatorname{NMR}\left(400 \mathrm{MHz}, \mathrm{CDCl}_{3}\right) \delta 7.75(\mathrm{~d}, J=7.9 \mathrm{~Hz}, 1 \mathrm{H}), 7.39(\mathrm{~d}, J=8.1 \mathrm{~Hz}$, $2 \mathrm{H}), 7.18-7.09(\mathrm{~m}, 3 \mathrm{H}), 7.04-6.99(\mathrm{~m}, 2 \mathrm{H}), 6.98-6.92(\mathrm{~m}, 1 \mathrm{H}), 6.57$ (br s, 1H), $4.99(\mathrm{~s}, 1 \mathrm{H}), 2.59$ (q, $J=7.6 \mathrm{~Hz}, 2 \mathrm{H}), 2.37$ (s, 3H), $2.41-$ $2.24(\mathrm{~m}, 4 \mathrm{H}), 1.92-1.75(\mathrm{~m}, 2 \mathrm{H}), 1.58(\mathrm{~s}, 3 \mathrm{H}), 1.19(\mathrm{t}, J=7.6 \mathrm{~Hz}$, $3 \mathrm{H}) ;{ }^{13} \mathrm{C} \mathrm{NMR}\left(101 \mathrm{MHz}, \mathrm{CDCl}_{3}\right) \delta 195.6,166.5,150.2,143.5,142.5$, $141.7,136.3,130.4,128.7,128.6,128.3,126.5,124.5,122.8,112.5$, $107.9,37.1,28.6,27.5,20.9,18.8,17.0,15.8$; ESI-HRMS calcd for $\mathrm{C}_{26} \mathrm{H}_{29} \mathrm{~N}_{2} \mathrm{O}_{2}(\mathrm{M}+\mathrm{H})^{+}$401.2224; found, 401.2241 .

4-(Furan-2-yl)-2-methyl-5-oxo- $N$-( $m$-tolyl)-1,4,5,6,7,8-hexahydroquinoline-3-carboxamide (13). 2,2,6-Trimethyl-4H-1,3-dioxin-4-one $(711 \mathrm{mg}, 5.0 \mathrm{mmol})$ and $m$-toluidine $(536 \mathrm{mg}, 5.0 \mathrm{mmol})$ were dissolved in toluene $(1 \mathrm{~mL})$ and heated to $110{ }^{\circ} \mathrm{C}$ for $7 \mathrm{~h}$. The reaction was cooled to room temperature, concentrated, and filtered through a small silica plug (EtOAc/petroleum ether, 1:4), and the crude product of 3-oxo- $N$-( $m$-tolyl $)$ butanamide was used directly in the next step.

Compound 13 was prepared from furan-2-carbaldehyde (192 mg, $2.00 \mathrm{mmol}), 3$-aminocyclohex-2-en-1-one $(222 \mathrm{mg}, 2.00 \mathrm{mmol})$, and 3oxo- $\mathrm{N}$-( $\mathrm{m}$-tolyl $)$ butanamide $(382 \mathrm{mg}, 2.00 \mathrm{mmol})$ according to the 
general procedure THQ to give $173 \mathrm{mg}(24 \%)$ of a brown solid $\left(t_{\mathrm{R}}=\right.$ $10.26 \mathrm{~min}$, purity $98.3 \%$ by HPLC) after purification by flash chromatography $\left(\mathrm{SiO}_{2}\right.$, EtOAc/petroleum ether, 1:1): ${ }^{1} \mathrm{H}$ NMR (400 $\left.\mathrm{MHz} \mathrm{CDCl}_{3}\right) \delta 7.87$ (br s, $\left.1 \mathrm{H}\right), 7.36-7.30(\mathrm{~m}, 2 \mathrm{H}), 7.19-7.14(\mathrm{~m}$, $2 \mathrm{H}), 6.91-6.85(\mathrm{~m}, 1 \mathrm{H}), 6.36(\mathrm{br} \mathrm{s}, 1 \mathrm{H}), 6.30(\mathrm{dd}, J=3.2,1.9 \mathrm{~Hz}, 1 \mathrm{H})$, $6.14(\mathrm{~d}, J=3.2 \mathrm{~Hz}, 1 \mathrm{H}), 5.10(\mathrm{~s}, 1 \mathrm{H}), 2.50-2.40(\mathrm{~m}, 3 \mathrm{H}), 2.40-2.32$ (m, $1 \mathrm{H}), 2.32(\mathrm{~s}, 6 \mathrm{H}), 2.04-1.92(\mathrm{~m}, 2 \mathrm{H}) ;{ }^{13} \mathrm{C}$ NMR $(101 \mathrm{MHz}$, $\left.\mathrm{CDCl}_{3}\right) \delta 195.4,166.1,157.1,151.4,142.2,142.1,138.9,138.4,128.8$, 125.0, 120.9, 117.3, 110.8, 108.8, 106.1, 105.8, 37.0, 31.2, 27.6, 21.6, 21.2, 19.2; ESI-HRMS calcd for $\mathrm{C}_{22} \mathrm{H}_{23} \mathrm{~N}_{2} \mathrm{O}_{3}(\mathrm{M}+\mathrm{H})^{+}$363.1703; found, 363.1694.

4-(Furan-2-yl)-2-methyl-5-oxo- $N$-( $p$-tolyl)-1,4,5,6,7,8-hexahydroquinoline-3-carboxamide (14). 2,2,6-Trimethyl-4H-1,3-dioxin-4-one (1422 mg, $10.0 \mathrm{mmol})$ and $p$-toluidine $(1072 \mathrm{mg}, 10.0$ $\mathrm{mmol})$ were dissolved in toluene $(2 \mathrm{~mL})$ and heated to $110^{\circ} \mathrm{C}$ for $6 \mathrm{~h}$. The reaction was cooled to room temperature and concentrated, and the residue was purified by flash chromatography $\left(\mathrm{SiO}_{2}, \mathrm{EtOAc} /\right.$ petroleum ether, $1: 4)$ to give $1456 \mathrm{mg}(76 \%)$ of 3 -oxo- $N$ - $(p$ tolyl)butanamide as a light brown solid that was used directly in the next step.

Compound 14 was prepared from furan-2-carbaldehyde $(192 \mathrm{mg}$, $2.00 \mathrm{mmol})$, 3-aminocyclohex-2-en-1-one ( $222 \mathrm{mg}, 2.00 \mathrm{mmol})$, and 3oxo- $\mathrm{N}$-( $p$-tolyl)butanamide $(382 \mathrm{mg}, 2.00 \mathrm{mmol}$ ) according to the general procedure THQ to give $292 \mathrm{mg}(40 \%)$ of a brown solid $\left(t_{\mathrm{R}}=\right.$ $10.23 \mathrm{~min}$, purity $98.3 \%$ by HPLC) after purification by flash chromatography $\left(\mathrm{SiO}_{2}, \mathrm{EtOAc} /\right.$ petroleum ether, $\left.1: 1\right):{ }^{1} \mathrm{H}$ NMR (400 $\left.\mathrm{MHz}, \mathrm{CDCl}_{3}\right) \delta 7.86($ br s, $1 \mathrm{H}), 7.34-7.28(\mathrm{~m}, 3 \mathrm{H}), 7.12-7.05(\mathrm{~m}$, $2 \mathrm{H}), 6.43(\mathrm{br} \mathrm{s}, 1 \mathrm{H}), 6.29(\mathrm{dd}, J=3.2,1.9 \mathrm{~Hz}, 1 \mathrm{H}), 6.13(\mathrm{~d}, J=3.2 \mathrm{~Hz}$, $1 \mathrm{H}), 5.10(\mathrm{~s}, 1 \mathrm{H}), 2.50-2.40(\mathrm{~m}, 3 \mathrm{H}), 2.40-2.32(\mathrm{~m}, 1 \mathrm{H}), 2.30(\mathrm{~s}$, $3 \mathrm{H}), 2.29(\mathrm{~s}, 3 \mathrm{H}), 2.03-1.88(\mathrm{~m}, 2 \mathrm{H}) ;{ }^{13} \mathrm{C} \mathrm{NMR}\left(101 \mathrm{MHz}, \mathrm{CDCl}_{3}\right) \delta$ 195.4, 166.1, 157.2, 151.5, 142.0, 135.9, 133.7, 129.5, 120.3, 110.8, 108.7, 106.0, 105.8, 37.0, 31.2, 27.6, 21.2, 21.0, 19.1; ESI-HRMS calcd for $\mathrm{C}_{22} \mathrm{H}_{22} \mathrm{~N}_{2} \mathrm{NaO}_{3}(\mathrm{M}+\mathrm{Na})^{+}$385.1523; found, 385.1528.

4-(Furan-2-yl)- $\mathrm{N}$-(2-methoxyphenyl)-2-methyl-5-oxo1,4,5,6,7,8-hexahydroquinoline-3-carboxamide (15). 2,2,6-Trimethyl-4H-1,3-dioxin-4-one $(711 \mathrm{mg}, 5.0 \mathrm{mmol})$ and 2-methoxyaniline $(616 \mathrm{mg}, 5.0 \mathrm{mmol})$ were dissolved in dry toluene $(1 \mathrm{~mL})$ and heated to $110{ }^{\circ} \mathrm{C}$ for $6 \mathrm{~h}$. The reaction was cooled to room temperature and filtrated. The solid was washed with ice cold toluene to give $268 \mathrm{mg}$ (26\%) of $\mathrm{N}$-(2-methoxyphenyl)-3-oxobutanamide as a light brown solid that was used directly in the next step.

Compound 15 was prepared from furan-2-carbaldehyde $(48 \mathrm{mg}$, $0.50 \mathrm{mmol})$, cyclohexane-1,3-dione $(56 \mathrm{mg}, 0.50 \mathrm{mmol}), \mathrm{N}-(2-$ methoxyphenyl)-3-oxobutanamide (104 $\mathrm{mg}, 0.50 \mathrm{mmol}$ ), and ammonium acetate $(39 \mathrm{mg}, 0.51)$ according to the general procedure THQ-II to give $32 \mathrm{mg}(17 \%)$ of a yellow solid $\left(t_{\mathrm{R}}=10.27 \mathrm{~min}\right.$, purity $97.7 \%$ by HPLC) after purification by flash chromatography $\left(\mathrm{SiO}_{2}\right.$, EtOAc/petroleum ether, 1:1): ${ }^{1} \mathrm{H}$ NMR $\left(400 \mathrm{MHz}, \mathrm{CDCl}_{3}\right) \delta 8.33(\mathrm{br}$ $\mathrm{s}, 1 \mathrm{H}), 8.30(\mathrm{dd}, J=8.0,1.5 \mathrm{~Hz}, 1 \mathrm{H}), 7.33-7.28(\mathrm{~m}, 1 \mathrm{H}), 6.99(\mathrm{td}, J=$ $7.8,1.6 \mathrm{~Hz}, 1 \mathrm{H}), 6.91(\mathrm{td}, J=7.8,1.2 \mathrm{~Hz}, 1 \mathrm{H}), 6.82(\mathrm{dd}, J=8.0,1.1 \mathrm{~Hz}$, $1 \mathrm{H}), 6.46(\mathrm{br} \mathrm{s}, 1 \mathrm{H}), 6.29(\mathrm{dd}, J=3.1,1.9 \mathrm{~Hz}, 1 \mathrm{H}), 6.19(\mathrm{~d}, J=3.1 \mathrm{~Hz}$, $1 \mathrm{H}), 5.13(\mathrm{~s}, 1 \mathrm{H}), 3.78(\mathrm{~s}, 3 \mathrm{H}), 2.50-2.38(\mathrm{~m}, 3 \mathrm{H}), 2.37-2.26(\mathrm{~m}$, $1 \mathrm{H}), 2.33(\mathrm{~s}, 3 \mathrm{H}), 2.06-1.88(\mathrm{~m}, 2 \mathrm{H}) ;{ }^{13} \mathrm{C} \mathrm{NMR}\left(101 \mathrm{MHz}, \mathrm{CDCl}_{3}\right) \delta$ 195.4, 166.1, 156.7, 151.4, 148.4, 142.1, 142.0, 128.3, 123.5, 121.0, 120.1, 110.4, 110.1, 109.0, 106.2, 106.1, 55.7, 37.0, 31.2, 27.6, 21.2, 19.1; ESI-HRMS calcd for $\mathrm{C}_{22} \mathrm{H}_{23} \mathrm{~N}_{2} \mathrm{O}_{4}(\mathrm{M}+\mathrm{H})^{+} 379.1652$; found, 379.1671.

4-Isobutyl-2-methyl-5-oxo- $N$-(o-tolyl)-1,4,5,6,7,8-hexahydroquinoline-3-carboxamide (17). Compound 17 was prepared from 3-aminocyclohex-2-en-1-one (111 mg, $1.00 \mathrm{mmol})$, 3-methylbutanal (110 $\mu \mathrm{L}, 1.02 \mathrm{mmol})$, and 3-oxo- $N$-(o-tolyl)butanamide (191 $\mathrm{mg}, 1.00 \mathrm{mmol}$ ) according to the general procedure THQ to give $96 \mathrm{mg}$ (27\%) of a pale yellow solid ( $t_{\mathrm{R}}=10.74 \mathrm{~min}$, purity $98.0 \%$ by HPLC) after purification by flash chromatography $\left(\mathrm{SiO}_{2}, \mathrm{EtOAc}\right):{ }^{1} \mathrm{H}$ NMR $\left(400 \mathrm{MHz}, \mathrm{DMSO}-d_{6}\right) \delta 9.10(\mathrm{~s}, 1 \mathrm{H}), 8.58(\mathrm{~s}, 1 \mathrm{H}), 7.31-7.03(\mathrm{~m}$, $4 \mathrm{H}), 3.83(\mathrm{t}, J=6.3 \mathrm{~Hz}, 1 \mathrm{H}), 2.46-2.14(\mathrm{~m}, 7 \mathrm{H}), 2.06(\mathrm{~s}, 3 \mathrm{H}), 1.98-$ $1.55(\mathrm{~m}, 3 \mathrm{H}), 1.33-0.96(\mathrm{~m}, 2 \mathrm{H}), 0.83(\mathrm{dd}, J=6.5,1.9 \mathrm{~Hz}, 6 \mathrm{H}) ;{ }^{13} \mathrm{C}$ NMR (101 MHz, DMSO- $\left.d_{6}\right) \delta 194.1,168.2,152.7,136.8,134.2,132.7$, 130.1, 125.7, 125.6, 125.0, 111.5, 109.4, 47.0, 36.9, 29.6, 26.5, 23.6,
23.4, 23.0, 20.9, 18.1, 17.0; ESI-HRMS calcd for $\mathrm{C}_{22} \mathrm{H}_{28} \mathrm{~N}_{2} \mathrm{NaO}_{2}(\mathrm{M}+$ $\mathrm{Na})^{+}$375.2043; found, 375.2052.

N-(2,3-Dimethylphenyl)-4-isobutyl-2-methyl-5-oxo1,4,5,6,7,8-hexahydroquinoline-3-carboxamide (18). A dry flask was charged with 2,3-dimethylaniline $(0.12 \mathrm{~mL}, 1.0 \mathrm{mmol}), 2,2,6$ trimethyl-4H-1,3-dioxin-4-one $(0.13 \mathrm{~mL}, 1.00 \mathrm{mmol})$, and toluene $(0.2$ $\mathrm{mL}$ ) and heated to reflux under argon for $5 \mathrm{~h}$. Afterward, the reaction was cooled to room temperature and concentrated in vacuo. The residue was purified by flash chromatography $\left(\mathrm{SiO}_{2}, \mathrm{EtOAc} /\right.$ petroleum ether, $1: 1)$ to give $138 \mathrm{mg}(67 \%)$ of $N$-(2,3-dimethylphenyl)-3oxobutanamide as a beige solid: $R_{\mathrm{f}}=0.20\left(\mathrm{SiO}_{2}, \mathrm{EtOAc} /\right.$ petroleum ether, $1: 1) ;{ }^{1} \mathrm{H} \mathrm{NMR}\left(400 \mathrm{MHz}, \mathrm{CDCl}_{3}\right) \delta 9.01(\mathrm{br} \mathrm{s}, 1 \mathrm{H}), 7.55(\mathrm{~d}, J=$ $8.0 \mathrm{~Hz}, 1 \mathrm{H}), 7.08(\mathrm{t}, J=7.8 \mathrm{~Hz}, 1 \mathrm{H}), 6.99(\mathrm{~d}, J=7.5 \mathrm{~Hz}, 1 \mathrm{H}), 3.60(\mathrm{~s}$, $2 \mathrm{H}), 2.31(\mathrm{~s}, 3 \mathrm{H}), 2.29(\mathrm{~s}, 3 \mathrm{H}), 2.18(\mathrm{~s}, 3 \mathrm{H}) ;{ }^{13} \mathrm{C}$ NMR $(101 \mathrm{MHz}$, $\left.\mathrm{CDCl}_{3}\right) \delta 205.7,163.9,137.5,135.3,128.9,127.3,125.9,121.6,49.5$, 31.3, 20.7, 13.8; ESI-HRMS calcd for $\mathrm{C}_{12} \mathrm{H}_{15} \mathrm{NNaO}_{2}\left(\mathrm{M}+\mathrm{Na}^{+}\right)$ 228.0995; found, 228.0991.

Compound 18 was prepared from 3-aminocyclohex-2-en-1-one (83 $\mathrm{mg}, 0.74 \mathrm{mmol}), 3$-methylbutanal $(0.72 \mathrm{~mL}, 6.6 \mathrm{mmol})$, and $\mathrm{N}-(2,3-$ dimethylphenyl)-3-oxobutanamide ( $144 \mathrm{mg}, 0.70 \mathrm{mmol}$ ) according to the general procedure THQ to give $22 \mathrm{mg}(9 \%)$ of a white solid $\left(t_{\mathrm{R}}=\right.$ $11.08 \mathrm{~min}$, purity $96.2 \%$ by HPLC) after purification by flash chromatography $\left(\mathrm{SiO}_{2}, \mathrm{EtOAc} /\right.$ petroleum ether, 1:1 $\rightarrow$ 1:0): ${ }^{1} \mathrm{H}$ $\operatorname{NMR}\left(400 \mathrm{MHz}, \mathrm{CDCl}_{3}\right) \delta 7.42(\mathrm{~s}, 1 \mathrm{H}), 7.39(\mathrm{~d}, J=7.9 \mathrm{~Hz}, 1 \mathrm{H}), 7.09$ $(\mathrm{t}, J=7.7 \mathrm{~Hz}, 1 \mathrm{H}), 7.00(\mathrm{~d}, J=7.4 \mathrm{~Hz}, 1 \mathrm{H}), 6.32(\mathrm{br} \mathrm{s}, 1 \mathrm{H}), 3.92(\mathrm{t}, J=$ $6.6 \mathrm{~Hz}, 1 \mathrm{H}), 2.53-2.45(\mathrm{~m}, 1 \mathrm{H}), 2.42-2.37(\mathrm{~m}, 2 \mathrm{H}), 2.34-2.30(\mathrm{~m}$, $1 \mathrm{H}), 2.30(\mathrm{~s}, 3 \mathrm{H}), 2.26(\mathrm{~s}, 3 \mathrm{H}), 2.18(\mathrm{~s}, 3 \mathrm{H}), 2.04-1.90(\mathrm{~m}, 2 \mathrm{H})$, $1.64-1.51(\mathrm{~m}, 1 \mathrm{H}), 1.27-1.24(\mathrm{~m}, 2 \mathrm{H}), 0.97(\mathrm{~d}, J=6.5 \mathrm{~Hz}, 3 \mathrm{H}), 0.88$ $(\mathrm{d}, J=6.6 \mathrm{~Hz}, 3 \mathrm{H}) ;{ }^{13} \mathrm{C} \mathrm{NMR}\left(101 \mathrm{MHz}, \mathrm{CDCl}_{3}\right) \delta 196.3,167.5,152.0$, $139.8,137.6,135.7,130.3,127.4,125.9,122.7,111.8,109.8,77.2$, 47.0, 37.2, 29.7, 27.7, 24.1, 23.7, 23.0, 21.2, 20.7, 18.7, 14.3; ESI-HRMS calcd for $\mathrm{C}_{23} \mathrm{H}_{30} \mathrm{~N}_{2} \mathrm{NaO}_{2}\left(\mathrm{M}+\mathrm{Na}^{+}\right)$389.2199; found, 389.2202.

$\mathrm{N}$-(2-lodophenyl)-4-isobutyl-2-methyl-5-oxo-1,4,5,6,7,8hexahydroquinoline-3-carboxamide (19). A dry flask was charged with 2-iodoaniline $(258 \mathrm{mg}, 1.18 \mathrm{mmol}), 2,2,6$-trimethyl-4H-1,3dioxin-4-one $(0.22 \mathrm{~mL}, 1.20 \mathrm{mmol})$, and toluene $(0.25 \mathrm{~mL})$ and heated to reflux under argon for $22 \mathrm{~h}$. Afterward, the reaction was cooled to room temperature and concentrated in vacuo. The residue was purified by flash chromatography $\left(\mathrm{SiO}_{2}, \mathrm{EtOAc} /\right.$ petroleum ether, 1:2) to give $113 \mathrm{mg}$ (31\%) of $\mathrm{N}$-(2-iodophenyl)-3-oxobutanamide as a pale yellow solid: $R_{\mathrm{f}}=0.19\left(\mathrm{SiO}_{2}\right.$, EtOAc/petroleum ether, $\left.1: 2\right) ;{ }^{1} \mathrm{H}$ NMR (400 $\left.\mathrm{MHz}, \mathrm{CDCl}_{3}\right) \delta 9.16(\mathrm{br} \mathrm{s}, 1 \mathrm{H}), 8.12(\mathrm{dd}, J=8.2,1.0 \mathrm{~Hz}, 1 \mathrm{H}), 7.80(\mathrm{dd}$, $J=8.0,1.4 \mathrm{~Hz}, 1 \mathrm{H}), 7.36-7.29(\mathrm{~m}, 1 \mathrm{H}), 6.88-6.81(\mathrm{~m}, 1 \mathrm{H}), 3.63(\mathrm{~s}$, $2 \mathrm{H}), 2.33(\mathrm{~s}, 3 \mathrm{H}) ;{ }^{13} \mathrm{C} \mathrm{NMR}\left(101 \mathrm{MHz}, \mathrm{CDCl}_{3}\right) \delta 204.5,163.8,139.3$, 138.5, 129.1, 126.5, 123.0, 90.2, 50.0, 31.4; ESI-HRMS calcd for $\mathrm{C}_{10} \mathrm{H}_{10} \mathrm{INNaO}_{2}\left(\mathrm{M}+\mathrm{Na}^{+}\right)$325.9648; found, 325.9661.

Compound 19 was prepared from 3-aminocyclohex-2-en-1-one (40 $\mathrm{mg}, 0.36 \mathrm{mmol}), 3$-methylbutanal $(39 \mu \mathrm{L}, 0.36 \mathrm{mmol})$, and $\mathrm{N}$-(2iodophenyl)-3-oxobutanamide ( $106 \mathrm{mg}, 0.35 \mathrm{mmol}$ ) according to the general procedure THQ to give $14 \mathrm{mg}(9 \%)$ of a white solid $\left(t_{\mathrm{R}}=11.84\right.$ min, purity $98.4 \%$ by HPLC) after purification by flash chromatography $\left(\mathrm{SiO}_{2}\right.$, EtOAc/petroleum ether, 1:1): ${ }^{1} \mathrm{H}$ NMR $\left(400 \mathrm{MHz}, \mathrm{CDCl}_{3}\right) \delta$ $8.19(\mathrm{dd}, J=8.2,1.4 \mathrm{~Hz}, 1 \mathrm{H}), 7.82(\mathrm{br} \mathrm{s}, 1 \mathrm{H}), 7.78(\mathrm{dd}, J=7.9,1.3 \mathrm{~Hz}$, $1 \mathrm{H}), 7.36-7.30(\mathrm{~m}, 1 \mathrm{H}), 6.82(\mathrm{td}, J=7.6,1.4 \mathrm{~Hz}, 1 \mathrm{H}), 6.12(\mathrm{br} \mathrm{s}, 1 \mathrm{H})$, $4.06(\mathrm{dd}, J=7.9,5.6 \mathrm{~Hz}, 1 \mathrm{H}), 2.53-2.42(\mathrm{~m}, 3 \mathrm{H}), 2.36-2.26(\mathrm{~m}, 1 \mathrm{H})$ $2.30(\mathrm{~s}, 3 \mathrm{H}), 2.11-1.93(\mathrm{~m}, 2 \mathrm{H}), 1.60-1.50(\mathrm{~m}, 1 \mathrm{H}), 1.35-1.23(\mathrm{~m}$, $2 \mathrm{H}), 0.99(\mathrm{~d}, J=6.5 \mathrm{~Hz}, 3 \mathrm{H}), 0.86(\mathrm{~d}, J=6.6 \mathrm{~Hz}, 3 \mathrm{H}) ;{ }^{13} \mathrm{C} \mathrm{NMR}(101$ $\left.\mathrm{MHz}, \mathrm{CDCl}_{3}\right) \delta 196.0,167.0,151.3,140.6,139.0,138.9,129.1,125.8$, 122.6 , 112.2, 109.8, 90.8, 46.6, 37.2, 29.6, 27.8, 24.2, 23.8, 23.3, 21.2, 19.1; ESI-HRMS calcd for $\mathrm{C}_{21} \mathrm{H}_{25} \mathrm{IN}_{2} \mathrm{NaO}_{2}\left(\mathrm{M}+\mathrm{Na}^{+}\right)$487.0853; found, 487.0875 .

$N$-(2-Chlorophenyl)-4-isobutyl-2-methyl-5-oxo-1,4,5,6,7,8hexahydroquinoline-3-carboxamide (20). A dry flask was charged with 2-chloroaniline $(0.50 \mathrm{~mL}, 4.75 \mathrm{mmol}), 2,2,6$-trimethyl-4H-1,3dioxin-4-one $(0.70 \mathrm{~mL}, 5.27 \mathrm{mmol})$, and toluene $(1 \mathrm{~mL})$ and heated to reflux under argon for $6 \mathrm{~h}$. Afterward, the reaction was cooled to room temperature and concentrated in vacuo. The crude was dissolved in boiling acetone, and petroleum ether was added until precipitation started, and the solution was stored in the fridge overnight. The precipitate was isolated by filtration, washed with petroleum ether, and 
dried to give $342 \mathrm{mg}$ (34\%) of $\mathrm{N}$-(2-chlorophenyl)-3-oxobutanamide as a beige solid, $90 \%$ pure by ${ }^{1} \mathrm{H}$ NMR: $R_{\mathrm{f}}=0.09\left(\mathrm{SiO}_{2}\right.$, acetone/ petroleum ether, 1:4); ${ }^{1} \mathrm{H} \mathrm{NMR}\left(400 \mathrm{MHz}, \mathrm{CDCl}_{3}\right) \delta 9.61(\mathrm{br} \mathrm{s}, 1 \mathrm{H})$, $8.33(\mathrm{dd}, J=8.3,1.3 \mathrm{~Hz}, 1 \mathrm{H}), 7.38(\mathrm{dd}, J=8.0,1.4 \mathrm{~Hz}, 1 \mathrm{H}), 7.28-7.22$ $(\mathrm{m}, 1 \mathrm{H}), 7.05(\mathrm{dt}, J=7.9,1.5 \mathrm{~Hz}, 1 \mathrm{H}), 3.64(\mathrm{~s}, 2 \mathrm{H}), 2.34(\mathrm{~s}, 3 \mathrm{H}) ;{ }^{13} \mathrm{C}$ NMR $\left(101 \mathrm{MHz}, \mathrm{CDCl}_{3}\right) \delta 204.9,163.7,134.7,129.3,127.7,125.1$, 123.6, 122.1, 49.8, 31.4.

Compound 20 was prepared from 3-aminocyclohex-2-en-1-one (111 $\mathrm{mg}, 1.00 \mathrm{mmol})$, 3-methylbutanal $(0.12 \mathrm{~mL}, 1.1 \mathrm{mmol})$, and $\mathrm{N}-(2-$ chlorophenyl)-3-oxobutanamide (214 mg, $1.01 \mathrm{mmol})$ according to the general procedure THQ to give $100 \mathrm{mg}(27 \%)$ of a yellow foam $\left(t_{\mathrm{R}}\right.$ $=11.55 \mathrm{~min}$, purity $98.7 \%$ by HPLC) after purification by flash chromatography $\left(\mathrm{SiO}_{2}, \mathrm{EtOAc} /\right.$ petroleum ether, 1:1 $\rightarrow$ 1:0): ${ }^{1} \mathrm{H}$ NMR $\left(400 \mathrm{MHz}, \mathrm{CDCl}_{3}\right) \delta 8.34(\mathrm{dd}, J=8.3,1.5 \mathrm{~Hz}, 1 \mathrm{H}), 7.99(\mathrm{~s}, 1 \mathrm{H}), 7.36$ (dd, $J=8.0,1.5 \mathrm{~Hz}, 1 \mathrm{H}), 7.25(\mathrm{dt}, J=8.2,1.4 \mathrm{~Hz}, 1 \mathrm{H}), 7.04-6.98(\mathrm{~m}$, $1 \mathrm{H}), 6.36(\mathrm{~s}, 1 \mathrm{H}), 3.96(\mathrm{t}, J=6.8 \mathrm{~Hz}, 1 \mathrm{H}), 2.53-2.41(\mathrm{~m}, 3 \mathrm{H}), 2.36-$ $2.25(\mathrm{~m}, 4 \mathrm{H}), 2.09-1.90(\mathrm{~m}, 2 \mathrm{H}), 1.59-1.47(\mathrm{~m}, 1 \mathrm{H}), 1.30-1.25(\mathrm{~m}$, $2 \mathrm{H}), 0.98(\mathrm{~d}, J=6.4 \mathrm{~Hz}, 3 \mathrm{H}), 0.85(\mathrm{~d}, J=6.6 \mathrm{~Hz}, 3 \mathrm{H}) ;{ }^{13} \mathrm{C}$ NMR $(101$ $\left.\mathrm{MHz}, \mathrm{CDCl}_{3}\right) \delta 196.0,166.8,151.5,141.0,135.2,129.2,127.7,124.4$, 123.5, 122.1, 112.1, 109.6, 46.7, 37.2, 29.4, 27.8, 24.1, 23.7, 22.9, 21.2, 19.1; ESI-HRMS calcd for $\mathrm{C}_{21} \mathrm{H}_{26} \mathrm{ClN}_{2} \mathrm{O}_{2}\left(\mathrm{M}+\mathrm{H}^{+}\right) 373.1677$; found, 373.1662 .

$\mathrm{N}$-(2,6-Difluorophenyl)-4-isobutyl-2-methyl-5-oxo$1,4,5,6,7,8$-hexahydroquinoline-3-carboxamide (21). A dry flask was charged with 2,6-difluoroaniline $(0.18 \mathrm{~mL}, 1.67 \mathrm{mmol}), 2,2,6$ trimethyl-4H-1,3-dioxin-4-one $(0.22 \mathrm{~mL}, 1.66 \mathrm{mmol})$, and toluene $(0.3$ $\mathrm{mL}$ ) and heated to reflux under argon for $22 \mathrm{~h}$. Afterwards the reaction was cooled to room temperature and concentrated in vacuo. The residue was purified by flash chromatography $\left(\mathrm{SiO}_{2}, \mathrm{EtOAc} /\right.$ petroleum ether, $2: 3)$ to give $182 \mathrm{mg}$ (51\%) of $\mathrm{N}$-(2,6-difluorophenyl)-3oxobutanamide as a pale yellow solid: $R_{\mathrm{f}}=0.19\left(\mathrm{SiO}_{2}\right.$, EtOAc/ petroleum ether, 2:3); ${ }^{1} \mathrm{H}$ NMR $\left(400 \mathrm{MHz}, \mathrm{CDCl}_{3}\right) \delta 8.81(\mathrm{br} \mathrm{s}, 1 \mathrm{H})$, $7.18(\mathrm{dq}, J=8.4,6.2 \mathrm{~Hz}, 1 \mathrm{H}), 7.01-6.82(\mathrm{~m}, 2 \mathrm{H}), 3.63(\mathrm{~s}, 2 \mathrm{H}), 2.31(\mathrm{~s}$, $3 \mathrm{H}) ;{ }^{13} \mathrm{C}$ NMR $\left(101 \mathrm{MHz}, \mathrm{CDCl}_{3}\right) \delta 204.6,164.5,157.8(\mathrm{dd}, J=250.9$, $3.4 \mathrm{~Hz}), 127.9(\mathrm{t}, J=9.1 \mathrm{~Hz}), 113.6(\mathrm{t}, J=16.4 \mathrm{~Hz}), 111.8(\mathrm{~d}, J=22.1$ $\mathrm{Hz}), 49.1$, 30.9; ESI-HRMS calcd for $\mathrm{C}_{10} \mathrm{H}_{9} \mathrm{~F}_{2} \mathrm{NNaO}_{2}\left(\mathrm{M}+\mathrm{Na}^{+}\right)$ 236.0494; found, 236.0465 .

Compound 21 was prepared from 3-aminocyclohex-2-en-1-one (58 $\mathrm{mg}, 0.52 \mathrm{mmol}), 3$-methylbutanal $(56 \mu \mathrm{L}, 0.52 \mathrm{mmol})$, and $\mathrm{N}$ - $(2,6-$ difluorophenyl)-3-oxobutanamide ( $109 \mathrm{mg}, 0.51 \mathrm{mmol}$ ) according to the general procedure THQ to give $8 \mathrm{mg}(4 \%)$ of a white solid $\left(t_{\mathrm{R}}=\right.$ $10.50 \mathrm{~min}$, purity $99.9 \%$ by HPLC) after purification by flash chromatography $\left(\mathrm{SiO}_{2}\right.$, EtOAc/petroleum ether, 2:1): ${ }^{1} \mathrm{H}$ NMR (400 $\left.\mathrm{MHz}, \mathrm{CDCl}_{3}\right) \delta 7.20($ br s, $1 \mathrm{H}), 7.19-7.12(\mathrm{~m}, 1 \mathrm{H}), 6.98-6.91(\mathrm{~m}$, $2 \mathrm{H}), 6.06(\mathrm{br} \mathrm{s}, 1 \mathrm{H}), 3.91(\mathrm{t}, J=6.5 \mathrm{~Hz}, 1 \mathrm{H}), 2.53-2.40(\mathrm{~m}, 3 \mathrm{H})$, $2.35-2.23(\mathrm{~m}, 1 \mathrm{H}), 2.28(\mathrm{~s}, 3 \mathrm{H}), 2.10-1.92(\mathrm{~m}, 2 \mathrm{H}), 1.67-1.54(\mathrm{~m}$, $1 \mathrm{H}), 1.31-1.21(\mathrm{~m}, 2 \mathrm{H}), 0.95(\mathrm{~d}, J=6.5 \mathrm{~Hz}, 3 \mathrm{H}), 0.89(\mathrm{~d}, J=6.6 \mathrm{~Hz}$, $3 \mathrm{H}) ;{ }^{13} \mathrm{C}$ NMR $\left(101 \mathrm{MHz}, \mathrm{CDCl}_{3}\right) \delta 196.3,167.1,158.0(\mathrm{dd}, J=250.2$, $4.3 \mathrm{~Hz}), 151.5,141.1,127.2(\mathrm{t}, J=9.4 \mathrm{~Hz}), 114.6(\mathrm{t}, J=16.1 \mathrm{~Hz}), 112.4$, $111.8(\mathrm{~d}, J=22.6 \mathrm{~Hz}), 108.6,47.1,37.2,29.7,27.8,24.1,23.5,23.1$, 21.2, 19.0; ESI-HRMS calcd for $\mathrm{C}_{21} \mathrm{H}_{24} \mathrm{~F}_{2} \mathrm{~N}_{2} \mathrm{NaO}_{2}\left(\mathrm{M}+\mathrm{Na}^{+}\right)$ 397.1698; found, 397.1703.

2-Ethyl-4-(furan-2-yl)-5-oxo- $N$-(o-tolyl)-1,4,5,6,7,8-hexahydroquinoline-3-carboxamide (22). A dry $5 \mathrm{~mL}$ vial under argon atmosphere was charged with $o$-toluidine $(0.21 \mathrm{~mL}, 1.98 \mathrm{mmol})$ and methyl 3-oxopentanoate $(0.25 \mathrm{~mL}, 1.99 \mathrm{mmol})$ and heated to $100{ }^{\circ} \mathrm{C}$ for $17 \mathrm{~h}$. The reaction was cooled to room temperature and purified by flash column chromatography $\left(\mathrm{SiO}_{2}, \mathrm{EtOAc} /\right.$ petroleum ether, $\left.1: 2\right)$ to give $112 \mathrm{mg}(28 \%)$ of 3-oxo- $\mathrm{N}$-(o-tolyl)pentanamide as a yellow solid that was used directly in the next step.

Compound 22 was prepared from furan-2-carbaldehyde ( $55 \mu \mathrm{L}, 0.66$ $\mathrm{mmol})$, 3-aminocyclohex-2-en-1-one $(74 \mathrm{mg}, 0.67 \mathrm{mmol})$, and 3-oxo$\mathrm{N}$-(o-tolyl)pentanamide ( $132 \mathrm{mg}, 0.64 \mathrm{mmol}$ ) according to the general procedure THQ to give $56 \mathrm{mg}(23 \%)$ of an orange foam $\left(t_{\mathrm{R}}=10.37\right.$ min, purity $95.7 \%$ by HPLC) after purification by flash chromatography $\left(\mathrm{SiO}_{2}, \mathrm{EtOAc} /\right.$ petroleum ether, $\left.1: 2 \rightarrow 1: 0\right):{ }^{1} \mathrm{H}$ NMR $(400 \mathrm{MHz}$, DMSO- $\left.d_{6}\right) \delta 9.04(\mathrm{~s}, 1 \mathrm{H}), 8.80(\mathrm{~s}, 1 \mathrm{H}), 7.43(\mathrm{dd}, J=1.8,0.9 \mathrm{~Hz}, 1 \mathrm{H})$, $7.28-7.21(\mathrm{~m}, 1 \mathrm{H}), 7.21-7.02(\mathrm{~m}, 3 \mathrm{H}), 6.27(\mathrm{dd}, J=3.1,1.8 \mathrm{~Hz}, 1 \mathrm{H})$, $5.93(\mathrm{~d}, J=3.1 \mathrm{~Hz}, 1 \mathrm{H}), 5.10(\mathrm{~s}, 1 \mathrm{H}), 2.64-2.29(\mathrm{~m}, 4 \mathrm{H}), 2.27-2.21$ $(\mathrm{m}, 2 \mathrm{H}), 2.10(\mathrm{~s}, 3 \mathrm{H}), 1.97-1.77(\mathrm{~m}, 2 \mathrm{H}), 1.10(\mathrm{t}, J=7.4 \mathrm{~Hz}, 3 \mathrm{H}) ;{ }^{13} \mathrm{C}$
NMR $\left(101 \mathrm{MHz}, \mathrm{DMSO}-d_{6}\right) \delta 193.7,166.9,158.4,153.1,141.9,141.0$, $136.8,132.5,130.1,125.7,125.6,125.0,110.1,106.8,106.0,104.5,36.7$, 31.9, 26.4, 23.7, 20.8, 17.8, 13.3; ESI-HRMS calcd for $\mathrm{C}_{23} \mathrm{H}_{24} \mathrm{~N}_{2} \mathrm{NaO}_{3}$ $(\mathrm{M}+\mathrm{Na})^{+}$399.1679; found, 399.1685.

4-(Furan-2-yl)-5-oxo-2-phenyl- $N$-(o-tolyl)-1,4,5,6,7,8-hexahydroquinoline-3-carboxamide (23). A dry $5 \mathrm{~mL}$ vial under argon atmosphere was charged with $o$-toluidine $(0.21 \mathrm{~mL}, 1.98 \mathrm{mmol})$ and ethyl 3-oxo-3-phenylpropanoate $(0.35 \mathrm{~mL}, 2.02 \mathrm{mmol})$ and heated to $100{ }^{\circ} \mathrm{C}$ for $17 \mathrm{~h}$. The reaction was cooled to room temperature and purified by flash column chromatography $\left(\mathrm{SiO}_{2}, \mathrm{EtOAc} /\right.$ petroleum ether, 1:4) to give $291 \mathrm{mg}$ (58\%) of 3-oxo-3-phenyl- $\mathrm{N}$-(o-tolyl)propanamide as a pale yellow solid that was used directly in the next step.

Compound 23 was prepared from furan-2-carbaldehyde ( $55 \mu \mathrm{L}, 0.66$ $\mathrm{mmol})$, 3-aminocyclohex-2-en-1-one $(71 \mathrm{mg}, 0.64 \mathrm{mmol})$, and 3-oxo3 -phenyl- $\mathrm{N}$-(o-tolyl)propanamide $(160 \mathrm{mg}, 0.63 \mathrm{mmol})$ according to the general procedure THQ to give $155 \mathrm{mg}(58 \%)$ of a beige solid $\left(t_{\mathrm{R}}=\right.$ 10.83 min, purity $96.9 \%$ by HPLC) after washing the crude with cold EtOAc: ${ }^{1} \mathrm{H}$ NMR $\left(400 \mathrm{MHz}, \mathrm{DMSO}-d_{6}\right) \delta 9.06(\mathrm{~s}, 1 \mathrm{H}), 8.33(\mathrm{~s}, 1 \mathrm{H})$ 7.47-7.41 (m, 6H), 7.23-7.15 (m, 1H), 7.08-7.00 (m, 2H), 6.99$6.92(\mathrm{~m}, 1 \mathrm{H}), 6.30(\mathrm{dd}, J=3.1,1.8 \mathrm{~Hz}, 1 \mathrm{H}), 6.03(\mathrm{~d}, J=3.2 \mathrm{~Hz}, 1 \mathrm{H})$, $5.14(\mathrm{~s}, 1 \mathrm{H}), 2.62-2.45(\mathrm{~m}, 2 \mathrm{H}), 2.33-2.23(\mathrm{~m}, 2 \mathrm{H}), 2.00-1.76(\mathrm{~m}$, $2 \mathrm{H}), 1.66(\mathrm{~s}, 3 \mathrm{H}) ;{ }^{13} \mathrm{C}$ NMR $\left(101 \mathrm{MHz}\right.$, DMSO- $\left.d_{6}\right) \delta 194.0,166.5$, 158.2 , 153.3, 141.0, 137.9, 136.3, 135.0, 131.0, 129.9, 129.1, 128.8, 128.3, 125.6, 124.6, 124.0, 110.2, 109.2, 106.1, 104.6, 36.8, 32.2, 26.4, 20.8, 16.9; ESI-HRMS calcd for $\mathrm{C}_{27} \mathrm{H}_{24} \mathrm{~N}_{2} \mathrm{NaO}_{3}(\mathrm{M}+\mathrm{Na})^{+} 447.1679$; found, 447.1696.

4-(Furan-2-yl)-2-methyl-5-oxo- $\mathrm{N}$-(o-tolyl)-5,6,7,8-tetrahydroquinoline-3-carboxamide (24). 4-(Furan-2-yl)-2-methyl-5-oxo$\mathrm{N}$-(o-tolyl)-1,4,5,6,7,8-hexahydroquinoline-3-carboxamide (100 mg, $0.28 \mathrm{mmol}$ ) and $\mathrm{MnO}_{2}$ (400 $\mathrm{mg}, 4.60 \mathrm{mmol}$ ) were dissolved in $\mathrm{CHCl}_{3}(13 \mathrm{~mL})$ and stirred at room temperature for $19 \mathrm{~h}$. The reaction mixture was filtered through a pad of Celite and concentrated in vacuo to give $59 \mathrm{mg}(60 \%)$ of $\mathbf{2 4}$ as a yellow solid $\left(t_{\mathrm{R}}=9.88 \mathrm{~min}\right.$, purity $97.0 \%$ by HPLC): ${ }^{1} \mathrm{H}$ NMR $\left(400 \mathrm{MHz}, \mathrm{CDCl}_{3}\right) \delta 7.59(\mathrm{~d}, J=7.9 \mathrm{~Hz}, 1 \mathrm{H})$, $7.51(\mathrm{~d}, J=1.1 \mathrm{~Hz}, 1 \mathrm{H}), 7.24-7.07(\mathrm{~m}, 3 \mathrm{H}), 6.98(\mathrm{br} \mathrm{s}, 1 \mathrm{H}), 6.58(\mathrm{dd}, J$ $=3.4,0.4 \mathrm{~Hz}, 1 \mathrm{H}), 6.47(\mathrm{dd}, J=3.4,1.8 \mathrm{~Hz}, 1 \mathrm{H}), 3.17(\mathrm{t}, J=6.2 \mathrm{~Hz}$, $2 \mathrm{H}), 2.73(\mathrm{~s}, 3 \mathrm{H}), 2.71-2.65(\mathrm{~m}, 2 \mathrm{H}), 2.25-2.15(\mathrm{~m}, 2 \mathrm{H}), 2.04(\mathrm{~s}$, $3 \mathrm{H}) ;{ }^{13} \mathrm{C} \mathrm{NMR}\left(101 \mathrm{MHz}, \mathrm{CDCl}_{3}\right) \delta 196.7,165.6,164.7,159.5,148.0$, $143.6,136.0,134.9,132.3,130.7,130.0,126.9,126.2,124.5,123.7$, 111.9, 111.2, 39.8, 33.5, 23.4, 21.5, 17.7; ESI-HRMS calcd for $\mathrm{C}_{22} \mathrm{H}_{21} \mathrm{~N}_{2} \mathrm{O}_{3}(\mathrm{M}+\mathrm{H})^{+} 361.1547$; found, 361.1562.

5-Benzoyl-4-isobutyl-2,6-dimethyl- $\mathrm{N}$-(o-tolyl)-1,4-dihydropyridine-3-carboxamide (25). A microwave vial was charged with 1phenylbutane-1,3-dione (163 mg, $1.01 \mathrm{mmol})$, IPA $(2.5 \mathrm{~mL})$, and $\mathrm{NH}_{4} \mathrm{OAc}(83 \mathrm{mg}, 1.08 \mathrm{mmol})$ and stirred at room temperature under an argon atmosphere for two days. Afterward, 3-methylbutanal (0.12 $\mathrm{mL}, 1.11 \mathrm{mmol})$ and 3-oxo- $\mathrm{N}$-(o-tolyl)butanamide (192 mg, 1.00 $\mathrm{mmol}$ ) was added, and the microwave vial was capped and heated to 80 ${ }^{\circ} \mathrm{C}$. After three days, the reaction was cooled to room temperature, diluted with EtOAc, and concentrated in vacuo on Celite. The residue was purified by flash column chromatography $\left(\mathrm{SiO}_{2}, \mathrm{EtOAc} /\right.$ petroleum ether, $1: 1)$ to give $128 \mathrm{mg}(32 \%)$ of $\mathbf{2 5}$ as a bright yellow foam $\left(t_{\mathrm{R}}=\right.$ $12.54 \mathrm{~min}, 95.1 \%$ pure by HPLC): ${ }^{1} \mathrm{H}$ NMR $\left(400 \mathrm{MHz}, \mathrm{CDCl}_{3}\right) \delta$ 7.86-7.81 (m, 1H), 7.73-7.66 (m, 2H), 7.51-7.45 (m, 1H), 7.45$7.39(\mathrm{~m}, 2 \mathrm{H}), 7.24-7.11(\mathrm{~m}, 3 \mathrm{H}), 7.08-7.02(\mathrm{~m}, 1 \mathrm{H}), 6.08(\mathrm{br} \mathrm{s}, 1 \mathrm{H})$, $3.77-3.69(\mathrm{~m}, 1 \mathrm{H}), 2.37(\mathrm{~s}, 3 \mathrm{H}), 2.15(\mathrm{~s}, 3 \mathrm{H}), 2.02(\mathrm{~s}, 3 \mathrm{H}), 1.67-1.55$ (m, $1 \mathrm{H}), 1.44-1.35(\mathrm{~m}, 1 \mathrm{H}), 1.15-1.08(\mathrm{~m}, 1 \mathrm{H}), 0.78(\mathrm{~d}, J=6.6 \mathrm{~Hz}$, $3 \mathrm{H}), 0.67(\mathrm{~d}, J=6.5 \mathrm{~Hz}, 3 \mathrm{H}) ;{ }^{13} \mathrm{C} \mathrm{NMR}\left(101 \mathrm{MHz}, \mathrm{CDCl}_{3}\right) \delta 198.3$, $166.8,142.4,141.9,140.4,136.3,131.7,130.6,129.2$, 128.7, 128.6, $126.8,124.9,123.4,112.5,106.7,46.9,35.5,23.7,23.6,22.3,19.2,18.9$, 18.1; ESI-HRMS calcd for $\mathrm{C}_{26} \mathrm{H}_{30} \mathrm{~N}_{2} \mathrm{NaO}_{2}(\mathrm{M}+\mathrm{Na})^{+} 425.2199$; found, 425.2218 .

Methyl 4-isobutyl-2,6-dimethyl-5-(o-tolylcarbamoyl)-1,4-dihydropyridine-3-carboxylate (26). Compound 26 was prepared from methyl (E)-3-aminobut-2-enoate $(112 \mathrm{mg}, 0.97 \mathrm{mmol}), 3-$ methylbutanal $(0.15 \mathrm{~mL}, 1.39 \mathrm{mmol})$, and 3 -oxo- $\mathrm{N}$-(o-tolyl)butanamide $(192 \mathrm{mg}, 1.00 \mathrm{mmol})$ according to the general procedure THQ to give $207 \mathrm{mg}(60 \%)$ of a pale yellow foam $\left(t_{\mathrm{R}}=12.03 \mathrm{~min}\right.$, $98.6 \%$ pure by HPLC) after purification by flash chromatography 
( $\mathrm{SiO}_{2}$, EtOAc/petroleum ether, 1:1): ${ }^{1} \mathrm{H}$ NMR (400 MHz, acetone- $\left.d_{6}\right)$ $\delta 8.21($ br s, $1 \mathrm{H}), 7.70-7.64(\mathrm{~m}, 1 \mathrm{H}), 7.59(\mathrm{br} \mathrm{s}, 1 \mathrm{H}), 7.22-7.12(\mathrm{~m}$, $2 \mathrm{H}), 7.06-7.00(\mathrm{~m}, 1 \mathrm{H}), 3.89(\mathrm{t}, J=6.7 \mathrm{~Hz}, 1 \mathrm{H}), 3.64(\mathrm{~s}, 3 \mathrm{H}), 2.30(\mathrm{~s}$, $3 \mathrm{H}), 2.29(\mathrm{~s}, 3 \mathrm{H}), 2.20(\mathrm{~s}, 3 \mathrm{H}), 1.77-1.64(\mathrm{~m}, 1 \mathrm{H}), 1.37-1.26(\mathrm{~m}$, $1 \mathrm{H}), 1.25-1.15(\mathrm{~m}, 1 \mathrm{H}), 0.89(\mathrm{dd}, J=6.5,3.2 \mathrm{~Hz}, 6 \mathrm{H}) ;{ }^{13} \mathrm{C}$ NMR $(101$ $\mathrm{MHz}$, acetone- $\left.d_{6}\right) \delta 168.8,168.7,147.5,138.4,138.3,131.7,131.1$, 126.9, 125.4, 125.0, 110.1, 101.5, 50.7, 47.9, 34.1, 24.6, 23.7, 23.5, 19.1, 18.5, 17.7; ESI-HRMS calcd for $\mathrm{C}_{21} \mathrm{H}_{28} \mathrm{~N}_{2} \mathrm{NaO}_{3}(\mathrm{M}+\mathrm{Na})^{+}$379.1992; found, 379.1992 .

5-Cyano-4-isobutyl-2,6-dimethyl- $\mathrm{N}$-(o-tolyl)-1,4-dihydropyridine-3-carboxamide (27). Compound 27 was prepared from (E)-3-aminobut-2-enenitrile $(84 \mathrm{mg}, 1.02 \mathrm{mmol})$, 3-methylbutanal $(0.15 \mathrm{~mL}, 1.39 \mathrm{mmol})$, and 3-oxo- $N$-(o-tolyl)butanamide $(192 \mathrm{mg}$, $1.01 \mathrm{mmol}$ ) according to the general procedure THQ to give $209 \mathrm{mg}$ $(64 \%)$ of a white solid ( $t_{\mathrm{R}}=11.55 \mathrm{~min}, 97.6 \%$ pure by HPLC) after purification by flash chromatography $\left(\mathrm{SiO}_{2}, \mathrm{EtOAc} /\right.$ petroleum ether, 1:1): ${ }^{1} \mathrm{H}$ NMR (400 MHz, acetone- $\left.d_{6}\right) \delta 8.49$ (br s, $\left.1 \mathrm{H}\right), 7.79$ (br s, $1 \mathrm{H}), 7.56-7.50(\mathrm{~m}, 1 \mathrm{H}), 7.24-7.12(\mathrm{~m}, 2 \mathrm{H}), 7.11-7.04(\mathrm{~m}, 1 \mathrm{H})$, 3.61-3.53 (m, 1H), $2.29(\mathrm{~s}, 3 \mathrm{H}), 2.15(\mathrm{~s}, 3 \mathrm{H}), 2.07(\mathrm{~s}, 3 \mathrm{H}), 2.02-1.89$ $(\mathrm{m}, 1 \mathrm{H}), 1.49-1.32(\mathrm{~m}, 2 \mathrm{H}), 0.93(\mathrm{dd}, J=15.5,6.6 \mathrm{~Hz}, 6 \mathrm{H}) ;{ }^{13} \mathrm{C} \mathrm{NMR}$ $\left(101 \mathrm{MHz}\right.$, acetone- $\left.d_{6}\right) \delta 168.3,148.7,137.9,137.4,132.7,131.2$, 126.9, 125.9, 125.8, 121.4, 108.7, 82.8, 48.3, 35.6, 24.7, 23.9, 22.8, 18.6, 18.1, 17.8; ESI-HRMS calcd for $\mathrm{C}_{20} \mathrm{H}_{26} \mathrm{~N}_{3} \mathrm{O}(\mathrm{M}+\mathrm{H})^{+}$324.2070; found, 324.2086.

Methyl 4-isobutyl-2-methyl-5-oxo-1,4,5,6,7,8-hexahydroquinoline-3-carboxylate (28). Compound 28 was prepared from 3-aminocyclohex-2-en-1-one (112 mg, $1.01 \mathrm{mmol}), 3$-methylbutanal $(0.15 \mathrm{~mL}, 1.39 \mathrm{mmol})$, and methyl 3-oxobutanoate $(0.15 \mathrm{~mL}, 1.39$ $\mathrm{mmol}$ ) according to the general procedure THQ to give $178 \mathrm{mg}(64 \%)$ of a pale yellow solid $\left(t_{\mathrm{R}}=10.77 \mathrm{~min}, 96.0 \%\right.$ pure by HPLC) after purification by flash chromatography $\left(\mathrm{SiO}_{2}, \mathrm{EtOAc} /\right.$ petroleum ether, $1: 1 \rightarrow 1: 0):{ }^{1} \mathrm{H}$ NMR $\left(400 \mathrm{MHz}\right.$, DMSO- $\left.d_{6}\right) \delta 9.02(\mathrm{~s}, 1 \mathrm{H}), 3.83(\mathrm{t}, J=$ $6.7 \mathrm{~Hz}, 1 \mathrm{H}), 3.59(\mathrm{~s}, 3 \mathrm{H}), 2.45-2.33(\mathrm{~m}, 2 \mathrm{H}), 2.20(\mathrm{~s}, 3 \mathrm{H}), 2.29-2.10$ $(\mathrm{m}, 2 \mathrm{H}), 1.94-1.70(\mathrm{~m}, 2 \mathrm{H}), 1.39-1.27(\mathrm{~m}, 1 \mathrm{H}), 1.00-0.88(\mathrm{~m}, 2 \mathrm{H})$, $0.82(\mathrm{~d}, J=6.5 \mathrm{~Hz}, 3 \mathrm{H}), 0.78(\mathrm{~d}, J=6.6 \mathrm{~Hz}, 3 \mathrm{H}) ;{ }^{13} \mathrm{C} \mathrm{NMR}(101 \mathrm{MHz}$, DMSO- $\left.d_{6}\right) \delta 194.9,167.7,151.9,145.2,111.2,103.7,50.5,46.9,36.8$, 27.0, 26.2, 23.4, 23.2, 23.0, 20.9, 18.1; ESI-HRMS calcd for $\mathrm{C}_{16} \mathrm{H}_{23} \mathrm{NNaO}_{3}(\mathrm{M}+\mathrm{Na})^{+} 300.1570$; found, 300.1570 .

3-Benzoyl-4-isobutyl-2-methyl-4,6,7,8-tetrahydroquinolin$5(1 H)$-one (29). Compound 29 was prepared from 3-aminocyclohex2-en-1-one (112 mg, $1.01 \mathrm{mmol})$, 3-methylbutanal (0.1 mL, 0.91 $\mathrm{mmol})$, and 1-phenylbutane-1,3-dione (163 $\mathrm{mg}, 1.01 \mathrm{mmol}$ ) according to the general procedure THQ to give $100 \mathrm{mg}$ (34\%) of a yellow solid $\left(t_{\mathrm{R}}=11.38 \mathrm{~min}\right.$, purity $98.2 \%$ by HPLC) after purification by flash chromatography $\left(\mathrm{SiO}_{2}\right.$, EtOAc/petroleum ether, 1:1): ${ }^{1} \mathrm{H}$ NMR (400 $\left.\mathrm{MHz}, \mathrm{CDCl}_{3}\right) \delta 7.70-7.64(\mathrm{~m}, 2 \mathrm{H}), 7.50-7.43(\mathrm{~m}, 1 \mathrm{H}), 7.42-7.35$ $(\mathrm{m}, 2 \mathrm{H}), 6.88(\mathrm{br} \mathrm{s}, 1 \mathrm{H}), 4.00(\mathrm{dd}, J=7.7,5.9 \mathrm{~Hz}, 1 \mathrm{H}), 2.52-2.39(\mathrm{~m}$, $3 \mathrm{H}), 2.39-2.28(\mathrm{~m}, 1 \mathrm{H}), 2.08-1.89(\mathrm{~m}, 2 \mathrm{H}), 1.97(\mathrm{~s}, 3 \mathrm{H}), 1.52-1.37$ $(\mathrm{m}, 1 \mathrm{H}), 1.22-1.12(\mathrm{~m}, 1 \mathrm{H}), 1.02-0.91(\mathrm{~m}, 1 \mathrm{H}), 0.73(\mathrm{~d}, J=6.5 \mathrm{~Hz}$, $3 \mathrm{H}), 0.62(\mathrm{~d}, J=6.5 \mathrm{~Hz}, 3 \mathrm{H}) ;{ }^{13} \mathrm{C} \mathrm{NMR}\left(101 \mathrm{MHz}, \mathrm{CDCl}_{3}\right) \delta 199.0$, 196.2, 151.8, 139.4, 139.1, 132.0, 128.9, 128.6, 116.4, 112.5, 47.4, 37.4, $30.7,27.7,24.1,23.4,22.5,21.4,18.3$; ESI-HRMS calcd for $\mathrm{C}_{21} \mathrm{H}_{26} \mathrm{NO}_{2}$ $\left(\mathrm{M}+\mathrm{H}^{+}\right)$324.1958; found, 324.1972.

4-(sec-Butyl)-2-methyl-5-oxo- $N$-(o-tolyl)-1,4,5,6,7,8-hexahydroquinoline-3-carboxamide (30). Compound 30 was prepared from 3-aminocyclohex-2-en-1-one (112 mg, $1.01 \mathrm{mmol}), 2$-methylbutanal (108 $\mu \mathrm{L}, 1.01 \mathrm{mmol})$, and 3-oxo- $N$-(o-tolyl)butanamide (193 $\mathrm{mg}, 1.01 \mathrm{mmol}$ ) according to the general procedure THQ to give $18 \mathrm{mg}$ $(5 \%)$ of a white solid and mixture of diasteromers $\left(t_{\mathrm{R}}=10.6 \mathrm{~min}, 97.6 \%\right.$ pure by HPLC) after purification by flash chromatography $\left(\mathrm{SiO}_{2}\right.$, EtOAc/petroleum ether, 4:1) followed by washing with petroleum ether: ${ }^{1} \mathrm{H}$ NMR $\left(400 \mathrm{MHz}\right.$, acetone- $\left.d_{6}\right) \delta 8.40(\mathrm{br} \mathrm{s}, 1 \mathrm{H}), 8.39$ (br s, $1 \mathrm{H}), 7.75$ (br s, 1H), 7.69 (br s, $1 \mathrm{H}), 7.66-7.58(\mathrm{~m}, 2 \mathrm{H}), 7.20$ (d, $J=$ $7.5 \mathrm{~Hz}, 2 \mathrm{H}), 7.15(\mathrm{t}, J=7.6 \mathrm{~Hz}, 2 \mathrm{H}), 7.04(\mathrm{t}, J=7.5 \mathrm{~Hz}, 2 \mathrm{H}), 4.02(\mathrm{~d}, J$ $=3.4 \mathrm{~Hz}, 1 \mathrm{H}), 3.99(\mathrm{~d}, J=3.2 \mathrm{~Hz}, 1 \mathrm{H}), 2.54-2.45(\mathrm{~m}, 4 \mathrm{H}), 2.37-2.27$ (m, $2 \mathrm{H}), 2.30(\mathrm{~s}, 6 \mathrm{H}), 2.25-2.15(\mathrm{~m}, 2 \mathrm{H}), 2.19(\mathrm{~d}, J=6.0 \mathrm{~Hz}, 6 \mathrm{H})$, $2.02-1.87(\mathrm{~m}, 4 \mathrm{H}), 1.57-1.37(\mathrm{~m}, 4 \mathrm{H}), 1.19-1.01(\mathrm{~m}, 2 \mathrm{H}), 0.85(\mathrm{t}, J$ $=7.3 \mathrm{~Hz}, 6 \mathrm{H}), 0.82(\mathrm{~d}, J=1.8 \mathrm{~Hz}, 3 \mathrm{H}), 0.80(\mathrm{~d}, J=1.8 \mathrm{~Hz}, 3 \mathrm{H})$; ESIHRMS calcd for $\mathrm{C}_{22} \mathrm{H}_{29} \mathrm{~N}_{2} \mathrm{O}_{2}(\mathrm{M}+\mathrm{H})^{+}$353.2224; found, 353.2239.
4-Cyclohexyl-2-methyl-5-oxo-N-(o-tolyl)-1,4,5,6,7,8-hexahydroquinoline-3-carboxamide (31). Compound 31 was prepared from 3-aminocyclohex-2-en-1-one (111 mg, $1.00 \mathrm{mmol})$, cyclohexanecarboxaldehyde $(121 \mu \mathrm{L}, 1.00 \mathrm{mmol})$, and 3-oxo- $\mathrm{N}$-(o-tolyl)butanamide $(191 \mathrm{mg}, 1.00 \mathrm{mmol})$ according to the general procedure THQ to give $16 \mathrm{mg}(4 \%)$ of a brownish solid $\left(t_{\mathrm{R}}=11.18 \mathrm{~min}\right.$, purity $95.7 \%$ by HPLC) after purification by flash chromatography $\left(\mathrm{SiO}_{2}\right.$, EtOAc/petroleum ether, 1:3) followed by trituation with petroleum ether in EtOAc: ${ }^{1} \mathrm{H}$ NMR $\left(\mathrm{CDCl}_{3}\right) \delta 7.77(\mathrm{~d}, J=7.9 \mathrm{~Hz}, 1 \mathrm{H}), 7.34(\mathrm{~s}$, $1 \mathrm{H}), 7.22-7.15(\mathrm{~m}, 2 \mathrm{H}), 7.05(\mathrm{td}, J=7.5,0.9 \mathrm{~Hz}, 1 \mathrm{H}), 5.96(\mathrm{~s}, 1 \mathrm{H})$, $3.81(\mathrm{~d}, J=4.9 \mathrm{~Hz}, 1 \mathrm{H}), 2.56-2.49(\mathrm{~m}, 1 \mathrm{H}), 2.46-2.42(\mathrm{~m}, 2 \mathrm{H})$, 2.36-2.31 (m, 1H), $2.30(\mathrm{~s}, 3 \mathrm{H}), 2.28(\mathrm{~s}, 3 \mathrm{H}), 2.07-1.95(\mathrm{~m}, 2 \mathrm{H})$, $1.74-1.53(\mathrm{~m}, 6 \mathrm{H}), 1.13-0.94(\mathrm{~m}, 5 \mathrm{H}) ;{ }^{13} \mathrm{C} \mathrm{NMR}\left(\mathrm{CDCl}_{3}\right) \delta 196.4$, $167.9,152.1,139.9,136.2$, 130.6, 129.6, 126.8, 125.0, 123.4, 109.8, $108.0,46.1,37.5,37.3,29.5,29.1,27.8,26.7,26.6,21.2,18.7$, 18.2; ESIHRMS calcd for $\mathrm{C}_{24} \mathrm{H}_{31} \mathrm{~N}_{2} \mathrm{O}_{2}(\mathrm{M}+\mathrm{H})^{+}$379.2380; found, 379.2393 .

4-Cyclopentyl-2-methyl-5-oxo- $\mathrm{N}$-(o-tolyl)-1,4,5,6,7,8-hexahydroquinoline-3-carboxamide (32). Compound 32 was prepared from cyclopentanecarbaldehyde $(110 \mu \mathrm{L}, 1.03 \mathrm{mmol})$, 3-aminocyclohex-2-en-1-one $(111 \mathrm{mg}, 1.00 \mathrm{mmol})$, and 3-oxo- $\mathrm{N}$-(o-tolyl)butanamide $(192 \mathrm{mg}, 1.00 \mathrm{mmol}$ ) according to the general procedure THQ to give $16 \mathrm{mg}(4 \%)$ of a white solid $\left(t_{\mathrm{R}}=10.78 \mathrm{~min}\right.$, purity $98.3 \%$ by HPLC) after purification by flash chromatography ( $\mathrm{SiO}_{2}, \mathrm{EtOAc} /$ petroleum ether, $1: 1 \rightarrow 0: 1):{ }^{1} \mathrm{H}$ NMR $\left(500 \mathrm{MHz}, \mathrm{DMSO}-d_{6}\right) \delta 9.06$ $(\mathrm{s}, 1 \mathrm{H}), 8.59(\mathrm{~s}, 1 \mathrm{H}), 7.24(\mathrm{~d}, J=6.8 \mathrm{~Hz}, 1 \mathrm{H}), 7.20(\mathrm{~d}, J=7.4 \mathrm{~Hz}, 1 \mathrm{H})$, $7.17-7.13(\mathrm{~m}, 1 \mathrm{H}), 7.08(\mathrm{td}, J=7.4,1.1 \mathrm{~Hz}, 1 \mathrm{H}), 3.89(\mathrm{~d}, J=6.0 \mathrm{~Hz}$, $1 \mathrm{H}), 2.47-2.33(\mathrm{~m}, 2 \mathrm{H}), 2.29-2.12(\mathrm{~m}, 2 \mathrm{H}), 2.20(\mathrm{~s}, 3 \mathrm{H}), 2.09(\mathrm{~s}$, $3 \mathrm{H}), 1.95-1.70(\mathrm{~m}, 2 \mathrm{H}), 1.59-1.40(\mathrm{~m}, 4 \mathrm{H}), 1.40-1.28(\mathrm{~m}, 2 \mathrm{H})$, $1.27-1.15(\mathrm{~m}, 2 \mathrm{H}) ;{ }^{13} \mathrm{C}$ NMR (101 MHz, DMSO- $\left.d_{6}\right) \delta 194.6,168.8$, 153.2 , 137.0, 135.2, 132.9, 130.2, 125.8 (two CH), 125.1, 110.0, 108.2, 48.0, 37.1, 34.2, 28.0, 27.9, 26.6, 24.3, 24.2, 20.9, 18.2, 17.1; ESI-HRMS calcd for $\mathrm{C}_{23} \mathrm{H}_{29} \mathrm{~N}_{2} \mathrm{O}_{2}(\mathrm{M}+\mathrm{H})^{+}$365.2224; found, 365.2234 .

4-Cyclopropyl-2-methyl-5-oxo- $N$-(o-tolyl)-1,4,5,6,7,8-hexahydroquinoline-3-carboxamide (33). Compound 33 was prepared from 3-aminocyclohex-2-en-1-one (116 mg, $1.05 \mathrm{mmol})$, cyclopropanecarboxaldehyde (78 $\mu \mathrm{L}, 1.05 \mathrm{mmol})$, and 3-oxo- $\mathrm{N}$-(o-tolyl)butanamide $(200 \mathrm{mg}, 1.05 \mathrm{mmol}$ ) according to the general procedure THQ to give $44 \mathrm{mg}(13 \%)$ of a white solid $\left(t_{\mathrm{R}}=9.74 \mathrm{~min}\right.$, purity $98.3 \%$ by HPLC) after purification by flash chromatography $\left(\mathrm{SiO}_{2}, \mathrm{EtOAc} /\right.$ petroleum ether, 1:5): ${ }^{1} \mathrm{H} \operatorname{NMR}\left(\mathrm{CDCl}_{3}\right) \delta 7.73(\mathrm{~d}, J=7.9 \mathrm{~Hz}, 1 \mathrm{H})$, $7.48(\mathrm{~s}, 1 \mathrm{H}), 7.23-7.16(\mathrm{~m}, 2 \mathrm{H}), 7.10-7.04(\mathrm{~m}, 1 \mathrm{H}), 5.92(\mathrm{~s}, 1 \mathrm{H})$, $3.79(\mathrm{~d}, J=6.7 \mathrm{~Hz}, 1 \mathrm{H}), 2.55-2.47(\mathrm{~m}, 1 \mathrm{H}), 2.45-2.40(\mathrm{~m}, 2 \mathrm{H})$, $2.38-2.32(\mathrm{~m}, 1 \mathrm{H}), 2.30(\mathrm{~s}, 3 \mathrm{H}), 2.29(\mathrm{~s}, 3 \mathrm{H}), 2.08-1.99(\mathrm{~m}, 2 \mathrm{H})$, $1.09-0.96(\mathrm{~m}, 1 \mathrm{H}), 0.47-0.31(\mathrm{~m}, 3 \mathrm{H}), 0.30-0.18(\mathrm{~m}, 1 \mathrm{H}) ;{ }^{13} \mathrm{C}$ $\operatorname{NMR}\left(\mathrm{CDCl}_{3}\right) \delta 196.3,167.2,151.1,140.8,136.2,130.7,129.9,126.8$, 125.1, 123.7, 111.3, 107.1, 37.2, 32.8, 27.7, 21.4, 19.0, 18.3, 2.9, 2.8; ESI-HRMS calcd for $\mathrm{C}_{21} \mathrm{H}_{24} \mathrm{~N}_{2} \mathrm{NaO}_{2}(\mathrm{M}+\mathrm{Na})^{+} 359.1730$; found, 359.1717.

4-Ethyl-2-methyl-5-oxo-N-(o-tolyl)-1,4,5,6,7,8-hexahydroquinoline-3-carboxamide (34). Compound 34 was prepared from 3-aminocyclohex-2-en-1-one (111 mg, $1.00 \mathrm{mmol})$, propionaldehyde $(0.08 \mathrm{~mL}, 1.10 \mathrm{mmol})$, and 3-oxo- $\mathrm{N}$-(o-tolyl)butanamide $(193 \mathrm{mg}$, $1.01 \mathrm{mmol}$ ) according to the general procedure THQ to give $46 \mathrm{mg}$ (14\%) of a pale yellow foam $\left(t_{\mathrm{R}}=9.65 \mathrm{~min}, 96.6 \%\right.$ pure by HPLC) after purification by flash chromatography $\left(\mathrm{SiO}_{2}, \mathrm{EtOAc} /\right.$ petroleum ether, 1:1): ${ }^{1} \mathrm{H}$ NMR (400 MHz, $\mathrm{CDCl}_{3}$ ) $\delta 7.73-7.68(\mathrm{~m}, 1 \mathrm{H}), 7.38$ (br s, $1 \mathrm{H}), 7.21-7.15(\mathrm{~m}, 2 \mathrm{H}), 7.09-7.03(\mathrm{~m}, 1 \mathrm{H}), 6.24(\mathrm{br} \mathrm{s}, 1 \mathrm{H}), 3.92(\mathrm{t}, J$ $=5.1 \mathrm{~Hz}, 1 \mathrm{H}), 2.51-2.29(\mathrm{~m}, 4 \mathrm{H}), 2.27(\mathrm{~s}, 3 \mathrm{H}), 2.26(\mathrm{~s}, 2 \mathrm{H}), 2.03-$ $1.91(\mathrm{~m}, 2 \mathrm{H}), 1.62-1.50(\mathrm{~m}, 1 \mathrm{H}), 1.50-1.38(\mathrm{~m}, 1 \mathrm{H}), 0.82(\mathrm{t}, J=7.5$ $\mathrm{Hz}, 3 \mathrm{H}) ;{ }^{13} \mathrm{C}$ NMR $\left(101 \mathrm{MHz}, \mathrm{CDCl}_{3}\right) \delta 196.1,167.2,152.3,140.1$, 136.1, 130.6, 130.1, 126.8, 125.2, 123.8, 110.3, 108.4, 37.2, 33.0, 29.0, 27.6, 21.4, 18.7, 18.1, 9.4; ESI-HRMS calcd for $\mathrm{C}_{20} \mathrm{H}_{25} \mathrm{~N}_{2} \mathrm{O}_{2}(\mathrm{M}+\mathrm{H})^{+}$ 325.1911; found, 325.1925.

2-Methyl-5-oxo-4-propyl- $N$-(o-tolyl)-1,4,5,6,7,8-hexahydroquinoline-3-carboxamide (35). Compound 35 was prepared from 3-aminocyclohex-2-en-1-one (113 mg, $1.01 \mathrm{mmol})$, butyraldehyde (91 $\mu \mathrm{L}, 1.01 \mathrm{mmol})$, and 3-oxo- $\mathrm{N}$-(o-tolyl)butanamide (193 mg, 1.01 $\mathrm{mmol}$ ) according to the general procedure THQ to give $92 \mathrm{mg}(27 \%)$ of a pale yellow solid $\left(t_{\mathrm{R}}=10.25 \mathrm{~min}, 98.4 \%\right.$ pure by HPLC) after purification by flash chromatography $\left(\mathrm{SiO}_{2}, \mathrm{EtOAc}\right)$ followed by 
washing with petroleum ether: ${ }^{1} \mathrm{H}$ NMR $\left(400 \mathrm{MHz}\right.$, acetone- $\left.d_{6}\right) \delta 8.36$ (br s, $1 \mathrm{H}), 7.71($ br s, $1 \mathrm{H}), 7.66-7.58(\mathrm{~m}, 1 \mathrm{H}), 7.23-7.11(\mathrm{~m}, 2 \mathrm{H})$, $7.08-7.02(\mathrm{~m}, 1 \mathrm{H}), 3.96(\mathrm{t}, J=4.5 \mathrm{~Hz}, 1 \mathrm{H}), 2.49-2.44(\mathrm{~m}, 2 \mathrm{H}), 2.30$ (s, 3H), 2.34-2.16 (m, 4H), $2.19(\mathrm{~s}, 3 \mathrm{H}), 2.01-1.83(\mathrm{~m}, 2 \mathrm{H}), 1.54-$ $1.41(\mathrm{~m}, 1 \mathrm{H}), 1.41-1.23(\mathrm{~m}, 3 \mathrm{H}), 0.87-0.80(\mathrm{~m}, 3 \mathrm{H}) ;{ }^{13} \mathrm{C} \mathrm{NMR}(101$ $\mathrm{MHz}$, acetone- $\left.d_{6}\right) \delta 195.1,168.4,153.3,153.2,138.2,138.1,132.4$, 131.1, 126.8, 125.59, 125.55, 125.4, 110.9, 110.9, 110.84, 110.81, 110.6 $110.5,39.8,38.0,32.8,27.7,27.6,22.2,18.9,18.5,17.82,17.75,14.8$ (contains rotamers); ESI-HRMS calcd for $\mathrm{C}_{21} \mathrm{H}_{27} \mathrm{~N}_{2} \mathrm{O}_{2}(\mathrm{M}+\mathrm{H})^{+}$ 339.2067; found, 339.2077.

2-Methyl-5-oxo-4-butyl-N-(o-tolyl)-1,4,5,6,7,8-hexahydroquinoline-3-carboxamide (36). Compound 36 was prepared from 3-aminocyclohex-2-en-1-one (111 mg, $1.00 \mathrm{mmol})$, pentanal $(0.15 \mathrm{~mL}$, $1.41 \mathrm{mmol})$, and 3-oxo- $\mathrm{N}$-(o-tolyl)butanamide $(191 \mathrm{mg}, 1.00 \mathrm{mmol})$ according to the general procedure THQ to give $145 \mathrm{mg}$ (41\%) of a yellow solid $\left(t_{\mathrm{R}}=10.75 \mathrm{~min}, 96.5 \%\right.$ pure by HPLC) after purification by flash chromatography $\left(\mathrm{SiO}_{2}, \mathrm{EtOAc}\right)$ followed by washing with petroleum ether: ${ }^{1} \mathrm{H}$ NMR (400 $\left.\mathrm{MHz}, \mathrm{CDCl}_{3}\right) \delta$ 7.72-7.66 (m, $1 \mathrm{H}), 7.39(\mathrm{~s}, 1 \mathrm{H}), 7.21-7.15(\mathrm{~m}, 2 \mathrm{H}), 7.09-7.03(\mathrm{~m}, 1 \mathrm{H}), 6.44(\mathrm{~s}$, $1 \mathrm{H}), 3.91(\mathrm{t}, J=5.4 \mathrm{~Hz}, 1 \mathrm{H}), 2.46(\mathrm{dt}, J=16.7,4.6 \mathrm{~Hz}, 1 \mathrm{H}), 2.41-2.28$ $(\mathrm{m}, 3 \mathrm{H}), 2.27(\mathrm{~s}, 3 \mathrm{H}), 2.25(\mathrm{~s}, 3 \mathrm{H}), 2.04-1.90(\mathrm{~m}, 2 \mathrm{H}), 1.56-1.45(\mathrm{~m}$, $1 \mathrm{H}), 1.45-1.31(\mathrm{~m}, 1 \mathrm{H}), 1.31-1.17(\mathrm{~m}, 4 \mathrm{H}), 0.84(\mathrm{t}, J=6.8 \mathrm{~Hz}, 3 \mathrm{H})$; ${ }^{13} \mathrm{C}$ NMR $\left(101 \mathrm{MHz}, \mathrm{CDCl}_{3}\right) \delta 196.1,167.2,152.2,140.1,136.1$, 130.6, 130.1, 126.7, 125.3, 123.9, 110.9, 108.8, 37.2, 36.5, 32.0, 27.5, 27.3, 23.1, 21.3, 18.7, 18.2, 14.3; ESI-HRMS calcd for $\mathrm{C}_{22} \mathrm{H}_{29} \mathrm{~N}_{2} \mathrm{O}_{2}(\mathrm{M}$ $+\mathrm{H})^{+}$353.2224; found, 353.2206 .

2-Methyl-5-oxo-4-pentyl- $N$-(o-tolyl)-1,4,5,6,7,8-hexahydroquinoline-3-carboxamide (37). Compound 37 was prepared from 3-aminocyclohex-2-en-1-one (111 mg, $1.00 \mathrm{mmol})$, hexanal $(0.12 \mathrm{~mL}$, $0.99 \mathrm{mmol})$, and 3-oxo- $\mathrm{N}$-(o-tolyl)butanamide $(193 \mathrm{mg}, 1.01 \mathrm{mmol})$ according to the general procedure THQ to give $105 \mathrm{mg}$ (29\%) of a yellow solid $\left(t_{\mathrm{R}}=11.36 \mathrm{~min}, 96.5 \%\right.$ pure by HPLC) after purification by flash chromatography $\left(\mathrm{SiO}_{2}\right.$, EtOAc/petroleum ether, $\left.2: 3\right)$ followed by washing with petroleum ether: ${ }^{1} \mathrm{H}$ NMR $\left(400 \mathrm{MHz}\right.$, acetone- $\left.d_{6}\right) \delta 8.40$ (br s, $1 \mathrm{H}), 7.74($ br s, $1 \mathrm{H}), 7.62-7.56(\mathrm{~m}, 1 \mathrm{H}), 7.22-7.18(\mathrm{~m}, 1 \mathrm{H})$, 7.18-7.12 (m, 1H), 7.08-7.02 (m, 1H), 4.00-3.93 (m, 1H), 2.49$2.43(\mathrm{~m}, 2 \mathrm{H}), 2.30(\mathrm{~s}, 3 \mathrm{H}), 2.35-2.20(\mathrm{~m}, 2 \mathrm{H}), 2.18(\mathrm{~s}, 3 \mathrm{H}), 2.03-$ $1.83(\mathrm{~m}, 2 \mathrm{H}), 1.40-1.17(\mathrm{~m}, 8 \mathrm{H}), 0.84(\mathrm{t}, J=6.9 \mathrm{~Hz}, 3 \mathrm{H}) ;{ }^{13} \mathrm{C} \mathrm{NMR}$ $\left(101 \mathrm{MHz}\right.$, acetone- $\left.d_{6}\right) \delta 195.2,168.5,153.3,153.2,138.2,138.1$, $132.5,132.3,131.1,126.8,125.62,125.60,125.5,110.9,110.6,38.0$, 37.2, 33.1, 32.9, 27.7, 27.6, 25.4, 23.4, 22.2, 18.5, 17.82, 17.75, 14.4 (contains rotamers); ESI-HRMS calcd for $\mathrm{C}_{23} \mathrm{H}_{31} \mathrm{~N}_{2} \mathrm{O}_{2}(\mathrm{M}+\mathrm{H})^{+}$ 367.2380; found, 367.2363 .

2-Methyl-5-oxo-4-phenethyl- $N$-(o-tolyl)-1,4,5,6,7,8-hexahydroquinoline-3-carboxamide (38). Compound 38 was prepared from 3-aminocyclohex-2-en-1-one $(111 \mathrm{mg}, 1.00 \mathrm{mmol})$, 3-phenylpropanal $(0.15 \mathrm{~mL}, 1.14 \mathrm{mmol})$, and 3-oxo- $\mathrm{N}$-(o-tolyl)butanamide (191 mg, $1.00 \mathrm{mmol}$ ) according to the general procedure THQ to give $123 \mathrm{mg}(31 \%)$ of a pale yellow solid $\left(t_{\mathrm{R}}=11.08 \mathrm{~min}, 97.1 \%\right.$ pure by HPLC) after purification by flash chromatography $\left(\mathrm{SiO}_{2}, \mathrm{EtOAc} /\right.$ petroleum ether, $1: 2 \rightarrow 1: 1) ;{ }^{1} \mathrm{H}$ NMR $\left(400 \mathrm{MHz}, \mathrm{CDCl}_{3}\right) \delta 7.70-$ $7.63(\mathrm{~m}, 1 \mathrm{H}), 7.33(\mathrm{br} \mathrm{s}, 1 \mathrm{H}), 7.24-7.03(\mathrm{~m}, 9 \mathrm{H}), 6.41(\mathrm{br} \mathrm{s}, 1 \mathrm{H}), 4.04$ $(\mathrm{t}, J=5.2 \mathrm{~Hz}, 1 \mathrm{H}), 2.65-2.56(\mathrm{~m}, 2 \mathrm{H}), 2.48-2.28(\mathrm{~m}, 4 \mathrm{H}), 2.26(\mathrm{~s}$, $3 \mathrm{H}), 2.22(\mathrm{~s}, 3 \mathrm{H}), 2.02-1.83(\mathrm{~m}, 3 \mathrm{H}), 1.81-1.68(\mathrm{~m}, 1 \mathrm{H}) ;{ }^{13} \mathrm{C} \mathrm{NMR}$ $\left(101 \mathrm{MHz} \mathrm{CDCl}_{3}\right) \delta 196.1,167.1,152.4,142.6,139.9,136.0,130.6$, $130.3,128.4,128.3,126.7,125.7,125.4,124.0,110.6,108.7,38.0,37.2$, 32.0, 31.5, 27.6, 21.3, 18.7, 18.1; ESI-HRMS calcd for $\mathrm{C}_{26} \mathrm{H}_{29} \mathrm{~N}_{2} \mathrm{O}_{2}(\mathrm{M}$ $+\mathrm{H})^{+}$401.2224; found, 401.2206 .

4-(2-(1H-Pyrazol-1-yl)ethyl)- $N$-(2,5-dichlorophenyl)-2-methyl-5-oxo-1,4,5,6,7,8-hexahydroquinoline-3-carboxamide (40). Compound 40 was prepared from 3-(1H-pyrazol-1-yl)propanal (62 $\mathrm{mg}, 0.5 \mathrm{mmol})$, 3-aminocyclohex-2-en-1-one ( $56 \mathrm{mg}, 0.5 \mathrm{mmol})$, and $\mathrm{N}$-(2,5-dichlorophenyl)-3-butanamide (123 $\mathrm{mg}, 0.5 \mathrm{mmol}$ ) according to the general procedure THQ to give $8 \mathrm{mg}$ (4\%) of a pale gray solid $\left(t_{\mathrm{R}}\right.$ $=10.75 \mathrm{~min}$, purity $98.2 \%$ by HPLC) after purification by flash chromatography (Reveleris X2, $12 \mathrm{~g}, \mathrm{MeOH}$ in DCM, $0 \%$ to $10 \%$ ): ${ }^{1} \mathrm{H}$ NMR $\left(400 \mathrm{MHz}, \mathrm{CDCl}_{3}\right) \delta 8.36(\mathrm{~d}, J=4.9 \mathrm{~Hz}, 1 \mathrm{H}), 8.17(\mathrm{~s}, 1 \mathrm{H})$, $7.45-7.40(\mathrm{~m}, 1 \mathrm{H}), 7.29(\mathrm{~d}, J=8.6 \mathrm{~Hz}, 1 \mathrm{H}), 7.21(\mathrm{~s}, 1 \mathrm{H}), 702(\mathrm{dd}, J=$ 8.6, $2.5 \mathrm{~Hz}, 1 \mathrm{H}), 6.19(\mathrm{t}, J=2.1 \mathrm{~Hz}, 1 \mathrm{H}), 4.19-4.03(\mathrm{~m}, 3 \mathrm{H}), 2.51-$ $2.39(\mathrm{~m}, 3 \mathrm{H}), 2.37-2.13(\mathrm{~m}, 5 \mathrm{H}), 2.07-1.81(\mathrm{~m}, 3 \mathrm{H}) ;{ }^{13} \mathrm{C}$ NMR $(101$
$\left.\mathrm{MHz}, \mathrm{CDCl}_{3}\right) \delta 196.0,166.3,152.6,141.5,138.9,135.8,133.3,129.7$, $129.5,124.6,122.4,122.0,110.0,107.5,105.3,48.7,37.0,36.5,29.5$, 27.4, 21.1, 18.8; ESI-HRMS calcd for $\mathrm{C}_{22} \mathrm{H}_{22} \mathrm{Cl}_{2} \mathrm{~N}_{4} \mathrm{NaO}_{2}(\mathrm{M}+\mathrm{Na})^{+}$ 467.1012; found, 467.1005 .

2-Methyl-4-(1-methyl-1H-pyrrol-2-yl)-5-oxo- $\mathrm{N}$-(o-tolyl)1,4,5,6,7,8-hexahydroquinoline-3-carboxamide (41). Compound 41 was prepared from 1-methyl- $1 H$-pyrrole-2-carbaldehyde ( $55 \mu \mathrm{L}, 0.51 \mathrm{mmol}), 3$-aminocyclohex-2-en-1-one $(57 \mathrm{mg}, 0.51 \mathrm{mmol}$ ), and 3-oxo- $\mathrm{N}$-(o-tolyl)butanamide $(90 \mathrm{mg}, 0.51 \mathrm{mmol})$ according to the general procedure THQ to give $8 \mathrm{mg}(4 \%)$ of a yellow foam $\left(t_{\mathrm{R}}=10.17\right.$ min, purity $82.1 \%$ by HPLC) after purification by flash chromatography $\left(\mathrm{SiO}_{2}, \mathrm{EtOAc} /\right.$ petroleum ether, 2:1): ${ }^{1} \mathrm{H}$ NMR $\left(400 \mathrm{MHz}\right.$, DMSO- $\left.d_{6}\right)$ $\delta 8.84(\mathrm{~s}, 1 \mathrm{H}), 8.72(\mathrm{~s}, 1 \mathrm{H}), 7.20-7.01(\mathrm{~m}, 4 \mathrm{H}), 6.42-6.37(\mathrm{~m}, 1 \mathrm{H})$, $5.80-5.77(\mathrm{~m}, 1 \mathrm{H}), 5.70(\mathrm{dd}, J=3.5,1.9 \mathrm{~Hz}, 1 \mathrm{H}), 4.89(\mathrm{~s}, 1 \mathrm{H}), 3.61(\mathrm{~s}$, $3 \mathrm{H}), 2.48-2.43(\mathrm{~m}, 2 \mathrm{H}), 2.21-2.15(\mathrm{~m}, 2 \mathrm{H}), 2.08(\mathrm{~s}, 3 \mathrm{H}), 1.93-1.70$ $(\mathrm{m}, 2 \mathrm{H}), 1.89(\mathrm{~s}, 3 \mathrm{H}) ;{ }^{13} \mathrm{C}$ NMR $\left(101 \mathrm{MHz}, \mathrm{DMSO}-d_{6}\right) \delta 194.1,167.4$, $151.4,138.7,136.6,133.3,132.5,130.1,125.7,125.4,125.0,120.4$, 110.4, 109.0, 106.9, 106.1, 36.8, 33.5, 29.7, 26.4, 20.8, 17.6, 17.0; ESIHRMS calcd for $\mathrm{C}_{23} \mathrm{H}_{25} \mathrm{~N}_{3} \mathrm{NaO}_{2}(\mathrm{M}+\mathrm{Na})^{+}$398.1839; found, 398.1856 .

2-Methyl-4-(5-methylfuran-2-yl)-5-oxo-N-(o-tolyl)1,4,5,6,7,8-hexahydroquinoline-3-carboxamide (42). Compound 42 was prepared from 5-methylfuran-2-carbaldehyde (50 $\mu \mathrm{L}$, $0.50 \mathrm{mmol}), 3$-aminocyclohex-2-en-1-one $(57 \mathrm{mg}, 0.51 \mathrm{mmol})$, and 3 oxo- $\mathrm{N}$-(o-tolyl)butanamide $(89 \mathrm{mg}, 0.50 \mathrm{mmol})$ according to the general procedure THQ to give $69 \mathrm{mg}(37 \%)$ of a pale yellow foam $\left(t_{\mathrm{R}}=\right.$ $10.28 \mathrm{~min}$, purity $99.9 \%$ by HPLC) after purification by flash chromatography $\left(\mathrm{SiO}_{2}, \mathrm{EtOAc} /\right.$ petroleum ether, $\left.2: 1\right):{ }^{1} \mathrm{H}$ NMR (400 MHz, DMSO- $\left.d_{6}\right) \delta 9.03(\mathrm{~s}, 1 \mathrm{H}), 8.81(\mathrm{~s}, 1 \mathrm{H}), 7.27-7.23(\mathrm{~m}, 1 \mathrm{H})$, $7.21-7.11(\mathrm{~m}, 2 \mathrm{H}), 7.10-7.04(\mathrm{~m}, 1 \mathrm{H}), 5.88-5.83(\mathrm{~m}, 1 \mathrm{H}), 5.73(\mathrm{~d}, J$ $=3.0 \mathrm{~Hz}, 1 \mathrm{H}), 5.02(\mathrm{~s}, 1 \mathrm{H}), 2.54-2.43(\mathrm{~m}, 2 \mathrm{H}), 2.29-2.20(\mathrm{~m}, 2 \mathrm{H})$, $2.16(\mathrm{~d}, J=0.7 \mathrm{~Hz}, 3 \mathrm{H}), 2.15(\mathrm{~s}, 3 \mathrm{H}), 2.09(\mathrm{~s}, 3 \mathrm{H}), 1.98-1.81(\mathrm{~m}, 2 \mathrm{H})$; ${ }^{13} \mathrm{C}$ NMR $\left(101 \mathrm{MHz}\right.$, DMSO- $\left.d_{6}\right) \delta 193.8,167.1,156.8,152.9,149.3$, $136.9,135.9,132.7,130.1,125.7,125.6,125.0,107.8,106.1$, 105.9, 105.0, 36.8, 31.5, 26.4, 20.9, 17.9, 17.2, 13.4; ESI-HRMS calcd for $\mathrm{C}_{23} \mathrm{H}_{24} \mathrm{~N}_{2} \mathrm{NaO}_{3}(\mathrm{M}+\mathrm{Na})^{+}$399.1679; found, 399.1696.

2-Methyl-4-(4-methylthiophen-2-yl)-5-oxo-N-(o-tolyl)1,4,5,6,7,8-hexahydroquinoline-3-carboxamide (43). Compound 43 was prepared from 4-methylthiophene-2-carbaldehyde (65 $\mu \mathrm{L}, 0.53 \mathrm{mmol})$, 3-aminocyclohex-2-en-1-one ( $56 \mathrm{mg}, 0.50 \mathrm{mmol})$, and 3 -oxo- $\mathrm{N}$-(o-tolyl)butanamide $(89 \mathrm{mg}, 0.50 \mathrm{mmol})$ according to the general procedure THQ to give $66 \mathrm{mg}(34 \%)$ of a pale orange foam $\left(t_{\mathrm{R}}\right.$ $=10.89 \mathrm{~min}$, purity $98.6 \%$ by HPLC) after purification by flash chromatography $\left(\mathrm{SiO}_{2}, \mathrm{EtOAc} /\right.$ petroleum ether, $\left.2: 1\right):{ }^{1} \mathrm{H}$ NMR (400 MHz, DMSO-d $\left.d_{6}\right) \delta 8.93(\mathrm{~s}, 1 \mathrm{H}), 8.90(\mathrm{~s}, 1 \mathrm{H}), 7.32-7.25(\mathrm{~m}, 1 \mathrm{H}), 7.14$ $(\mathrm{dt}, J=9.1,4.6 \mathrm{~Hz}, 2 \mathrm{H}), 7.05(\mathrm{td}, J=7.4,1.3 \mathrm{~Hz}, 1 \mathrm{H}), 6.80-6.76(\mathrm{~m}$, $1 \mathrm{H}), 6.60(\mathrm{~s}, 1 \mathrm{H}), 5.19(\mathrm{~s}, 1 \mathrm{H}), 2.52-2.44(\mathrm{~m}, 2 \mathrm{H}), 2.28-2.21(\mathrm{~m}$, $2 \mathrm{H}), 2.15(\mathrm{~s}, 3 \mathrm{H}), 2.10(\mathrm{~d}, J=0.9 \mathrm{~Hz}, 3 \mathrm{H}), 2.02(\mathrm{~s}, 3 \mathrm{H}), 1.96-1.75(\mathrm{~m}$, $2 \mathrm{H}) ;{ }^{13} \mathrm{C}$ NMR (101 MHz, DMSO-d 6 ) $\delta 193.9,166.9,152.0,151.1$, $136.7,136.2$, 136.1, 132.3, 130.1, 125.7, 125.4, 125.3, 125.0, 118.8, 109.4, 108.9, 36.7, 32.7, 26.3, 20.8, 17.7, 17.3, 15.5; ESI-HRMS calcd for $\mathrm{C}_{23} \mathrm{H}_{24} \mathrm{~N}_{2} \mathrm{NaO}_{2} \mathrm{~S}(\mathrm{M}+\mathrm{Na})^{+} 415.1451$; found, 415.1457 .

4-(5-Bromofuran-2-yl)-2-methyl-5-oxo- $N$-(o-tolyl)1,4,5,6,7,8-hexahydroquinoline-3-carboxamide (44). Compound 44 was prepared from 5-bromofuran-2-carbaldehyde $(88 \mathrm{mg}$, $0.50 \mathrm{mmol})$, 3-aminocyclohex-2-en-1-one ( $56 \mathrm{mg}, 0.50 \mathrm{mmol})$, and 3oxo- $N$-(o-tolyl)butanamide $(89 \mathrm{mg}, 0.50 \mathrm{mmol})$ according to the general procedure THQ to give $84 \mathrm{mg}(38 \%)$ of a pale yellow solid $\left(t_{\mathrm{R}}=\right.$ $10.59 \mathrm{~min}$, purity $99.9 \%$ by HPLC) after purification by flash chromatography $\left(\mathrm{SiO}_{2}, \mathrm{EtOAc} /\right.$ petroleum ether, 2:1): ${ }^{1} \mathrm{H}$ NMR (400 MHz, DMSO-d $\left.d_{6}\right) \delta 9.18(\mathrm{~s}, 1 \mathrm{H}), 8.88(\mathrm{~s}, 1 \mathrm{H}), 7.27-7.04(\mathrm{~m}, 4 \mathrm{H}), 6.35$ $(\mathrm{d}, J=3.2 \mathrm{~Hz}, 1 \mathrm{H}), 5.94(\mathrm{dd}, J=3.3,0.7 \mathrm{~Hz}, 1 \mathrm{H}), 5.09(\mathrm{~s}, 1 \mathrm{H}), 2.55-$ $2.42(\mathrm{~m}, 2 \mathrm{H}), 2.30-2.19(\mathrm{~m}, 2 \mathrm{H}), 2.14(\mathrm{~s}, 3 \mathrm{H}), 2.09(\mathrm{~s}, 3 \mathrm{H}), 1.98-$ $1.81(\mathrm{~m}, 2 \mathrm{H}) ;{ }^{13} \mathrm{C}$ NMR $\left(101 \mathrm{MHz}\right.$, DMSO- $\left.d_{6}\right) \delta 193.8,166.9,160.8$, $153.4,136.7,135.7,133.1,130.1,126.0,125.7,125.3,118.3,112.0$, 107.4, 107.3, 105.0, 36.7, 32.1, 26.4, 20.8, 18.0, 17.2; ESI-HRMS calcd for $\mathrm{C}_{22} \mathrm{H}_{21} \mathrm{BrN}_{2} \mathrm{NaO}_{3}(\mathrm{M}+\mathrm{Na})^{+}$463.0628; found, 463.0617.

4-(Benzofuran-2-yl)-2-methyl-5-oxo- $N$-(o-tolyl)-1,4,5,6,7,8hexahydroquinoline-3-carboxamide (45). Compound 45 was prepared from benzofuran-2-carbaldehyde $(65 \mu \mathrm{L}, 0.54 \mathrm{mmol}), 3$ - 
aminocyclohex-2-en-1-one $(57 \mathrm{mg}, 0.51 \mathrm{mmol})$, and 3-oxo- $\mathrm{N}$ - $(o-$ tolyl)butanamide $(89 \mathrm{mg}, 0.50 \mathrm{mmol})$ according to the general procedure THQ to give $67 \mathrm{mg}(32 \%)$ of a pale yellow foam $\left(t_{\mathrm{R}}=10.89\right.$ min, purity $96.1 \%$ by HPLC) after purification by flash chromatography $\left(\mathrm{SiO}_{2}, \mathrm{EtOAc} /\right.$ petroleum ether, 2:1): ${ }^{1} \mathrm{H}$ NMR (400 MHz, DMSO- $\left.d_{6}\right)$ $\delta 9.22(\mathrm{~s}, 1 \mathrm{H}), 8.93(\mathrm{~s}, 1 \mathrm{H}), 7.52-7.38(\mathrm{~m}, 2 \mathrm{H}), 7.27-7.04(\mathrm{~m}, 6 \mathrm{H})$, $6.38(\mathrm{~s}, 1 \mathrm{H}), 5.26(\mathrm{~s}, 1 \mathrm{H}), 2.57-2.48(\mathrm{~m}, 2 \mathrm{H}), 2.32-2.25(\mathrm{~m}, 2 \mathrm{H})$, $2.12(\mathrm{~s}, 3 \mathrm{H}), 2.11(\mathrm{~s}, 3 \mathrm{H}), 1.98-1.88(\mathrm{~m}, 2 \mathrm{H}) ;{ }^{13} \mathrm{C} \mathrm{NMR}(101 \mathrm{MHz}$, DMSO- $\left.d_{6}\right) \delta 193.9,167.0,161.6,154.0,153.6,136.7,135.9,133.0$, $130.1,128.5,125.9,125.7,125.2,123.1,122.4,120.4,110.7,107.4$, 105.1, 101.2, 36.7, 32.4, 26.5, 20.9, 17.9, 17.2; ESI-HRMS calcd for $\mathrm{C}_{26} \mathrm{H}_{24} \mathrm{~N}_{2} \mathrm{NaO}_{3}(\mathrm{M}+\mathrm{Na})^{+}$435.1679; found, 435.1686.

4-(Benzo[b]thiophen-3-yl)-2-methyl-5-oxo- N-(o-tolyl)$1,4,5,6,7,8$-hexahydroquinoline-3-carboxamide (46). Compound 46 was prepared from benzo[ $b]$ thiophene-3-carbaldehyde (83 $\mathrm{mg}, 0.51 \mathrm{mmol})$, 3-aminocyclohex-2-en-1-one $(56 \mathrm{mg}, 0.50 \mathrm{mmol})$ and 3-oxo- $N$-(o-tolyl)butanamide $(89 \mathrm{mg}, 0.50 \mathrm{mmol})$ according to the general procedure THQ to give $60 \mathrm{mg}(28 \%)$ of a pale yellow foam $\left(t_{\mathrm{R}}=\right.$ 11.10 min, purity $94.3 \%$ by HPLC) after purification by flash chromatography $\left(\mathrm{SiO}_{2}\right.$, EtOAc/petroleum ether, 2:1): ${ }^{1} \mathrm{H}$ NMR (400 MHz, DMSO- $\left.d_{6}\right) \delta 8.96(\mathrm{~s}, 1 \mathrm{H}), 8.91(\mathrm{~s}, 1 \mathrm{H}), 8.09-8.03(\mathrm{~m}, 1 \mathrm{H})$, 7.91-7.85 (m, 1H), 7.35-7.27 (m, 2H), 7.24 (s, 1H), 7.11-6.98 (m, $5 \mathrm{H}), 5.39(\mathrm{~s}, 1 \mathrm{H}), 2.59-2.46(\mathrm{~m}, 2 \mathrm{H}), 2.27-2.15(\mathrm{~m}, 2 \mathrm{H}), 2.11(\mathrm{~s}$, $3 \mathrm{H}), 1.97-1.79(\mathrm{~m}, 2 \mathrm{H}), 1.77(\mathrm{~s}, 3 \mathrm{H}) ;{ }^{13} \mathrm{C}$ NMR (101 MHz, DMSO$\left.d_{6}\right) \delta 193.9,167.3,152.7,142.4,139.9,137.8,136.5,133.9,132.6,130.0$, $125.60,125.58,125.1,123.7,123.6,123.5,123.0,122.5,110.5,108.2$, 36.8, 32.1, 26.5, 20.8, 17.5, 17.0; ESI-HRMS calcd for $\mathrm{C}_{26} \mathrm{H}_{24} \mathrm{~N}_{2} \mathrm{NaO}_{2} \mathrm{~S}$ $(\mathrm{M}+\mathrm{Na})^{+} 451.1451$; found, 451.1429 .

$\mathrm{N}$-(2,5-Dichlorophenyl)-2-methyl-5-oxo-4-(thiazol-2-yl)1,4,5,6,7,8-hexahydroquinoline-3-carboxamide (47). Compound 47 was prepared from thiazole-2-carbaldehyde $(50 \mu \mathrm{L}, 0.57$ $\mathrm{mmol})$, 3-aminocyclohex-2-en-1-one $(56 \mathrm{mg}, 0.50 \mathrm{mmol})$, and $\mathrm{N}$ - $(2,5$ dichlorophenyl)-3-oxobutanamide $(123 \mathrm{mg}, 0.50 \mathrm{mmol})$ according to the general procedure THQ to give $95 \mathrm{mg}$ (44\%) of a pale yellow solid $\left(t_{\mathrm{R}}=11.68 \mathrm{~min}\right.$, purity $98.2 \%$ by HPLC) after purification by filtration followed by washing with IPA: ${ }^{1} \mathrm{H}$ NMR $\left(500 \mathrm{MHz}, \mathrm{DMSO}-d_{6}\right) \delta 10.76$ $(\mathrm{s}, 1 \mathrm{H}), 9.52(\mathrm{~s}, 1 \mathrm{H}), 8.11(\mathrm{~d}, J=2.6 \mathrm{~Hz}, 1 \mathrm{H}), 7.76(\mathrm{~d}, J=3.3 \mathrm{~Hz}, 1 \mathrm{H})$, $7.56(\mathrm{~d}, J=3.3 \mathrm{~Hz}, 1 \mathrm{H}), 7.54(\mathrm{~d}, J=8.6 \mathrm{~Hz}, 1 \mathrm{H}), 7.21(\mathrm{dd}, J=8.6,2.6$ $\mathrm{Hz}, 1 \mathrm{H}), 5.23(\mathrm{~s}, 1 \mathrm{H}), 2.61(\mathrm{dd}, J=7.5,4.7 \mathrm{~Hz}, 2 \mathrm{H}), 2.34(\mathrm{dd}, J=8.0$, $5.0 \mathrm{~Hz}, 2 \mathrm{H}), 2.13(\mathrm{~s}, 3 \mathrm{H}), 2.08-1.88(\mathrm{~m}, 2 \mathrm{H}) ;{ }^{13} \mathrm{C} \mathrm{NMR}(101 \mathrm{MHz}$, DMSO- $\left.d_{6}\right) \delta 194.2,177.4,166.2,154.0,143.2,142.4,137.2,131.5$, $130.7,124.6,123.4,123.0,119.9,107.4,105.7,36.6,34.1,26.2,20.8$, 17.9; ESI-HRMS calcd for $\mathrm{C}_{20} \mathrm{H}_{18} \mathrm{Cl}_{2} \mathrm{~N}_{3} \mathrm{O}_{2} \mathrm{~S}(\mathrm{M}+\mathrm{H})^{+}$434.0491; found, 434.0510 .

$\mathrm{N}$-(2,5-Dichlorophenyl)-2-methyl-5-oxo-4-(thiazol-5-yl)1,4,5,6,7,8-hexahydroquinoline-3-carboxamide (48). Compound 48 was prepared from thiazole-5-carbaldehyde $(50 \mu \mathrm{L}, 0.58$ $\mathrm{mmol}), 3$-aminocyclohex-2-en-1-one $(56 \mathrm{mg}, 0.50 \mathrm{mmol})$, and $\mathrm{N}$ - $(2,5$ dichlorophenyl)-3-oxobutanamide ( $123 \mathrm{mg}, 0.50 \mathrm{mmol}$ ) according to the general procedure THQ to give $138 \mathrm{mg}(63 \%)$ of a white solid $\left(t_{\mathrm{R}}=\right.$ $10.51 \mathrm{~min}$, purity $96.2 \%$ by HPLC) after purification by filtration followed by washing with IPA: ${ }^{1} \mathrm{H}$ NMR $\left(500 \mathrm{MHz}, \mathrm{DMSO}-d_{6}\right) \delta 9.21$ $(\mathrm{s}, 1 \mathrm{H}), 9.19(\mathrm{~s}, 1 \mathrm{H}), 8.82(\mathrm{~s}, 1 \mathrm{H}), 7.76(\mathrm{~d}, J=2.6 \mathrm{~Hz}, 1 \mathrm{H}), 7.57(\mathrm{~s}$, $1 \mathrm{H}), 7.50(\mathrm{~d}, J=8.6 \mathrm{~Hz}, 1 \mathrm{H}), 7.24(\mathrm{dd}, J=8.6,2.6 \mathrm{~Hz}, 1 \mathrm{H}), 5.30(\mathrm{~s}$, $1 \mathrm{H}), 2.49-2.46(\mathrm{~m}, 2 \mathrm{H}), 2.30-2.24(\mathrm{~m}, 2 \mathrm{H}), 2.23(\mathrm{~s}, 3 \mathrm{H}), 1.96-1.74$ $(\mathrm{m}, 2 \mathrm{H}) ;{ }^{13} \mathrm{C}$ NMR $\left(101 \mathrm{MHz}, \mathrm{DMSO}-d_{6}\right) \delta 194.0,166.5,152.9,152.3$, $144.7,140.1,139.4,136.5,131.4,130.7,125.6,125.4,125.0,109.0$, $106.8,36.6,30.0,26.2,20.8,17.7$; ESI-HRMS calcd for $\mathrm{C}_{20} \mathrm{H}_{18} \mathrm{Cl}_{2} \mathrm{~N}_{3} \mathrm{O}_{2} \mathrm{~S}(\mathrm{M}+\mathrm{H})^{+} 434.0491$; found, 434.0508 .

$\mathrm{N}$-(2,5-Dichlorophenyl)-2-methyl-5-oxo-4-(thiazol-4-yl)$1,4,5,6,7,8$-hexahydroquinoline-3-carboxamide (49). Compound 49 was prepared from thiazole-4-carbaldehyde $(58 \mathrm{mg}, 0.51$ $\mathrm{mmol})$, 3-aminocyclohex-2-en-1-one ( $56 \mathrm{mg}, 0.50 \mathrm{mmol})$, and $\mathrm{N}$ - $(2,5$ dichlorophenyl)-3-oxobutanamide ( $124 \mathrm{mg}, 0.50 \mathrm{mmol}$ ) according to the general procedure THQ to give $130 \mathrm{mg}(60 \%)$ of a white solid $\left(t_{\mathrm{R}}=\right.$ 11.31 min, purity $98.3 \%$ by HPLC) after purification by filtration followed by washing with IPA: ${ }^{1} \mathrm{H}$ NMR $\left(500 \mathrm{MHz}\right.$, DMSO- $\left.d_{6}\right) \delta 10.92$ $(\mathrm{s}, 1 \mathrm{H}), 9.32(\mathrm{~s}, 1 \mathrm{H}), 9.14(\mathrm{~d}, J=2.1 \mathrm{~Hz}, 1 \mathrm{H}), 8.16(\mathrm{~d}, J=2.5 \mathrm{~Hz}, 1 \mathrm{H})$, $7.54(\mathrm{~d}, J=8.6 \mathrm{~Hz}, 1 \mathrm{H}), 7.19(\mathrm{dd}, J=8.6,2.4 \mathrm{~Hz}, 1 \mathrm{H}), 7.11(\mathrm{~d}, J=1.3$ $\mathrm{Hz}, 1 \mathrm{H}), 5.04(\mathrm{~s}, 1 \mathrm{H}), 2.65-2.53(\mathrm{~m}, 2 \mathrm{H}), 2.37-2.25(\mathrm{~m}, 2 \mathrm{H}), 2.10(\mathrm{~s}$,
$3 \mathrm{H}), 2.07-1.95(\mathrm{~m}, 2 \mathrm{H}) ;{ }^{13} \mathrm{C}$ NMR (101 MHz, DMSO- $\left.d_{6}\right) \delta 194.3$ $166.7,159.6,154.8,153.5,143.8,137.4,131.5,130.7,124.2$, 123.0, 122.7, 114.1, 107.3, 106.0, 36.7, 32.3, 26.3, 20.8, 18.0; ESI-HRMS calcd for $\mathrm{C}_{20} \mathrm{H}_{18} \mathrm{Cl}_{2} \mathrm{~N}_{3} \mathrm{O}_{2} \mathrm{~S}(\mathrm{M}+\mathrm{H})^{+}$434.0491; found, 434.0513 .

$\mathrm{N}$-(2,5-Dichlorophenyl)-2-methyl-4-(oxazol-4-yl)-5-oxo$1,4,5,6,7,8$-hexahydroquinoline-3-carboxamide (50). Compound 50 was prepared from oxazole-4-carbaldehyde $(49 \mathrm{mg}, 0.50$ $\mathrm{mmol})$, 3-aminocyclohex-2-en-1-one $(56 \mathrm{mg}, 0.50 \mathrm{mmol})$, and $\mathrm{N}$ - $(2,5$ dichlorophenyl)-3-oxobutanamide (123 $\mathrm{mg}, 0.50 \mathrm{mmol}$ ) according to the general procedure THQ to give $77 \mathrm{mg}(37 \%)$ of a brown solid $\left(t_{\mathrm{R}}=\right.$ 10.77 min, purity $97.8 \%$ by HPLC) after purification by filtration followed by washing with IPA: ${ }^{1} \mathrm{H}$ NMR $\left(500 \mathrm{MHz}, \mathrm{DMSO}-d_{6}\right) \delta 10.11$ $(\mathrm{s}, 1 \mathrm{H}), 9.24(\mathrm{~s}, 1 \mathrm{H}), 8.34(\mathrm{~d}, J=1.0 \mathrm{~Hz}, 1 \mathrm{H}), 8.10(\mathrm{~d}, J=2.6 \mathrm{~Hz}, 1 \mathrm{H})$, $7.69-7.62(\mathrm{~m}, 1 \mathrm{H}), 7.53(\mathrm{~d}, J=8.6 \mathrm{~Hz}, 1 \mathrm{H}), 7.20(\mathrm{dd}, J=8.6,2.6 \mathrm{~Hz}$, $1 \mathrm{H}), 4.83(\mathrm{~s}, 1 \mathrm{H}), 2.58-2.44(\mathrm{~m}, 2 \mathrm{H}), 2.33-2.20(\mathrm{~m}, 2 \mathrm{H}), 2.12(\mathrm{~s}$, $3 \mathrm{H}), 2.04-1.88(\mathrm{~m}, 2 \mathrm{H}) ;{ }^{13} \mathrm{C}$ NMR (101 MHz, DMSO- $\left.d_{6}\right) \delta 194.1$, 166.5 , 153.4, 152.2, 143.1, 142.8, 137.1, 135.0, 131.5, 130.7, 124.6, 123.4, 123.3, 106.3, 105.3, 36.6, 28.4, 26.3, 20.7, 17.9; ESI-HRMS calcd for $\mathrm{C}_{20} \mathrm{H}_{18} \mathrm{Cl}_{2} \mathrm{~N}_{3} \mathrm{O}_{3}(\mathrm{M}+\mathrm{H})^{+}$418.0720; found, 418.0733.

$\mathrm{N}$-(2,5-Dichlorophenyl)-2-methyl-4-(oxazol-2-yl)-5-oxo1,4,5,6,7,8-hexahydroquinoline-3-carboxamide (51). Compound 51 was prepared from oxazole-2-carbaldehyde $(49 \mathrm{mg}, 0.50$ $\mathrm{mmol}), 3$-aminocyclohex-2-en-1-one $(56 \mathrm{mg}, 0.50 \mathrm{mmol})$, and $\mathrm{N}$-(2,5dichlorophenyl)-3-butanamide (123 $\mathrm{mg}, 0.50 \mathrm{mmol}$ ) according to the general procedure THQ to give $12 \mathrm{mg}(6 \%)$ of a pale yellow solid $\left(t_{\mathrm{R}}=\right.$ $10.43 \mathrm{~min}$, purity $99.0 \%$ by HPLC) after purification by flash chromatography (Reveleris X2, $12 \mathrm{~g}$, EtOAc in petroleum ether, 0 to 100\%): ${ }^{1} \mathrm{H}$ NMR $\left(400 \mathrm{MHz}, \mathrm{CDCl}_{3}\right) \delta 9.69(\mathrm{~s}, 1 \mathrm{H}), 9.23(\mathrm{~s}, 1 \mathrm{H}), 7.91$ $(\mathrm{d}, J=0.7 \mathrm{~Hz}, 1 \mathrm{H}), 7.88(\mathrm{~d}, J=2.5 \mathrm{~Hz}, 1 \mathrm{H}), 7.52(\mathrm{~d}, J=8.6 \mathrm{~Hz}, 1 \mathrm{H})$, $7.24(\mathrm{dd}, J=8.6,2.6 \mathrm{~Hz}, 1 \mathrm{H}), 7.08(\mathrm{~d}, J=0.7 \mathrm{~Hz}, 1 \mathrm{H}), 5.19(\mathrm{~s}, 1 \mathrm{H})$, $2.58-2.47(\mathrm{~m}, 2 \mathrm{H}), 2.34-2.24(\mathrm{~m}, 2 \mathrm{H}), 2.15(\mathrm{~s}, 3 \mathrm{H}), 2.03-1.81(\mathrm{~m}$, $2 \mathrm{H}) ;{ }^{13} \mathrm{C} \mathrm{NMR}\left(101 \mathrm{MHz}, \mathrm{CDCl}_{3}\right) \delta 194.1,166.4,165.7,153.3,141.1$, 139.0, 136.8, 131.4, 130.7, 126.7, 125.2, 124.6, 104.9, 103.9, 36.5, 31.8, 26.3, 20.9, 17.7; ESI-HRMS calcd for $\mathrm{C}_{20} \mathrm{H}_{17} \mathrm{Cl}_{2} \mathrm{~N}_{3} \mathrm{NaO}_{3}(\mathrm{M}+\mathrm{Na})^{+}$ 440.0539; found, 440.0539 .

4-(Aminomethyl)- $\mathrm{N}$-(2,5-dichlorophenyl)-2-methyl-5-oxo$1,4,5,6,7,8$-hexahydroquinoline-3-carboxamide Hydrochloride (52). Compound $\mathbf{5 2}$ was prepared from tert-butyl ((3-) (2,5dichlorophenyl)carbamoyl)-2-methyl-5-oxo-1,4,5,6,7,8-hexahydroquinolin-4-yl)methyl)carbamate ( $8 \mathrm{mg}, 17 \mu \mathrm{mol})$ which was dissolved in 1 $\mathrm{mL}$ of $4 \mathrm{M} \mathrm{HCl}$ in 1,4-dioxane at $0{ }^{\circ} \mathrm{C}$. The mixture was stirred overnight at room temperature and concentrated to give $7 \mathrm{mg}$ (quant.) of a yellow solid $\left(t_{R}=7.00 \mathrm{~min}\right.$, purity $96.4 \%$ by HPLC): ${ }^{1} \mathrm{H}$ NMR (400 MHz, DMSO-d $)_{6} \delta 9.75(\mathrm{~s}, 1 \mathrm{H}), 9.15(\mathrm{~s}, 1 \mathrm{H}), 7.86(\mathrm{~d}, J=2.5 \mathrm{~Hz}, 1 \mathrm{H})$, $7.78(\mathrm{~s}, 2 \mathrm{H}), 7.55(\mathrm{~d}, J=8.7 \mathrm{~Hz}, 1 \mathrm{H}), 7.30(\mathrm{dd}, J=8.6,2.6 \mathrm{~Hz}, 1 \mathrm{H})$, $4.00(\mathrm{t}, J=4.2 \mathrm{~Hz}, 1 \mathrm{H}), 2.80-2.69(\mathrm{~m}, 1 \mathrm{H}), 2.64-2.54(\mathrm{~m}, 1 \mathrm{H}), 2.46-$ $2.21(\mathrm{~m}, 4 \mathrm{H}), 2.18(\mathrm{~s}, 3 \mathrm{H}), 2.06-1.97(\mathrm{~m}, 1 \mathrm{H}), 1.94-1.83(\mathrm{~m}, 1 \mathrm{H})$; ${ }^{13} \mathrm{C}$ NMR $\left(101 \mathrm{MHz}\right.$, DMSO- $\left.d_{6}\right) \delta 195.1,167.3,155.2,139.6,136.3$, $131.3,130.7,126.08,126.07,125.8,104.3,104.2,42.9,36.6,30.9,26.4$, 20.4, 17.8; ESI-HRMS calcd for $\mathrm{C}_{18} \mathrm{H}_{20} \mathrm{Cl}_{2} \mathrm{~N}_{3} \mathrm{O}_{2}(\mathrm{M}+\mathrm{H})^{+} 380.0927$; found, 380.0925 .

$\mathrm{N}$-(2,5-Dichlorophenyl)-2-methyl-5-oxo-4-(piperidin-4-ylmethyl)-1,4,5,6,7,8-hexahydroquinoline-3-carboxamide Hydrochloride (53). Compound $\mathbf{5 3}$ was prepared from tert-butyl 4((3-((2,5-dichlorophenyl) carbamoyl)-2-methyl-5-oxo-1,4,5,6,7,8-hexahydroquinolin-4-yl)methyl)piperidine-1-carboxylate (30 mg, 55 $\mu \mathrm{mol}$ ) which was dissolved in $2 \mathrm{~mL}$ of $4 \mathrm{M} \mathrm{HCl}$ in 1,4-dioxane at 0 ${ }^{\circ} \mathrm{C}$. The mixture was stirred overnight at room temperature and concentrated to give $26 \mathrm{mg}$ (quant.) of a yellow solid $\left(t_{\mathrm{R}}=7.27 \mathrm{~min}\right.$, purity $95.1 \%$ by HPLC): ${ }^{1} \mathrm{H}$ NMR $\left(400 \mathrm{MHz}, \mathrm{DMSO}-d_{6}\right) \delta 9.23(\mathrm{~s}$, $1 \mathrm{H}), 9.01(\mathrm{~s}, 1 \mathrm{H}), 8.82(\mathrm{~d}, J=9.6 \mathrm{~Hz}, 1 \mathrm{H}), 8.62-8.48(\mathrm{~m}, 1 \mathrm{H}), 7.80(\mathrm{~d}$, $J=2.5 \mathrm{~Hz}, 1 \mathrm{H}), 7.54(\mathrm{~d}, J=8.6 \mathrm{~Hz}, 1 \mathrm{H}), 7.26(\mathrm{dd}, J=8.6,2.6 \mathrm{~Hz}, 1 \mathrm{H})$, $3.85-3.77(\mathrm{~m}, 2 \mathrm{H}), 3.24-3.10(\mathrm{~m}, 2 \mathrm{H}), 2.75-2.59(\mathrm{~m}, 2 \mathrm{H}), 2.53-$ $2.36(\mathrm{~m}, 2 \mathrm{H}), 2.35-2.18(\mathrm{~m}, 2 \mathrm{H}), 2.15(\mathrm{~s}, 3 \mathrm{H}), 2.07-1.68(\mathrm{~m}, 4 \mathrm{H})$, $1.52-1.38(\mathrm{~m}, 2 \mathrm{H}), 1.32-1.06(\mathrm{~m}, 4 \mathrm{H}) ;{ }^{13} \mathrm{C}$ NMR $(101 \mathrm{MHz}, \mathrm{DMSO}-$ $\left.d_{6}\right) \delta 194.6,167.5,152.9,138.4,136.7,131.3,130.7,125.51,125.50$, 125.0, 109.3, 108.8, 43.6, 43.1, 43.0, 36.8, 29.2, 28.8, 28.4, 28.1, 26.4, 20.8, 17.5; ESI-HRMS calcd for $\mathrm{C}_{23} \mathrm{H}_{28} \mathrm{Cl}_{2} \mathrm{~N}_{3} \mathrm{O}_{2}(\mathrm{M}+\mathrm{Na})^{+} 448.1553$; found, 448.1568 . 
$\mathrm{N}$-(2,5-Dichlorophenyl)-4-((2-(diethylamino)ethoxy)methyl)-2-methyl-5-oxo-1,4,5,6,7,8-hexahydroquinoline-3carboxamide (54). 2-(Diethylamino)ethan-1-ol (500 mg, 4.27 $\mathrm{mmol}$ ) was added dropwise to a suspension of $\mathrm{NaH}$ (266 mg, 50\%) in $5 \mathrm{~mL}$ of dry THF. The mixture was heated at $50^{\circ} \mathrm{C}$ for $10 \mathrm{~min}$, before dropwise addition of 2-bromo-1,1-diethoxyethane $(0.77 \mathrm{~mL}, 5.12$ $\mathrm{mmol}$ ). The mixture was afterward heated to $100{ }^{\circ} \mathrm{C}$ overnight. The reaction mixture was cooled down, quenched with water, and extracted with EtOAc $(\times 3)$. The organic phases were combined, washed with brine, dried over $\mathrm{Na}_{2} \mathrm{SO}_{4}$, and concentrated. The crude 2-(2,2diethoxyethoxy)- $\mathrm{N}, \mathrm{N}$-diethylethan-1-amine was used directly in the next step.

$N, N$-Diethyl-2-(2-oxoethoxy)ethan-1-aminium 2,2,2-trifluoroacetate was prepared from 2-(2,2-diethoxyethoxy)- $N, N$-diethylethan-1amine $(730 \mathrm{mg}, 3.13 \mathrm{mmol})$ and TFA $(5 \mathrm{~mL})$, and the mixture was stirred at rt overnight. Afterward, the reaction mixture was concentrated and dried, and the crude was used in the next step without any further purification: ${ }^{1} \mathrm{H} \mathrm{NMR}\left(400 \mathrm{MHz}, \mathrm{CDCl}_{3}\right) \delta 9.61(\mathrm{~s}, 1 \mathrm{H}), 9.18(\mathrm{~s}, 1 \mathrm{H})$, $4.31(\mathrm{~s}, 2 \mathrm{H}), 3.93-3.86(\mathrm{~m} \mathrm{2H}), 3.45-3.25(\mathrm{~m}, 6 \mathrm{H}), 1.37(\mathrm{t}, J=7.3$ $\mathrm{Hz}, 6 \mathrm{H})$; ESI-HRMS calcd for $\mathrm{C}_{8} \mathrm{H}_{18} \mathrm{NO}_{2}(\mathrm{M}+\mathrm{H})^{+}$160.1332; found, 160.1325 .

Compound 54 was prepared from $N, N$-diethyl-2-(2-oxoethoxy)ethan-1-aminium 2,2,2-trifluoroacetate $(138 \mathrm{mg}, 0.51 \mathrm{mmol})$, 3aminocyclohex-2-en-1-one $(56 \mathrm{mg}, 0.51 \mathrm{mmol})$, and $\mathrm{N}$-(2,5-dichlorophenyl)-3-butanamide ( $125 \mathrm{mg}, 0.51 \mathrm{mmol}$ ) according to the general procedure THQ to give $15 \mathrm{mg}(6 \%)$ of a pale yellow solid $\left(t_{\mathrm{R}}=7.38\right.$ min, purity $99.4 \%$ by HPLC) after purification by flash chromatography $\left(\mathrm{SiO}_{2}, \mathrm{MeOH}\right.$ in EtOAc, $0 \%$ to $\left.8 \%\right):{ }^{1} \mathrm{H} \mathrm{NMR}\left(400 \mathrm{MHz}, \mathrm{CDCl}_{3}\right) \delta$ $9.21(\mathrm{~s}, 1 \mathrm{H}), 8.34(\mathrm{~d}, J=2.5 \mathrm{~Hz}, 1 \mathrm{H}), 7.28(\mathrm{~d}, J=8.6 \mathrm{~Hz}, 1 \mathrm{H}), 6.99(\mathrm{dd}$, $J=8.6,2.5 \mathrm{~Hz}, 1 \mathrm{H}), 6.21(\mathrm{~s}, 1 \mathrm{H}), 4.18-4.11(\mathrm{~m}, 1 \mathrm{H}), 3.67-3.52(\mathrm{~m}$, $2 \mathrm{H}), 3.31-3.22(\mathrm{~m}, 2 \mathrm{H}), 2.69-2.62(\mathrm{~m}, 2 \mathrm{H}), 2.59-2.40(\mathrm{~m}, 8 \mathrm{H})$, $2.37-2.25(\mathrm{~m}, 5 \mathrm{H}), 2.10-2.91(\mathrm{~m}, 3 \mathrm{H}), 0.97(\mathrm{t}, J=7.2 \mathrm{~Hz}, 6 \mathrm{H}) ;{ }^{13} \mathrm{C}$ NMR $\left(101 \mathrm{MHz}, \mathrm{CDCl}_{3}\right) \delta 196.6,167.3,160.5,155.1,143.1,136.3$, 133.6, 130.0, 124.4, 121.7, 121.3, 107.2, 106.4, 74.9, 65.6, 56.7, 56.3, 51.5, 48.6, 47.9, 47.8, 36.9, 32.6, 27.3, 21.3, 18.9, 8.9; ESI-HRMS calcd for $\mathrm{C}_{24} \mathrm{H}_{32} \mathrm{Cl}_{2} \mathrm{~N}_{3} \mathrm{O}_{2}(\mathrm{M}+\mathrm{Na})^{+} 480.1815$; found, 480.1828 .

tert-Butyl((3-((2,5-dichlorophenyl)carbamoyl)-2-methyl-5oxo-1,4,5,6,7,8-hexahydroquinolin-4-yl)methyl)carbamate (55). Compound 55 was prepared from tert-butyl (2-oxoethyl)carbamate $(80 \mathrm{mg}, 0.50 \mathrm{mmol}), 3$-aminocyclohex-2-en-1-one $(56 \mathrm{mg}$, $0.50 \mathrm{mmol}$ ), and $\mathrm{N}$-(2,5-dichlorophenyl)-3-oxobutanamide (125 mg, $0.51 \mathrm{mmol}$ ) according to the general procedure THQ to give $41 \mathrm{mg}$ (17\%) of a white solid ( $t_{\mathrm{R}}=11.76 \mathrm{~min}$, purity $97.2 \%$ by HPLC) after purification by flash chromatography $\left(\mathrm{SiO}_{2}, \mathrm{EtOAc}\right):{ }^{1} \mathrm{H}$ NMR (400 $\left.\mathrm{MHz}, \mathrm{CD}_{3} \mathrm{OD}\right) \delta 8.13(\mathrm{~d}, J=1.4 \mathrm{~Hz}, 1 \mathrm{H}), 7.45(\mathrm{~d}, J=8.6 \mathrm{~Hz}, 1 \mathrm{H}), 7.19$ $(\mathrm{dd}, J=8.6,2.4 \mathrm{~Hz}, 1 \mathrm{H}), 4.07-3.94(\mathrm{~m}, 1 \mathrm{H}), 3.16-2.93(\mathrm{~m}, 2 \mathrm{H})$, $2.60-2.25(\mathrm{~m}, 4 \mathrm{H}), 2.16(\mathrm{~s}, 3 \mathrm{H}), 2.12-1.94(\mathrm{~m}, 2 \mathrm{H}), 1.41(\mathrm{~s}, 9 \mathrm{H}) ;{ }^{13} \mathrm{C}$ NMR (101 MHz, CD $\left.{ }_{3} \mathrm{OD}\right) \delta 198.9,170.5,159.0,157.4,140.0,137.4$, $133.9,131.5,126.8,125.9,125.6,108.9,108.2,79.9,45.5,37.8,35.1$, 28.8, 27.9, 22.2, 17.7; ESI-HRMS calcd for $\mathrm{C}_{23} \mathrm{H}_{28} \mathrm{Cl}_{2} \mathrm{~N}_{3} \mathrm{O}_{4}(\mathrm{M}+\mathrm{H})^{+}$ 480.1451; found, 480.1445 .

tert-Butyl 4-((3-((2,5-dichlorophenyl)carbamoyl)-2-methyl5-oxo-1,4,5,6,7,8-hexahydroquinolin-4-yl)methyl)piperidine1-carboxylate (56). Compound 56 was prepared from tert-butyl 4-(2oxoethyl)piperidine-1-carboxylate $(115 \mathrm{mg}, 0.50 \mathrm{mmol}), 3$-aminocyclohex-2-en-1-one (113 mg, $1.02 \mathrm{mmol})$, and $\mathrm{N}$-(2,5-dichlorophenyl)-3-oxobutanamide $(125 \mathrm{mg}, 0.51 \mathrm{mmol})$ according to the general procedure THQ to give $142 \mathrm{mg}(52 \%)$ of a white solid $\left(t_{\mathrm{R}}=13.21 \mathrm{~min}\right.$, purity $99.1 \%$ by HPLC) after purification by flash chromatography $\left(\mathrm{SiO}_{2}\right.$, EtOAc): ${ }^{1} \mathrm{H}$ NMR $\left(400 \mathrm{MHz}\right.$, acetone- $\left.d_{6}\right) \delta 8.50(\mathrm{~d}, J=2.5 \mathrm{~Hz}$, $0.3 \mathrm{H}), 8.49$ (d, $J=2.5 \mathrm{~Hz}, 0.7 \mathrm{H}), 8.39(\mathrm{br} \mathrm{s}, 1 \mathrm{H}), 8.15$ (br s, $1 \mathrm{H}), 7.49$ $(\mathrm{d}, J=8.6 \mathrm{~Hz}, 1 \mathrm{H}), 7.15(\mathrm{dd}, J=8.6,2.6 \mathrm{~Hz}, 1 \mathrm{H}), 4.05-3.88(\mathrm{~m}, 3 \mathrm{H})$, $2.65-2.43(\mathrm{~m}, 4 \mathrm{H}), 2.30(\mathrm{~s}, 3 \mathrm{H}), 2.41-2.18(\mathrm{~m}, 2 \mathrm{H}), 2.03-1.87(\mathrm{~m}$, $3 \mathrm{H}), 1.60(\mathrm{~d}, J=13.0 \mathrm{~Hz}, 1 \mathrm{H}), 1.40(\mathrm{~s}, 9 \mathrm{H}), 1.46-1.17(\mathrm{~m}, 3 \mathrm{H}), 1.06-$ $0.90(\mathrm{~m}, 2 \mathrm{H}) ;{ }^{13} \mathrm{C}$ NMR $\left(101 \mathrm{MHz}\right.$, acetone- $\left.d_{6}\right) \delta 195.4,167.7,155.1$, $152.8,152.7,142.4,137.7,133.5,131.1,124.9,124.8,122.7,122.6$, 111.7, 109.2, 109.1, 79.0, 45.1, 44.7 (br s), 37.8, 33.8, 33.3, 32.8, 28.6, 27.64, 27.56, 22.0, 18.5, 18.4 (contains rotamers); ESI-HRMS calcd for $\mathrm{C}_{28} \mathrm{H}_{35} \mathrm{Cl}_{2} \mathrm{~N}_{3} \mathrm{NaO}_{4}(\mathrm{M}+\mathrm{Na})^{+}$570.1897; found, 570.1880.
$N$-(2,5-Dichlorophenyl)-2-methyl-5-oxo-4-propyl1,4,5,6,7,8-hexahydroquinoline-3-carboxamide (57). Compound 57 was prepared from butyraldehyde $(65 \mu \mathrm{L}, 0.72 \mathrm{mmol}), 3-$ aminocyclohex-2-en-1-one $(70 \mathrm{mg}, 0.63 \mathrm{mmol})$, and $\mathrm{N}$-(2,5-dichlorophenyl)-3-oxobutanamide $(155 \mathrm{mg}, 0.63 \mathrm{mmol}$ ) according to the general procedure THQ to give $85 \mathrm{mg}(34 \%)$ of a pale yellow solid $\left(t_{\mathrm{R}}=\right.$ $12.34 \mathrm{~min}$, purity $96.1 \%$ by HPLC) after purification by flash chromatography $\left(\mathrm{SiO}_{2}, \mathrm{EtOAc} /\right.$ petroleum ether, 1:1): ${ }^{1} \mathrm{H}$ NMR (500 $\left.\mathrm{MHz}, \mathrm{DMSO}-d_{6}\right) \delta 9.14(\mathrm{~s}, 1 \mathrm{H}), 8.72(\mathrm{~s}, 1 \mathrm{H}), 7.80(\mathrm{~d}, J=2.5 \mathrm{~Hz}, 1 \mathrm{H})$, $7.53(\mathrm{~d}, J=8.6 \mathrm{~Hz}, 1 \mathrm{H}), 7.25(\mathrm{dd}, J=8.6,2.5 \mathrm{~Hz}, 1 \mathrm{H}), 3.85(\mathrm{t}, J=4.7$ $\mathrm{Hz}, 1 \mathrm{H}), 2.44-2.33(\mathrm{~m}, 2 \mathrm{H}), 2.30-2.15(\mathrm{~m}, 2 \mathrm{H}), 2.12(\mathrm{~s}, 3 \mathrm{H}), 1.94-$ $1.77(\mathrm{~m}, 2 \mathrm{H}), 1.39-1.12(\mathrm{~m}, 4 \mathrm{H}), 0.79(\mathrm{t}, J=7.1 \mathrm{~Hz}, 3 \mathrm{H}) ;{ }^{13} \mathrm{C} \mathrm{NMR}$ $\left(101 \mathrm{MHz}, \mathrm{DMSO}-d_{6}\right) \delta 194.5,167.5,152.8,138.8,136.7,131.4,130.6$, 125.51, 125.46, 125.1, 108.9, 108.1, 38.6, 36.9, 31.1, 26.3, 21.0, 17.6, 17.5, 14.3; ESI-HRMS calcd for $\mathrm{C}_{20} \mathrm{H}_{23} \mathrm{Cl}_{2} \mathrm{~N}_{2} \mathrm{O}_{2}(\mathrm{M}+\mathrm{H})^{+}$393.1131; found, 393.1112 .

$N$-(2-Chlorophenyl)-2-methyl-5-oxo-4-propyl-1,4,5,6,7,8hexahydroquinoline-3-carboxamide (58). Compound 58 was prepared from butyraldehyde ( $36 \mathrm{mg}, 0.50 \mathrm{mmol})$, 3-aminocyclohex-2en-1-one $(55 \mathrm{mg}, 0.50 \mathrm{mmol})$, and $\mathrm{N}$-(2-chlorophenyl)-3-oxobutanamide (105 $\mathrm{mg}, 0.50 \mathrm{mmol}$ ) according to the general procedure THQ to give $38 \mathrm{mg}(21 \%)$ of a pale yellow solid $\left(t_{\mathrm{R}}=11.07 \mathrm{~min}\right.$, purity $97.3 \%$ by HPLC) after purification by flash chromatography (Reveleris X2, $24 \mathrm{~g}$, EtOAc/petroleum ether, 3:2): ${ }^{1} \mathrm{H}$ NMR $\left(400 \mathrm{MHz}, \mathrm{CDCl}_{3}\right) \delta 8.34$ $(\mathrm{dd}, J=1.5,8.3 \mathrm{~Hz}, 1 \mathrm{H}), 8.03(\mathrm{~s}, 1 \mathrm{H}), 7.37(\mathrm{dd}, J=1.5,8.0 \mathrm{~Hz}, 1 \mathrm{H})$, $7.29-7.23(\mathrm{~m}, 1 \mathrm{H}), 7.05-6.99(\mathrm{~m}, 1 \mathrm{H}), 6.42(\mathrm{~s}, 1 \mathrm{H}), 3.96(\mathrm{t}, J=5.5$ $\mathrm{Hz}, 1 \mathrm{H}), 2.53-2.40(\mathrm{~m}, 3 \mathrm{H}), 2.37-2.27(\mathrm{~m}, 4 \mathrm{H}), 2.08-1.93(\mathrm{~m}, 2 \mathrm{H})$, $1.64-1.20(\mathrm{~m}, 4 \mathrm{H}), 0.86(\mathrm{t}, J=7.2 \mathrm{~Hz}, 3 \mathrm{H}) ;{ }^{13} \mathrm{C}$ NMR $(101 \mathrm{MHz}$, $\left.\mathrm{CDCl}_{3}\right) \delta 195.9,166.7,151.7,140.9,135.1,129.1,127.5,124.3,123.4$, 122.0, 111.2, 108.6, 39.0, 37.1, 31.5, 27.5, 21.2, 18.9, 18.3, 14.3; ESIHRMS calcd for $\mathrm{C}_{20} \mathrm{H}_{24} \mathrm{ClN}_{2} \mathrm{O}_{2}(\mathrm{M}+\mathrm{Na})^{+} 359.1521$; found, 359.1537 .

$\mathrm{N}$-(3-Chlorophenyl)-2-methyl-5-oxo-4-propyl-1,4,5,6,7,8hexahydroquinoline-3-carboxamide (59). $\mathrm{N}$-(3-Chlorophenyl)3-oxobutanamide was prepared from 2-chloroaniline $(1.10 \mathrm{~g}, 8.61$ $\mathrm{mmol}$ ) and $2 \mathrm{~mL}$ of methyl acetoacetate. The mixture was stirred at 110 ${ }^{\circ} \mathrm{C}$ overnight, cooled down, and dry loaded on silica. Purification by flash chromatography (Reveleris X2, $12 \mathrm{~g}$, EtOAc in petroleum ether, 0 to $100 \%)$ gave $536 \mathrm{mg}(29 \%)$ of an off-white solid: ${ }^{1} \mathrm{H}$ NMR (400 $\left.\mathrm{MHz}, \mathrm{CDCl}_{3}\right) \delta 9.28(\mathrm{~s}, 1 \mathrm{H}), 7.68(\mathrm{t}, J=2.0 \mathrm{~Hz}, 1 \mathrm{H}), 7.40-7.34(\mathrm{~m}$, $1 \mathrm{H}), 7.28-7.20(\mathrm{~m}, 1 \mathrm{H}), 7.12-7.06(\mathrm{~m}, 1 \mathrm{H}), 3.59(\mathrm{~s}, 2 \mathrm{H}), 2.32(\mathrm{~s}$, $3 \mathrm{H}) ;{ }^{13} \mathrm{C} \mathrm{NMR}\left(101 \mathrm{MHz}, \mathrm{CDCl}_{3}\right) \delta 205.3,163.5,138.6,134.7,130.0$, 124.6, 120.3, 118.1, 49.4, 31.3; ESI-HRMS calcd for $\mathrm{C}_{10} \mathrm{H}_{10} \mathrm{ClNNaO}_{2}$ $(\mathrm{M}+\mathrm{Na})^{+}$234.0292; found, 234.0302 .

Compound 59 was prepared from butyraldehyde $(36 \mathrm{mg}, 0.50$ $\mathrm{mmol})$, 3-aminocyclohex-2-en-1-one (55 mg, $0.50 \mathrm{mmol})$, and $\mathrm{N}$-(3chlorophenyl)-3-oxobutanamide $(105 \mathrm{mg}, 0.50 \mathrm{mmol}$ ) according to the general procedure THQ to give $25 \mathrm{mg}$ (14\%) of a pale yellow solid $\left(t_{\mathrm{R}}=11.27 \mathrm{~min}\right.$, purity $97.5 \%$ by HPLC) after purification by flash chromatography (Reveleris X2, $24 \mathrm{~g}, \mathrm{MeOH}$ in DCM, 0 to $10 \%):{ }^{1} \mathrm{H}$ $\operatorname{NMR}\left(400 \mathrm{MHz}, \mathrm{CDCl}_{3}\right) \delta 7.88(\mathrm{~s}, 1 \mathrm{H}), 7.74(\mathrm{t}, J=2 \mathrm{~Hz}, 1 \mathrm{H}), 7.35-$ $7.30(\mathrm{~m}, 1 \mathrm{H}), 7.22(\mathrm{t}, J=7.1 \mathrm{~Hz}, 1 \mathrm{H}), 7.08-7.03(\mathrm{~m}, 1 \mathrm{H}), 6.18(\mathrm{~s}, 1 \mathrm{H})$, $3.88(\mathrm{t}, J=5.9 \mathrm{~Hz}, 1 \mathrm{H}), 2.52-2.39(\mathrm{~m}, 3 \mathrm{H}), 2.35-2.26(\mathrm{~m}, 1 \mathrm{H}), 2.25$ $(\mathrm{s}, 3 \mathrm{H}), 2.07-1.94(\mathrm{~m}, 2 \mathrm{H}), 1.49-1.19(\mathrm{~m}, 4 \mathrm{H}), 0.83(\mathrm{t}, J=7.1 \mathrm{~Hz}$, $3 \mathrm{H}) ;{ }^{13} \mathrm{C} \mathrm{NMR}\left(101 \mathrm{MHz}, \mathrm{CDCl}_{3}\right) \delta 196.2,167.3,151.9,140.0,139.5$, 134.6, 129.8, 124.0, 120.4, 118.2, 111.0, 108.9, 39.1, 37.1, 31.7, 27.6, 21.2, 18.6, 18.2, 14.3; ESI-HRMS calcd for $\mathrm{C}_{20} \mathrm{H}_{23} \mathrm{ClN}_{2} \mathrm{NaO}_{2}(\mathrm{M}+$ $\mathrm{Na})^{+}$381.1340; found, 381.1343.

$\mathrm{N}$-(2-Chloro-5-methylphenyl)-2-methyl-5-oxo-4-propyl1,4,5,6,7,8-hexahydroquinoline-3-carboxamide (60). $\mathrm{N}$-(2Chloro-5-methylphenyl)-3-oxobutanamide was prepared from 2chloro-5-methylaniline (1.0 g, $7.06 \mathrm{mmol}), 2 \mathrm{~mL}$ of methyl acetoacetate, and a catalytic amount of potassium $t$-butoxide. The mixture was heated in a $\mathrm{MW}$ reactor at $120^{\circ} \mathrm{C}$ for $2 \mathrm{~h}$. After completion, the reaction mixture was cooled to rt, dry loaded on silica, and purified by flash chromatography $\left(\mathrm{SiO}_{2}, \mathrm{EtOAc} /\right.$ petroleum ether, 1:4) to yield $640 \mathrm{mg}(40 \%)$ of a yellow solid: ${ }^{1} \mathrm{H}$ NMR $\left(400 \mathrm{MHz}, \mathrm{CDCl}_{3}\right) \delta 9.49(\mathrm{~s}$, $1 \mathrm{H}), 8.15(\mathrm{~d}, J=1.4 \mathrm{~Hz}, 1 \mathrm{H}), 7.24(\mathrm{~d}, J=8.2 \mathrm{~Hz}, 1 \mathrm{H}), 6.88-6.84(\mathrm{~m}$, $1 \mathrm{H}), 3.63(\mathrm{~s}, 2 \mathrm{H}), 2.34(\mathrm{~s}, 3 \mathrm{H}), 2.32(\mathrm{~s}, 3 \mathrm{H}) ;{ }^{13} \mathrm{C}$ NMR $(101 \mathrm{MHz}$, $\left.\mathrm{CDCl}_{3}\right) \delta 204.6,163.6,137.7,134.1,128.7,125.8,122.6,120.5,49.9$, 
31.2, 21.3; ESI-HRMS calcd for $\mathrm{C}_{11} \mathrm{H}_{12} \mathrm{ClNNaO}_{2}(\mathrm{M}+\mathrm{Na})^{+}$248.0449; found, 248.0457 .

Compound 60 was prepared from butyraldehyde $(34 \mathrm{mg}, 0.47$ $\mathrm{mmol}$ ), 3-aminocyclohex-2-en-1-one ( $52 \mathrm{mg}, 0.47 \mathrm{mmol})$, and $\mathrm{N}$-(2chloro-5-methylphenyl)-3-oxobutanamide (105 mg, $0.47 \mathrm{mmol}$ ) according to the general procedure THQ to give $39 \mathrm{mg}(22 \%)$ of a pale yellow solid ( $t_{\mathrm{R}}=11.63 \mathrm{~min}$, purity $98.7 \%$ by HPLC) after purification by flash chromatography $\left(\mathrm{SiO}_{2}, \mathrm{EtOAc}\right.$ in petroleum ether, $50 \%$ to $70 \%):{ }^{1} \mathrm{H}$ NMR $\left(400 \mathrm{MHz}, \mathrm{CDCl}_{3}\right) \delta 8.18(\mathrm{~d}, J=1.6 \mathrm{~Hz}, 1 \mathrm{H})$, $7.99(\mathrm{~s}, 1 \mathrm{H}), 7.23(\mathrm{~d}, J=8.2 \mathrm{~Hz}, 1 \mathrm{H}), 6.86-6.80(\mathrm{~m}, 1 \mathrm{H}), 6.56(\mathrm{~s}, 1 \mathrm{H})$, $3.96(\mathrm{t}, J=5.5 \mathrm{~Hz}, 1 \mathrm{H}), 2.54-2.39(\mathrm{~m}, 3 \mathrm{H}), 2.37-2.26(\mathrm{~m}, 7 \mathrm{H}), 2.07-$ $1.93(\mathrm{~m}, 2 \mathrm{H}), 1.55-1.34(\mathrm{~m}, 2 \mathrm{H}), 1.33-1.21(\mathrm{~m}, 2 \mathrm{H}), 0.91-0.81(\mathrm{~m}$, $3 \mathrm{H}) ;{ }^{13} \mathrm{C}$ NMR $\left(101 \mathrm{MHz}, \mathrm{CDCl}_{3}\right) \delta 196.0,166.8,151.8,140.8,137.7$, 134.6, 128.6, 125.2, 122.5, 120.4, 111.1, 108.7, 39.0, 37.1, 31.5, 27.5, 21.3, 21.2, 18.9, 18.3, 14.3; ESI-HRMS calcd for $\mathrm{C}_{21} \mathrm{H}_{25} \mathrm{ClN}_{2} \mathrm{NaO}_{2}(\mathrm{M}$ $+\mathrm{Na})^{+}$395.1497; found, 395.1513 .

$\mathrm{N}$-(2-Chloro-5-methoxyphenyl)-2-methyl-5-oxo-4-propyl1,4,5,6,7,8-hexahydroquinoline-3-carboxamide (61). $\mathrm{N}$-(2Chloro-5-methoxyphenyl)-3-oxobutanamide was prepared from 2chloro-5-methoxylaniline $(1.0 \mathrm{~g}, 7.06 \mathrm{mmol}), 2 \mathrm{~mL}$ of methyl acetoacetate, and a catalytic amount of potassium $t$-butoxide. The mixture was heated in a $\mathrm{MW}$ reactor at $120^{\circ} \mathrm{C}$ for $2 \mathrm{~h}$. After completion, the reaction mixture was cooled to rt, dry loaded on silica, and purified by flash chromatography $\left(\mathrm{SiO}_{2}, \mathrm{EtOAc} /\right.$ petroleum ether, 1:4) to yield $617 \mathrm{mg}(30 \%)$ of a yellow solid: ${ }^{1} \mathrm{H}$ NMR $\left(400 \mathrm{MHz}, \mathrm{CDCl}_{3}\right) \delta 9.59(\mathrm{~s}$, $1 \mathrm{H}), 8.04(\mathrm{~d}, J=3.0 \mathrm{~Hz}, 1 \mathrm{H}), 7.25(\mathrm{~d}, J=8.9 \mathrm{~Hz}, 1 \mathrm{H}), 6.61(\mathrm{dd}, J=8.9$, $3.0 \mathrm{~Hz}, 1 \mathrm{H}), 3.79(\mathrm{~s}, 3 \mathrm{H}), 3.64(\mathrm{~s}, 2 \mathrm{H}), 2.34(\mathrm{~s}, 3 \mathrm{H}) ;{ }^{13} \mathrm{C}$ NMR $(101$ $\left.\mathrm{MHz}, \mathrm{CDCl}_{3}\right) \delta 204.6,163.6,158.8,135.2,129.3,114.6,111.2,107.1$, 55.6, 49.8, 31.2; ESI-HRMS calcd for $\mathrm{C}_{11} \mathrm{H}_{12} \mathrm{ClNNaO}_{3}(\mathrm{M}+\mathrm{Na})^{+}$ 264.0398; found, 264.0389 .

Compound 61 was prepared from butyraldehyde $(36 \mathrm{mg}, 0.50$ $\mathrm{mmol}$ ), 3-aminocyclohex-2-en-1-one (55 $\mathrm{mg}, 0.50 \mathrm{mmol})$, and $\mathrm{N}$-(2chloro-5-methoxyphenyl)-3-oxobutanamide $(120 \mathrm{mg}, 0.50 \mathrm{mmol})$ according to the general procedure THQ to give $48 \mathrm{mg}(25 \%)$ of a pale yellow solid $\left(t_{\mathrm{R}}=11.42 \mathrm{~min}\right.$, purity $97.6 \%$ by HPLC) after purification by flash chromatography $\left(\mathrm{SiO}_{2}, \mathrm{EtOAc}\right.$ in petroleum ether, $50 \%$ to $70 \%):{ }^{1} \mathrm{H}$ NMR $\left(400 \mathrm{MHz}, \mathrm{CDCl}_{3}\right) \delta 8.07(\mathrm{~d}, J=3.0 \mathrm{~Hz}, 1 \mathrm{H})$, $8.03(\mathrm{~s}, 1 \mathrm{H}), 7.24(\mathrm{~d}, J=8.9 \mathrm{~Hz}, 1 \mathrm{H}), 6.66(\mathrm{~s}, 1 \mathrm{H}), 6.58(\mathrm{dd}, J=8.9,3.0$ $\mathrm{Hz}, 1 \mathrm{H}), 3.96(\mathrm{t}, J=5.5 \mathrm{~Hz}, 1 \mathrm{H}), 3.81(\mathrm{~s}, 3 \mathrm{H}), 2.53-2.40(\mathrm{~m}, 3 \mathrm{H})$, $2.37-2.26(\mathrm{~m}, 4 \mathrm{H}), 2.07-1.89(\mathrm{~m}, 2 \mathrm{H}), 1.55-1.45(\mathrm{~m}, 1 \mathrm{H}), 1.44-$ $1.34(\mathrm{~m}, 1 \mathrm{H}), 1.33-1.20(\mathrm{~m}, 2 \mathrm{H}), 0.85(\mathrm{t}, J=7.2 \mathrm{~Hz}, 3 \mathrm{H}) ;{ }^{13} \mathrm{C} \mathrm{NMR}$ $\left(101 \mathrm{MHz} \mathrm{CDCl}_{3}\right) \delta 196.0,166.8,158.9,151.9,140.9,135.7,129.2$, 114.5, 111.1, 110.7, 108.8, 106.9, 55.7, 39.0, 37.1, 31.5, 27.5, 21.2, 18.8, 18.3, 14.3; ESI-HRMS calcd for $\mathrm{C}_{21} \mathrm{H}_{25} \mathrm{ClN}_{2} \mathrm{NaO}_{3}(\mathrm{M}+\mathrm{Na})^{+}$ 411.1446; found, 411.1467 .

4-Cyclopropyl- $N$-(2,5-dichlorophenyl)-2-methyl-5-oxo1,4,5,6,7,8-hexahydroquinoline-3-carboxamide (62). Compound 62 was prepared from cyclopropanecarbaldehyde $(36 \mathrm{mg}$, $0.51 \mathrm{mmol}), 3$-aminocyclohex-2-en-1-one ( $56 \mathrm{mg}, 0.51 \mathrm{mmol}$ ), and $\mathrm{N}$ (2,5-dichlorophenyl)-3-oxobutanamide $(125 \mathrm{mg}, 0.51 \mathrm{mmol})$ according to the general procedure THQ to give $125 \mathrm{mg}(63 \%)$ of a pale yellow solid $\left(t_{\mathrm{R}}=11.85 \mathrm{~min}\right.$, purity $99.4 \%$ by HPLC) after purification by flash chromatography (Reveleris X2, $24 \mathrm{~g}$, EtOAc in petroleum ether, 0 to $100 \%):{ }^{1} \mathrm{H} \mathrm{NMR}\left(400 \mathrm{MHz}, \mathrm{CDCl}_{3}\right) \delta 8.46(\mathrm{~d}, J=2.5 \mathrm{~Hz}$, $1 \mathrm{H}), 8.15(\mathrm{~s}, 1 \mathrm{H}), 7.29(\mathrm{~d}, J=8.6 \mathrm{~Hz}, 1 \mathrm{H}), 7.00(\mathrm{dd}, J=8.6,2.5 \mathrm{~Hz}$, $1 \mathrm{H}), 5.93(\mathrm{~s}, 1 \mathrm{H}), 3.82(\mathrm{~d}, J=6.7 \mathrm{~Hz}, 1 \mathrm{H}), 2.57-2.42(\mathrm{~m}, 3 \mathrm{H}), 2.39-$ $2.29(\mathrm{~m}, 4 \mathrm{H}), 2.11-2.01(\mathrm{~m}, 2 \mathrm{H}), 1.10-1.00(\mathrm{~m}, 1 \mathrm{H}), 0.41-0.35(\mathrm{~m}$, $3 \mathrm{H}), 0.28-0.18(\mathrm{~m}, 1 \mathrm{H}) ;{ }^{13} \mathrm{C} \mathrm{NMR}\left(101 \mathrm{MHz}, \mathrm{CDCl}_{3}\right) \delta 196.0,166.8$, 150.4, 142.2, 136.1, 133.4, 129.7, 124.1, 121.7, 121.2, 111.7, 106.3, 37.1, $32.3,27.6,21.2,19.2,18.0,2.8,2.7$; ESI-HRMS calcd for $\mathrm{C}_{20} \mathrm{H}_{20} \mathrm{Cl}_{2} \mathrm{~N}_{2} \mathrm{NaO}_{2}(\mathrm{M}+\mathrm{Na})^{+}$413.0794; found, 413.0793.

4-Cyclopentyl- $\mathrm{N}$-(2,5-dichlorophenyl)-2-methyl-5-oxo$1,4,5,6,7,8$-hexahydroquinoline-3-carboxamide (63). Compound 63 was prepared from cyclopentanecarbaldehyde $(50 \mathrm{mg}, 0.51$ $\mathrm{mmol})$, 3-aminocyclohex-2-en-1-one ( $56 \mathrm{mg}, 0.51 \mathrm{mmol})$, and $\mathrm{N}$-(2,5dichlorophenyl)-3-oxobutanamide $(125 \mathrm{mg}, 0.51 \mathrm{mmol})$ according to the general procedure THQ to give $10 \mathrm{mg}(5 \%)$ of a pale yellow solid $\left(t_{\mathrm{R}}=12.83 \mathrm{~min}\right.$, purity $95.6 \%$ by HPLC) after purification by flash chromatography (Reveleris X2, $24 \mathrm{~g}$, EtOAc in petroleum ether, 0 to $100 \%):{ }^{1} \mathrm{H}$ NMR (400 MHz, DMSO- $\left.d_{6}\right) \delta 9.07(\mathrm{~s}, 1 \mathrm{H}), 8.81(\mathrm{~s}, 1 \mathrm{H})$, $7.84(\mathrm{~d}, J=2.6 \mathrm{~Hz}, 1 \mathrm{H}), 7.53(\mathrm{~d}, J=8.6 \mathrm{~Hz}, 1 \mathrm{H}), 7.24(\mathrm{dd}, J=8.6,2.6$ $\mathrm{Hz}, 1 \mathrm{H}), 3.90(\mathrm{~d}, J=6.1 \mathrm{~Hz}, 1 \mathrm{H}), 2.47-2.35(\mathrm{~m}, 2 \mathrm{H}), 2.34-2.12(\mathrm{~m}$, $5 \mathrm{H}), 1.97-1.87(\mathrm{~m}, 1 \mathrm{H}), 1.86-1.71(\mathrm{~m}, 2 \mathrm{H}), 1.55-1.08(\mathrm{~m}, 8 \mathrm{H}) ;{ }^{13} \mathrm{C}$ NMR $\left(101 \mathrm{MHz}, \mathrm{DMSO}-d_{6}\right) \delta 194.7,168.1,152.8,139.0,136.7,131.4$, 130.6, 125.2, 124.9, 124.5, 108.6, 107.6, 48.0, 37.0, 33.7, 27.9, 27.8, 26.5, 24.1, 24.0, 20.8; ESI-HRMS calcd for $\mathrm{C}_{22} \mathrm{H}_{24} \mathrm{Cl}_{2} \mathrm{~N}_{2} \mathrm{NaO}_{2}(\mathrm{M}+$ $\mathrm{Na})^{+}$441.1107; found, 441.1090.

Inhibition of cAMP Assay. HEK293 Flp-In T-Rex cells stably transfected with FFA3-eYFP receptors were incubated overnight with doxycycline to induce expression, then harvested, and cryopreserved. On the day of each experiment, cells were thawed and resuspended in stimulation buffer. Assays were carried out using a 384-well plate format with 3000 cells/well using the CisBio cAMP GS dynamic kit as per manufacturer's protocol. Compounds were tested for the ability to inhibit $0.3 \mu \mathrm{M}$ forskolin-induced cAMP production after co-incubation for $1 \mathrm{~h}$. Reactions were measured using a PHERAstar FS plate reader (BMGLabtech, Aylesbury, UK).

Membrane Preparation. Membranes were isolated from Flp-In TREx HEK293 cells treated with $100 \mathrm{ng} / \mathrm{mL}$ doxycycline to induce receptor expression. Cells were washed with ice-cold phosphatebuffered saline and removed from dishes by scraping before being centrifuged for $5 \mathrm{~min}$ at $4{ }^{\circ} \mathrm{C}, 3000 \mathrm{rpm}$. Pellets were resuspended in TE buffer (75 mM Tris-HCl, 5 mM EDTA; pH 7.5) with the addition of a protease inhibitor mixture (Roche Applied Science, West Sussex, UK). This was then homogenized with a $5 \mathrm{~mL}$ hand-held homogenizer and subsequently centrifuged at $1500 \mathrm{rpm}$ for $5 \mathrm{~min}$ at $4{ }^{\circ} \mathrm{C}$, from which the supernatant was collected and further centrifuged at $50000 \mathrm{rpm}$ for 30 min at $4{ }^{\circ} \mathrm{C}$. The resulting pellet was resuspended in TE buffer, and the protein content was measured using a BCA protein assay kit (Pierce, Fisher Scientific, Loughborough, UK).

$\left[{ }^{35} \mathrm{~S}\right] \mathrm{GTP} \gamma \mathrm{S}$ Incorporation Assay. $\left[{ }^{35} \mathrm{~S}\right] \mathrm{GTP} \gamma \mathrm{S}$ binding assays were performed in reactions with $5 \mu \mathrm{g}$ of cell membrane protein preincubated for $15 \mathrm{~min}$ at $25^{\circ} \mathrm{C}$ in assay buffer $(50 \mathrm{mM}$ Tris- $\mathrm{HCl}, \mathrm{pH}$ 7.4, $10 \mathrm{mM} \mathrm{MgCl}_{2}, 100 \mathrm{mM} \mathrm{NaCl}, 1 \mathrm{mM} \mathrm{EDTA}, 1 \mu \mathrm{M} \mathrm{GDP}$, and $0.1 \%$ fatty acid-free bovine serum albumin) containing the indicated concentrations of ligands. Reactions were initiated with the addition of $\left[{ }^{35} \mathrm{~S}\right] \mathrm{GTP} \gamma \mathrm{S}$ at $50 \mathrm{nCi}$ per tube; reactions were terminated after $1 \mathrm{~h}$ of incubation at $25^{\circ} \mathrm{C}$ by rapid filtration through GF/C glass filters using a 24-well Brandel cell harvester (Alpha Biotech, Glasgow, UK). Unbound radioligand was removed from filters by washing three times with icecold wash buffer ( $50 \mathrm{mM}$ Tris- $\mathrm{HCl}, \mathrm{pH} 7.4$, and $10 \mathrm{mM} \mathrm{MgCl}_{2}$ ), and $\left.{ }^{35} \mathrm{~S}\right] \mathrm{GTP} \gamma \mathrm{S}$ binding was determined by liquid scintillation spectrometry.

Physicochemical Properties. Solubility and $\log D_{7.4}$ measurements were performed in accordance to the previously published procedures. ${ }^{35}$

Microsomal Stability. The study was performed by Bienta (www. bienta.net). Mouse hepatic microsomes were isolated from pooled and perfused livers of male $\mathrm{BALB} / \mathrm{c}$ mice $(n=50)$. Isolation was performed according to the standard protocol. ${ }^{36}$ The batches of microsomes were tested for quality control using Imipramine and Propranolol as reference compounds.

Microsomal incubations were carried out in 96-well plates in 5 aliquots of $40 \mu \mathrm{L}$ each (one for each time point). Liver microsomal incubation medium comprised PBS (100 mM, pH 7.4), $\mathrm{MgCl}_{2}$ (3.3 $\mathrm{mM})$, NADPH (3 mM), glucose-6-phosphate (5.3 mM), and glucose6-phosphate dehydrogenase $(0.67$ units $/ \mathrm{mL})$ with $0.42 \mathrm{mg}$ of liver microsomal protein per ml. In the control reactions, the NADPHcofactor system was substituted with PBS. Test compounds $(2 \mu \mathrm{M}$, final solvent concentration $1.6 \%$ ) were incubated with microsomes at $37^{\circ} \mathrm{C}$, shaking at $100 \mathrm{rpm}$. Each reaction was performed in duplicates. Five time points over $40 \mathrm{~min}$ were analyzed. The reactions were stopped by adding 12 volumes of $90 \%$ acetonitrile-water to incubation aliquots, followed by protein sedimentation by centrifuging at $5500 \mathrm{rpm}$ for 3 min. Each reaction was performed in duplicates. Supernatants were analyzed using HPLC-MS/MS on an API 3000 PE instrument.

In Vivo Pharmacokinetics. The study was performed by Bienta (www.bienta.net). Study design, animal selection, handling, and treatment were all in accordance with the Enamine PK study protocols and Institutional Animal Care and Use Guidelines. Animal treatment 
and plasma samples preparation were conducted by the Animal Laboratory personnel at Enamine/Bienta. Male BALB/c mice (8-10 weeks old, body weight: $117.2 \mathrm{~g}$ to $29.5 \mathrm{~g}$ and average body weight across all groups $22.4 \pm 2.95 \mathrm{~g} ; 1618.0 \mathrm{~g}$ to $28.6 \mathrm{~g}$ and average body weight across all groups $22.8 \pm 2.34 \mathrm{~g} ; 5720.0 \mathrm{~g}$ to $37.4 \mathrm{~g}$ and average body weight across all groups $27.0 \pm 4.71 \mathrm{~g} ; 6317.6 \mathrm{~g}$ to $28.1 \mathrm{~g}$ and average body weight across all groups $22.0 \pm 2.61 \mathrm{~g}$ ) were used in this study. The animals were randomly assigned to the treatment groups before the pharmacokinetic study; all animals were fasted for $4 \mathrm{~h}$ before dosing. Nine time points $(5,15,30,60,120,240,360,480$, and 1440 min) were set for this pharmacokinetic study. Each of the time point treatment group included four animals. There was also a control group of two animals. Compound 1, 16, 57, and 63 in a vehicle (DMSOCremophor EL-water w/5\% mannitol, 1:1:8) was dosed at $10 \mathrm{mg} / \mathrm{kg}$ po or $5 \mathrm{mg} / \mathrm{kg}$ iv. Dosing volumes of compounds or vehicle was $5 \mathrm{~mL} /$ $\mathrm{kg}$. Mice were injected iv with 2,2,2-tribromoethanol at the dose of 150 $\mathrm{mg} / \mathrm{kg}$ prior to drawing the blood. Blood collection was performed from the orbital sinus in microtainers containing $\mathrm{K}_{2} \mathrm{EDTA}$. Animals were sacrificed by cervical dislocation after the blood sample collection. All samples were immediately processed, flash-frozen, and stored at $-70{ }^{\circ} \mathrm{C}$ until subsequent analysis. Before analysis, plasma samples (50 $\mu \mathrm{L})$ were added acetonitrile-methanol $(1: 1, \mathrm{v} / \mathrm{v}, 200 \mu \mathrm{L})$ containing an internal standard (IS-10784, $\mathrm{C}_{20} \mathrm{H}_{26} \mathrm{~N}_{8}, M_{\mathrm{w}} 378.47$ ) $200 \mathrm{ng} / \mathrm{mL}$ for 1 , $63400 \mathrm{ng} / \mathrm{mL}$ for 16, or $16200 \mathrm{ng} / \mathrm{mL}$ for 57 and 63, respectively). After mixing by pipetting and centrifuging for $4 \mathrm{~min}$ at $6000 \mathrm{rpm}, 0.5-1$ $\mu \mathrm{L}$ of each supernatant was analyzed by HPLC-MS/MS on an API 3000 PE instrument.

Dorsal Root Ganglion Assay. Colonic innervating DRGs were isolated from the T9-L2 region of the spinal cord of C57/BL6 mice and from FFA3 knock-out animals and immediately placed in cold Hanks' balanced salt solution (HBSS; Sigma-Aldrich). Isolated DRGs were initially digested with HBSS containing L-cysteine $(0.3 \mathrm{mg} / \mathrm{mL})$ and papain $(2.0 \mathrm{mg} / \mathrm{mL})$ for $20 \mathrm{~min}$ at $37^{\circ} \mathrm{C}$. The solution was removed and replaced with HBSS contain collagenase $(4.0 \mathrm{mg} / \mathrm{mL})$ and dispase $(4.0 \mathrm{mg} / \mathrm{mL})\left(20 \mathrm{~min}\right.$ at $\left.37^{\circ} \mathrm{C}\right)$ for further digestion. The collagenase solution was then replaced with DMEM to stop the reaction. The DRGs were finally dissociated by mechanical trituration using a pipette. Dissociated cells were plated on matrigel-coated coverslips and placed in an incubator $\left(37^{\circ} \mathrm{C}\right.$ and $\left.5 \% \mathrm{CO}_{2}\right)$. Following a $2 \mathrm{~h}$ incubation, cells were flooded with 90\% DMEM (Sigma) supplemented with $10 \%$ fetal calf serum and $1 \%$ PenStrep and further incubated overnight at $37^{\circ} \mathrm{C}$ and $5 \% \mathrm{CO}_{2}$.

To measure intracellular calcium and its potential regulation, dissociated cells on the coverslips were loaded with Fura 8-AM (3 $\mu \mathrm{M})$ (Stratech Scientific Limited) for $20 \mathrm{~min}$ at $37{ }^{\circ} \mathrm{C}$ in the dark. Coverslips were then placed in a recording chamber and mounted onto an inverted fluorescent microscope (Nikon TE2000-E; Nikon Instruments, Melville, NY) equipped with a $(\mathrm{NA}=1.3)$ oil-immersion Super Fluor objective lens $(\times 40)$, an Optoscan monochromator (Cairn Research, Faversham, Kent, UK), and a digital Cool Snap-HQ CCD camera (Roper Scientific/Photometrics, Tucson, AZ). Illumination of the preparation was achieved by a Meta Fluor imaging software (Molecular Devices, San Jose CA, version 7.8.8).

Cluster of cells were randomly selected for real time imaging and continuously perfused with HEPES buffer (composition: HEPES 10 $\mathrm{mM}, \mathrm{NaCl} 135 \mathrm{mM}$, glucose $10 \mathrm{mM}, \mathrm{KCl} 5 \mathrm{mM}, \mathrm{CaCl}_{2} 2 \mathrm{mM}$ and $\mathrm{MgCl}_{2} 1 \mathrm{mM}, \mathrm{pH}$ 7.4) for $20 \mathrm{~min}$ at room temperature. All test ligands were diluted in HEPES buffer and perfused through the chamber for 3 min, followed by a final application of the $\mathrm{Ca}^{2+}$ ionophore ionomycin ( 5 $\mu \mathrm{M})$, as a positive control.

\section{ASSOCIATED CONTENT}

\section{(s) Supporting Information}

The Supporting Information is available free of charge at https://pubs.acs.org/doi/10.1021/acs.jmedchem.9b02036.

\section{HPLC traces (PDF)}

Molecular strings formula (CSV)
Crystallographic data for $(R)-\mathbf{1}$ and $(R, S)-\mathbf{1}$, modeling procedure, stability of $\mathbf{5 7}$ in DMSO, and counterscreen data (PDF)

\section{Accession Codes}

Crystallographic data (CIF) for $(R)-1$ and $(R, S)-1$ have been deposited at the Cambridge Crystallographic Data Centre, CCDC1873629

\section{AUTHOR INFORMATION}

\section{Corresponding Author}

Elisabeth Rexen Ulven - Department of Drug Design and Pharmacology, University of Copenhagen, DK-2100 Copenhagen, Denmark; Department of Physics, Chemistry and Pharmacy, University of Southern Denmark, DK-5230 Odense M, Denmark; @ orcid.org/0000-0003-1243-7587; Email: eru@sund.ku.dk

\section{Authors}

Tezz Quon - Centre for Translational Pharmacology, Institute of Molecular, Cell and Systems Biology, College of Medical, Veterinary and Life Sciences, University of Glasgow, G12 8QQ Glasgow, U.K.

Eugenia Sergeev - Centre for Translational Pharmacology, Institute of Molecular, Cell and Systems Biology, College of Medical, Veterinary and Life Sciences, University of Glasgow, G12 8QQ Glasgow, U.K.

Natasja Barki - Centre for Translational Pharmacology, Institute of Molecular, Cell and Systems Biology, College of Medical, Veterinary and Life Sciences, University of Glasgow, G12 8QQ Glasgow, U.K.

Matjaz Brvar - Department of Physics, Chemistry and Pharmacy, University of Southern Denmark, DK-5230 Odense M, Denmark

Brian D. Hudson - Centre for Translational Pharmacology, Institute of Molecular, Cell and Systems Biology, College of Medical, Veterinary and Life Sciences, University of Glasgow, G12 8QQ Glasgow, U.K.

Palash Dutta - Department of Drug Design and Pharmacology, University of Copenhagen, DK-2100 Copenhagen, Denmark

Anders Højgaard Hansen - Department of Physics, Chemistry and Pharmacy, University of Southern Denmark, DK-5230 Odense M, Denmark

Line Ø. Bielefeldt - Department of Physics, Chemistry and Pharmacy, University of Southern Denmark, DK-5230 Odense M, Denmark

Andrew B. Tobin - Centre for Translational Pharmacology, Institute of Molecular, Cell and Systems Biology, College of Medical, Veterinary and Life Sciences, University of Glasgow, G12

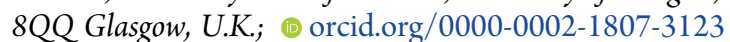

Christine J. McKenzie - Department of Physics, Chemistry and Pharmacy, University of Southern Denmark, DK-5230 Odense M, Denmark; 이이.org/0000-0001-5587-0626

Graeme Milligan - Centre for Translational Pharmacology, Institute of Molecular, Cell and Systems Biology, College of Medical, Veterinary and Life Sciences, University of Glasgow, G12 8QQ Glasgow, U.K.

Trond Ulven - Department of Drug Design and Pharmacology, University of Copenhagen, DK-2100 Copenhagen, Denmark; (D) orcid.org/0000-0002-8135-1755

Complete contact information is available at: https://pubs.acs.org/10.1021/acs.jmedchem.9b02036 


\section{Author Contributions}

The manuscript was written through contributions of all authors. All authors have given approval to the final version of the manuscript.

\section{Funding}

This work was supported by the Lundbeck Foundation (grant R181-2014-3247, R307-2018-2950), the Danish Council for Strategic Research/Innovation Fund Denmark (grant 11116196, 0603-00452B), and the Biotechnology and Biosciences Research Council (grant numbers BB/L027887/1 and BB/ LO278X/1).

\section{Notes}

The authors declare no competing financial interest.

\section{ACKNOWLEDGMENTS}

We thank Ole Buch Madsen, Rikke Linnet Jørgensen, and Lone Overgaard Storm for assistance with synthesis and Loukas Ieremias for assistance with counterscreening.

\section{ABBREVIATIONS}

C3, propionate; DRG, dorsal root ganglion; FFA2, free fatty acid receptor 2 (GPR43); FFA3, free fatty acid receptor 3 (GPR41); IPA, isopropanol; 1-MCPC, 1-methylcyclopropylcarboxylate; MLM, mouse liver microsomes; SCFA, short-chain fatty acids; THQ tetrahydroquinoline

\section{REFERENCES}

(1) Topping, D. L.; Clifton, P. M. Short-chain fatty acids and human colonic function: Roles of resistant starch and nonstarch polysaccharides. Physiol. Rev. 2001, 81, 1031-1064.

(2) Kuwahara, A. Contributions of colonic short-chain fatty acid receptors in energy homeostasis. Front. Endocrinol. 2014, 5, 144.

(3) Ulven, T. Short-chain free fatty acid receptors FFA2/GPR43 and FFA3/GPR41 as new potential therapeutic targets. Front. Endocrinol. 2012, 3, 111.

(4) Le Poul, E.; Loison, C.; Struyf, S.; Springael, J.-Y.; Lannoy, V.; Decobecq, M.-E.; Brezillon, S.; Dupriez, V.; Vassart, G.; Van Damme, J.; Parmentier, M.; Detheux, M. Functional characterization of human receptors for short chain fatty acids and their role in polymorphonuclear cell activation. J. Biol. Chem. 2003, 278, 25481-25489.

(5) Brown, A. J.; Goldsworthy, S. M.; Barnes, A. A.; Eilert, M. M.; Tcheang, L.; Daniels, D.; Muir, A. I.; Wigglesworth, M. J.; Kinghorn, I.; Fraser, N. J.; Pike, N. B.; Strum, J. C.; Steplewski, K. M.; Murdock, P. R.; Holder, J. C.; Marshall, F. H.; Szekeres, P. G.; Wilson, S.; Ignar, D. M.; Foord, S. M.; Wise, A.; Dowell, S. J. The orphan G protein-coupled receptors GPR41 and GPR43 are activated by propionate and other short chain carboxylic acids. J. Biol. Chem. 2003, 278, 11312-11319.

(6) Milligan, G.; Shimpukade, B.; Ulven, T.; Hudson, B. D. Complex pharmacology of free fatty acid receptors. Chem. Rev. 2017, 117, 67110.

(7) Tang, C.; Offermanns, S. FFA2 and FFA3 in metabolic regulation. Handb. Exp. Pharmacol. 2017, 236, 205-220.

(8) Steensels, S.; Cools, L.; Avau, B.; Vancleef, L.; Farré, R.; Verbeke, K.; Depoortere, I. Supplementation of oligofructose, but not sucralose, decreases high-fat diet induced body weight gain in mice independent of gustducin-mediated gut hormone release. Mol. Nutr. Food Res. 2017, 61, 1600716.

(9) Hudson, B. D.; Due-Hansen, M. E.; Christiansen, E.; Hansen, A. M.; Mackenzie, A. E.; Murdoch, H.; Pandey, S. K.; Ward, R. J.; Marquez, R.; Tikhonova, I. G.; Ulven, T.; Milligan, G. Defining the molecular basis for the first potent and selective orthosteric agonists of the FFA2 free fatty acid receptor. J. Biol. Chem. 2013, 288, 1729617312.

(10) Zaibi, M. S.; Stocker, C. J.; O’Dowd, J.; Davies, A.; Bellahcene, M.; Cawthorne, M. A.; Brown, A. J. H.; Smith, D. M.; Arch, J. R. S. Roles of GPR41 and GPR43 in leptin secretory responses of murine adipocytes to short chain fatty acids. FEBS Lett. 2010, 584, 2381-2386.

(11) Vermeire, S.; Kojecký, V.; Knoflícek, V.; Reinisch, W.; Van Kaem, T.; Namour, F.; Beetens, J.; Vanhoutte, F. GLPG0974, an FFA2 antagonist, in ulcerative colitis: efficacy and safety in a multicenter proof-of-concept study. J. Crohn's Colitis 2015, 9, S39.

(12) Tang, C.; Ahmed, K.; Gille, A.; Lu, S.; Gröne, H.-J.; Tunaru, S.; Offermanns, S. Loss of FFA2 and FFA3 increases insulin secretion and improves glucose tolerance in type 2 diabetes. Nat. Med. 2015, 21, $173-177$.

(13) Thirunavukkarasan, M.; Wang, C.; Rao, A.; Hind, T.; Teo, Y. R.; Siddiquee, A. A.-M.; Goghari, M. A. I.; Kumar, A. P.; Herr, D. R. Shortchain fatty acid receptors inhibit invasive phenotypes in breast cancer cells. PLoS One 2017, 12, No. e0186334.

(14) Hopkins, M. M.; Meier, K. E. Free fatty acid receptors and cancer: From nutrition to pharmacology. Handb. Exp. Pharmacol. 2017, 236, 233-251.

(15) Kimura, M.; Mizukami, Y.; Miura, T.; Fujimoto, K.; Kobayashi, S.; Matsuzaki, M. Orphan G protein-coupled receptor, GPR41, induces apoptosis via a p53/bax pathway during ischemic hypoxia and reoxygenation. J. Biol. Chem. 2001, 276, 26453-26460.

(16) Trompette, A.; Gollwitzer, E. S.; Yadava, K.; Sichelstiel, A. K.; Sprenger, N.; Ngom-Bru, C.; Blanchard, C.; Junt, T.; Nicod, L. P.; Harris, N. L.; Marsland, B. J. Gut microbiota metabolism of dietary fiber influences allergic airway disease and hematopoiesis. Nat. Med. 2014, 20, 159-166.

(17) Nøhr, M. K.; Egerod, K. L.; Christiansen, S. H.; Gille, A.; Offermanns, S.; Schwartz, T. W.; Møller, M. Expression of the short chain fatty acid receptor GPR41/FFAR3 in autonomic and somatic sensory ganglia. Neuroscience 2015, 290, 126-37.

(18) Kimura, I.; Inoue, D.; Maeda, T.; Hara, T.; Ichimura, A.; Miyauchi, S.; Kobayashi, M.; Hirasawa, A.; Tsujimoto, G. Short-chain fatty acids and ketones directly regulate sympathetic nervous system via G protein-coupled receptor 41 (GPR41). Proc. Natl. Acad. Sci. U.S.A. 2011, 108, 8030-8035.

(19) Hudson, B. D.; Tikhonova, I. G.; Pandey, S. K.; Ulven, T.; Milligan, G. Extracellular ionic locks determine variation in constitutive activity and ligand potency between species orthologs of the free fatty acid receptors FFA2 and FFA3. J. Biol. Chem. 2012, 287, 41195-41209.

(20) Milligan, G.; Bolognini, D.; Sergeev, E. Ligands at the Free Fatty Acid Receptors 2/3 (GPR43/GPR41). Handb. Exp. Pharmacol. 2017, 236, 17-32.

(21) Schmidt, J.; Smith, N. J.; Christiansen, E.; Tikhonova, I. G.; Grundmann, M.; Hudson, B. D.; Ward, R. J.; Drewke, C.; Milligan, G.; Kostenis, E.; Ulven, T. Selective orthosteric free fatty acid receptor 2 (FFA2) agonists. Identification of the structural and chemical requirements for selective activations of FFA2 versus FFA3. J. Biol. Chem. 2011, 286, 10628-10640.

(22) Hudson, B. D.; Christiansen, E.; Murdoch, H.; Jenkins, L.; Hansen, A. H.; Madsen, O.; Ulven, T.; Milligan, G. Complex pharmacology of novel allosteric free fatty acid 3 receptor ligands. Mol. Pharmacol. 2014, 86, 200-210.

(23) Leonard, J. N.; Chu, Z. L.; Bruce, M. A.; Boatman, P. D. GPR41 and Modulators Thereof for the Treatment of Insulin-Related Disorders. WO2006052566A2, 2006.

(24) Nøhr, M. K.; Pedersen, M. H.; Gille, A.; Egerod, K. L.; Engelstoft, M. S.; Husted, A. S.; Sichlau, R. M.; Grunddal, K. V.; Seier Poulsen, S.; Han, S.; Jones, R. M.; Offermanns, S.; Schwartz, T. W. GPR41/FFAR3 and GPR43/FFAR2 as cosensors for short-chain fatty acids in enteroendocrine cells vs FFAR3 in enteric neurons and FFAR2 in enteric leukocytes. Endocrinology 2013, 154, 3552-3564.

(25) Engelstoft, M. S.; Park, W.-m.; Sakata, I.; Kristensen, L. V.; Husted, A. S.; Osborne-Lawrence, S.; Piper, P. K.; Walker, A. K.; Pedersen, M. H.; Nøhr, M. K.; Pan, J.; Sinz, C. J.; Carrington, P. E.; Akiyama, T. E.; Jones, R. M.; Tang, C.; Ahmed, K.; Offermanns, S.; Egerod, K. L.; Zigman, J. M.; Schwartz, T. W. Seven transmembrane G protein-coupled receptor repertoire of gastric ghrelin cells. Mol. Metab. 2013, 2, 376-392. 
(26) Said, H.; Akiba, Y.; Narimatsu, K.; Maruta, K.; Kuri, A.; Iwamoto, K.-i.; Kuwahara, A.; Kaunitz, J. D. FFA3 activation stimulates duodenal bicarbonate secretion and prevents NSAID-induced enteropathy via the GLP-2 pathway in rats. Dig. Dis. Sci. 2017, 62, 1944-1952.

(27) Kaji, I.; Akiba, Y.; Konno, K.; Watanabe, M.; Kimura, S.; Iwanaga, T.; Kuri, A.; Iwamoto, K.-i.; Kuwahara, A.; Kaunitz, J. D. Neural FFA3 activation inversely regulates anion secretion evoked by nicotinic $\mathrm{ACh}$ receptor activation in rat proximal colon. J. Physiol. 2016, 594, 33393352.

(28) Kaji, I.; Akiba, Y.; Furuyama, T.; Adelson, D. W.; Iwamoto, K.; Watanabe, M.; Kuwahara, A.; Kaunitz, J. D. Free fatty acid receptor 3 activation suppresses neurogenic motility in rat proximal colon. Neurogastroenterol. Motil. 2018, 30, No. e13157.

(29) Carroll, W. A.; Agrios, K. A.; Altenbach, R. J.; Buckner, S. A.; Chen, Y.; Coghlan, M. J.; Daza, A. V.; Drizin, I.; Gopalakrishnan, M.; Henry, R. F.; Kort, M. E.; Kym, P. R.; Milicic, I.; Smith, J. C.; Tang, R.; Turner, S. C.; Whiteaker, K. L.; Zhang, H.; Sullivan, J. P. Synthesis and structure-activity relationships of a novel series of tricyclic dihydropyridine-based KATP openers that potently inhibit bladder contractions in vitro. J. Med. Chem. 2004, 47, 3180-3192.

(30) Harrison, C.; Traynor, J. R. The [35S]GTPgammaS binding assay: approaches and applications in pharmacology. Life Sci. 2003, 74, 489-508.

(31) Domljanovic, I.; Rexen Ulven, E.; Ulven, T.; Thomsen, R. P.; Okholm, A. H.; Kjems, J.; Voss, A.; Taskova, M.; Astakhova, K. Dihydropyridine fluorophores allow for specific detection of human antibodies in serum. ACS Omega 2018, 3, 7580-7586.

(32) Lu, J.; Byrne, N.; Wang, J.; Bricogne, G.; Brown, F. K.; Chobanian, H. R.; Colletti, S. L.; Di Salvo, J.; Thomas-Fowlkes, B.; Guo, Y.; Hall, D. L.; Hadix, J.; Hastings, N. B.; Hermes, J. D.; Ho, T.; Howard, A. D.; Josien, H.; Kornienko, M.; Lumb, K. J.; Miller, M. W.; Patel, S. B.; Pio, B.; Plummer, C. W.; Sherborne, B. S.; Sheth, P.; Souza, S.; Tummala, S.; Vonrhein, C.; Webb, M.; Allen, S. J.; Johnston, J. M.; Weinglass, A. B.; Sharma, S.; Soisson, S. M. Structural basis for the cooperative allosteric activation of the free fatty acid receptor GPR40. Nat. Struct. Mol. Biol. 2017, 24, 570-577.

(33) Dolomanov, O. V.; Bourhis, L. J.; Gildea, R. J.; Howard, J. A. K.; Puschmann, H. OLEX2: a complete structure solution, refinement and analysis program. J. Appl. Crystallogr. 2009, 42, 339-341.

(34) Sheldrick, G. M. SHELXT- Integrated space-group and crystalstructure determination. Acta Crystallogr., Sect. A: Found. Adv. 2015, 71, $3-8$.

(35) Rexen Ulven, E.; Trauelsen, M.; Brvar, M.; Lückmann, M.; Bielefeldt, L. Ø.; Jensen, L. K. I.; Schwartz, T. W.; Frimurer, T. M. Structure-Activity Investigations and Optimisations of Non-metabolite Agonists for the Succinate Receptor 1. Sci. Rep. 2018, 8, 10010.

(36) Hill, J. R. In vitro drug metabolism using liver microsomes. Curr. Protoc. Pharmacol. 2003, 23, 7.8.1-7.8.11. 